\title{
Phosphate-Mineral Interactions and Potential Consequences for Nutrient Cycling
}

\author{
By \\ Richard Hunter Oates, Jr \\ B.S. Earth and Atmospheric Sciences \\ Georgia Institute of Technology, 2005 \\ SUBMITTED TO THE DEPARTMENT OF MARINE CHEMISTRY AND \\ GEOCHEMISTRY IN PARTIAL FUFILLMENT OF THE REQUIREMENTS FOR \\ THE DEGREE OF \\ MASTER OF SCIENCE IN CHEMICAL OCEANOGRAPHY \\ at the \\ MASSACHUSETTS INSTITUTE OF TECHNOLOGY \\ and the \\ WOODS HOLE OCEANOGRAPHIC INSITUTION
}

JUNE 2008

(C) 2008 R. Hunter Oates Jr.

All Rights Reserved

The author hereby grants to MIT and WHOI permission to reproduce and to distribute publicly paper and electronic copies of this thesis document in whole or in part in any medium now known or hereafter created.

Signature of Author

Joint Program in Oceanography

Massachusetts Institute of Technology

And Woods Hole Oceanographic Institution February $8^{\text {th }}, 2008$

Certified by

Dr. William Martin

Associate Scientist of Marine Chemistry and Geochemistry

Woods Hole Oceanographic Institution

Thesis Advisor

Accepted by

Dr. Mark Kurz

Senior Scientist, Woods Hole Oceanographic Institution Chairman, Joint Committee on Chemical Oceanography 


\title{
PHOSPHATE-MINERAL INTERACTIONS AND POTENTIAL CONSEQUENCES FOR NUTRIENT CYCLING
}

\author{
By
}

\section{RICHARD HUNTER OATES, JR}

Submitted to the Dept. of Marine Chemistry and Geochemistry on February $8^{\text {th }}, 2008$ in partial fulfillment of the requirements of the Degree of Master of Science in Chemical Oceanography

\begin{abstract}
:
Biogeochemical cycling of phosphate is a key component in the overall production rate of coastal ecosystems. Mineral phases in the near-shore sediments play a significant role in the return of phosphate remineralized in the upper sediments to the water column. Sequential Extraction (SEDEX) of the solid-phase associated $\mathrm{PO}_{4}{ }^{-3}$ yielded reservoir profiles of phosphate at three sites off of the Massachusetts coast. These extractions found $\mathrm{Fe}$-associated $\mathrm{PO}_{4}$ to be the dominant phase associated with rapid porewater-solid $\mathrm{P}$ exchange. Additionally, a seasonal enrichment/depletion pattern of phosphate fluxes relative to total carbon was observed from the sediments. These observations established the behavior of phosphate in coastal sediments as interconnected with the ongoing Fecycling in the sediments as well.
\end{abstract}

Thesis Supervisor: Dr. William Martin

Title: Associate Scientist of Marine Chemistry and Geochemistry 
Table of Contents:

$\begin{array}{ll}\text { Introduction: } & \text { Page } 5\end{array}$

Methods: 9

Results:

Solid Phase: $\quad 13$

Porewater Data: $\quad 22$

Benthic Flux Chamber: $\quad 28$

Discussion: $\quad 30$

$\begin{array}{ll}\text { Conclusion: } & 38\end{array}$

Acknowledgments: $\quad 40$

Appendix: $\quad 41$

References: $\quad 45$

Tables: $\quad 48$

Figures: $\quad 56$ 


\section{Introduction:}

Phosphorus Cycling:

Phosphorus is one of the essential elements required for life on this planet and is a primary component of numerous biologically-necessary materials. Thus, phosphorus $($ elemental symbol $=\mathrm{P})$ and its availability are a principal constraint on productivity, both on local and global scales. The global phosphorus cycle consists of three primary parts: the uplift and subsequent weathering of continental P-bearing minerals, the transport of released $\mathrm{P}$ to the oceans via rivers, and the utilization and subsequent burial of $\mathrm{P}$ in marine sediments until tectonic processes move the P-bearing sediments back to the beginning of the cycle. (Ruttenberg 2003) On shorter timescales, regional cycling between bioavailable P and solid-bound-P may determine a region's level of potential productivity. Phosphorus occurs in nature in the $(+5)$ oxidation state, generally in the form of the phosphate ion $\left(\mathrm{PO}_{4}{ }^{-3}\right)$. This behaves as a triprotic acid, with a majority speciation of $\mathrm{HPO}_{4}{ }^{-2}$ and a minority speciation of $\mathrm{H}_{2} \mathrm{PO}_{4}{ }^{-}$at average ocean water $\mathrm{pH}$ (Morel and Hering 1993). The accepted Redfield Ratio of C:N:P of 106:16:1 in oceanic organic carbon $\left(\mathrm{C}_{\text {org }}\right)$ suggests that $\mathrm{P}$ should act as a limiting nutrient in many systems. Unlike $\mathrm{N}$, which can be fixed from dissolved $\mathrm{N}_{2}$ by microorganisms, the sources of $\mathrm{P}$ in a system are either terrestrial input or a return flux from diagenesis of $\mathrm{C}_{\text {org }}$. Therefore, it is crucial to understand the local cycling of $\mathrm{P}$ in order to establish a complete picture of the coastal productivity regime.

In the open ocean, most remineralization occurs in the water column, with only $\sim 1 \%$ of $\mathrm{C}_{\text {org }}$ reaching the sediments. (Druffel, Williams et al. 1992) This is not the case in near-shore shallow environments where a significant portion of the organic matter 
produced in the water column reaches the sediments. (Schuffert, Kastner et al. 1998; Slomp, Malschaert et al. 1998) Here, organisms use a variety of methods to oxidize this $\mathrm{C}_{\text {org }}$, remineralizing the nutrients in the process. These nutrients then are able to return to the overlying waters via diffusive fluxes. This process is not $100 \%$ efficient, and thus $\mathrm{P}$ is lost as increasing burial removes it further and further from the ecosystem above. (Ingall and Van Cappellen 1990) Additionally, as $\mathrm{PO}_{4}$ passes through the pore waters, chemical reactions causing the $\mathrm{PO}_{4}$ to become associated with the solid-phase portion of the sediments and removed from the porewaters. (Krom and Berner 1980; Lehtoranta and Pitkänen 2003)

A major focus of investigation has been the effect that Fe-bearing minerals and their cycling have on the return of $\mathrm{PO}_{4}$ to the water column. In the sediment column, $\mathrm{Fe}^{3+}$ is acts as an electron receptor after exhaustion of oxygen, nitrate and manganese. Respiration reduces the iron to $\mathrm{Fe}^{2+}$, which is soluble in water. $\mathrm{Fe}^{2+}$ builds up in the porewaters, generating a concentration gradient and producing an upward flux of dissolved iron. When this flux encounters the oxic/anoxic boundary layer, the $\mathrm{Fe}^{2+}$ reacts with the dissolved $\mathrm{O}_{2}$ and oxidizes back to $\mathrm{Fe}^{3+}$. This form of iron is highly insoluble and precipitates out, generally taking the form of a ferric oxy-hydroxide (Fe-OOH) or other oxide species. The cycle is completed by subsequent overlayering and movement of the reduction zone upwards in the sediment column, or by downward mixing through bioturbation back down into regions where Fe reduction is underway. (Burdige 2006) These Fe-bearing minerals have a very high affinity for $\mathrm{PO}_{4}$, encouraging adsorption of porewater $\mathrm{PO}_{4}$ and forming a pool of Fe-associated or "bound" $\mathrm{P}$ in the sediments. (Anschutz, Zhong et al. 1998; Rozan, Taillefert et al. 2002) This suggests a possible 
coupling between the Fe and P cycles in the sediments. How do these Fe oxides and other solid phases in the sediments ultimately affect $\mathrm{PO}_{4}$ return or burial? To answer this, we need a separation of the solid-phase $\mathrm{PO}_{4}$ into its component phases.

A method to measure the component fractions of $\mathrm{PO}_{4}$ was developed in the early 1990s by Kathleen Ruttenberg, who realized the difficulties involved with physically separating and identifying the minerals from sediment samples. This method employs techniques developed for soil analysis and lake sediment to assemble a series of chemical extractions that can provide the desired separation of the solid-phase $\mathrm{PO}_{4}$. Five phases are identified in this method: a "loosely sorbed" phase, an Fe-bound phase, a Ca-bound phase, a "detrital/refractory" phase, and an organic carbon $\left(\mathrm{C}_{\text {org }}\right)$-bound phase $\left(\mathrm{P}_{\text {org }}\right)$. (Ruttenberg 1992) This procedure is referred to as the Sediment Extraction Method (SEDEX). We chose this method as the best means of identifying the solid phases of $\mathrm{PO}_{4}$ that are commonly regarded as potential $\mathrm{PO}_{4}$-sinks: the Fe-bound, Ca-bound and $\mathrm{P}_{\text {org }}$ phases.

Sites:

Three sites in Buzzards Bay, Hingham Bay and Massachusetts Bay were selected for study, based on their different seasonal variations in $\mathrm{C}_{\text {org }}$ and $\mathrm{Fe}$ cycling. Additional data for each of the sites includes porewater profiles of $\mathrm{tCO}_{2}, \mathrm{PO}_{4}$ and $\mathrm{Fe}^{2+} . \mathrm{H}_{2} \mathrm{~S}$ profiles were also available for Hingham Bay. The cores were collected between 2002 and 2004.

Buzzards Bay: This site, collected at a water depth of $\sim 10 \mathrm{~m}$, possesses an intermediate rate of organic matter oxidation ( $400 \mathrm{umol} \mathrm{C} / \mathrm{cm}^{2} \mathrm{yr}$ ). It exhibits a wide seasonal variability in the both the Oxygen Penetration Depth (OPD) and in 
bioturbation/sediment irrigation rates. (Morford et al., submitted) No measurable amount of sulfide was found in the porewaters.

Hingham Bay: This site is located off the east coast of Paddock's Island in greater Boston Harbor at a depth of $\sim 5 \mathrm{~m}$. This site possesses a very high rate of organic deposition and respiration ( $\left.\sim 850 \mathrm{umol} \mathrm{C/ \textrm {cm } ^ { 2 }} \mathrm{yr}\right)$. The porewaters contain sulfide at a relatively shallow depth, around $6-8 \mathrm{~cm}$. (Morford, Martin et al. 2007)

Massachusetts Bay (Mass Bay): This site is located approximately $10 \mathrm{~km}$ from shore at water depth of $\sim 30 \mathrm{~m}$. $\mathrm{C}_{\text {org }}$ deposition and respiration at this site is still rapid ( $\sim 600$ umol $\mathrm{C} / \mathrm{cm}^{2}$ yr) although slower than at the Hingham Bay site. Sulfide was not observed in the porewaters until $\sim 30 \mathrm{~cm}$ depth, which is beyond the range of this study. (Kalnejais 2005; Kalnejais, Martin et al. 2007; Sayles 2007)

Through analysis of these sites at two separate times of the year, I have been able to construct a picture of $\mathrm{P}$ and its numerous reservoirs in the fine-grain sediments of coastal Massachusetts. I combine my results with supplemental data on porewater concentrations and additional solid phase data to produce a more detailed illustration of the solid-phase/porewater coupled system. 


\section{Methods:}

\section{Sample Gathering and Preparation}

Samples were collected from each location using either a ship-based coring device or hand collection by diver. Core sectioning and porewater extraction were performed under a nitrogen atmosphere. Solid samples were freeze-dried and ground to homogeneity.

Extraction:

8 depth points from the top 10 to $20 \mathrm{~cm}$ in each core were selected for extraction and analysis. The samples were chosen to provide greater resolution for the upper portions of the cores and still produce data for the lower portions which were not expected to exhibit many of the processes of interest. $0.50 \mathrm{~g}$ of each sediment sample was placed into $50 \mathrm{ml}$ polypropylene Falcon centrifuge tubes. The samples then underwent a modified version of the sequential extraction process developed and described in Ruttenberg. (Ruttenberg 1992) Each step of the extraction involved addition of reagent, agitation for a set time on a shaker table, centrifugation for 10 min to separate the aqueous fraction, and removal of the aqueous layer via a syringe and Luer-lock sipper. Each aqueous sample was filtered through a 0.45 micron Millipore syringe filter and, with one exception, acidified with concentrated $\mathrm{HCl}(432 \mathrm{ul}$ per $50 \mathrm{ml}$ of extractant) and stored refrigerated.

Step I of the sequence is designed to extract loosely-sorbed phosphate. This involves two extractions with $1 \mathrm{M} \mathrm{MgCl}_{2}$ (pH adjusted to 8 ) and one extraction with distilled, deionized water (DW), each for two hours. 
Step II is designed to extract phosphate associated with iron oxyhydroxides and other oxidized Fe-compounds. This step involves one extraction with $0.3 \mathrm{M}$ sodium citrate \& $1.0 \mathrm{M}$ sodium bicarbonate solution (buffered to $\mathrm{pH}=7.6$ ). Sodium dithionite is added in a ratio of $1.125 \mathrm{~g}$ per $45 \mathrm{ml}$ of solution, and each sample only uses $45 \mathrm{ml}$ per tube. This extraction is eight hours in duration, with small pauses to release built-up sulfur dioxide. Afterwards, the extractants are not acidified. The step concludes with one extraction in the $1 \mathrm{M} \mathrm{MgCl}_{2}$ solution and one extraction in DW, each for two hours.

Step III is designed to release carbonate-related phosphate. This reservoir includes chloro-fluoro-apatite, biogenic hyodroxyapaitite, and phosphate associated with $\mathrm{CaCO}_{3}$-bearing minerals. This step involves one extraction with $1.0 \mathrm{M}$ sodium acetate buffered with acetic acid to $\mathrm{pH}=4$ for six hours. The step concludes with two extractions with the $\mathrm{MgCl} 2$ solution and one extraction in $\mathrm{DW}$, each for two hours.

Step IV is designed to extract "detrital" phosphate and other inorganic forms of $\mathrm{PO}_{4}$. "Detrital" is operationally defined as the phosphate left over after the first 3 extraction steps. This step consists of a single wash in $1 \mathrm{~N} \mathrm{HCl}$ for 16 hours.

Step V involved some additional alteration of the solid sediments. The samples were removed from the centrifuge tubes and into pre-weighed Pyrex beakers using a DW squeeze bottle. These beakers were then placed into a 70 degree $\mathrm{C}$ drying oven overnight to remove all moisture from them. The samples were cooled and weighed before being placed inside a muffle furnace. The samples were ashed at a temperature of 550 degrees $\mathrm{C}$ for one hour, cooled, then reweighed to account for weight loss by $\mathrm{C}_{\text {org }}$ combustion. Following combustion, one 16 hour extraction in $1 \mathrm{~N} \mathrm{HCl}$ extracts organic bound phosphate $\left(\mathrm{P}_{\text {org }}\right)$. 
Analysis:

All extractants, with the exception of the citrate-dithionite-bicarbonate (CDB) step, are analyzed using the single solution colorimetric molybdate-blue method described in Methods of Seawater Analysis. (Strickland and Parsons 1960) Before analysis, samples were diluted per recommendations in Ruttenberg. The dilutions are as follows: 1:2 dilutions for $\mathrm{MgCl}_{2}, \mathrm{Na}$-Acetate and $\mathrm{H}_{2} \mathrm{O}$ supernatants, 1:5 dilution for $\mathrm{HCl}$ supernatants, no dilution for the CDB supernatants. Further dilutions were taken beyond these initial ones as needed to bring analyzed supernatants into concentrations covered by the calibration curve generated from a range of phosphate standards.

For the analysis of the CDB supernatant, a modified version of the stannous chloride-butanol method described in Watanabe and Olsen and expanded upon in Anschutz et al was developed and utilized. (Watanabe and Olsen 1962; Anschutz, Zhong et al. 1998) $25 \mathrm{ml}$ of the supernatant CDB solution is reacted with a $0.25 \mathrm{ml}$ of $1 \mathrm{M}$ ferric chloride solution and allowed to neutralize for 1 week in refrigeration. Before analysis, the samples are aerated for 15 minutes each with ambient air to neutralize any remaining dithionite. Properly neutralized solution will take on the color of golden to dark-golden amber.

$2 \mathrm{ml}$ of the supernatant is placed in a $15 \mathrm{ml}$ polypropylene Falcon tube. Then 4 $\mathrm{ml}$ of a molybdate solution (0.0405 $\mathrm{M}$ ammonium molybdate in $4.0 \mathrm{~N}$ sulfuric acid) and $3 \mathrm{ml}$ of iso-butanol are added. This is then mixed by hand agitation for 2 minutes, pausing to expel gas generated from the neutralizing acid. The solution is allowed to separate for 1 minute. A syringe coupled with a Luer-lock sipper attachment is used to remove the aqueous portion of the tube, leaving the iso-butanol layer. Next, the iso- 
butanol is rinsed with an addition of $3 \mathrm{ml}$ of $1 \mathrm{~N}$ sulfuric acid, shaken once and then allowed to separate for 1 minute. Again, the aqueous layer is removed, leaving the isobutanol layer intact. Following this, $5 \mathrm{ml}$ of a stannous chloride solution ( $7.56 \mathrm{~g}$ of $\mathrm{SnCl}_{2} * 2 \mathrm{H}_{2} \mathrm{O}$ in $25 \mathrm{ml}$ of concentrated $\mathrm{HCl}<48$ hrs. old) diluted $0.5 \mathrm{ml}$ into $100 \mathrm{ml}$ of $1 \mathrm{~N}$ $\mathrm{H}_{2} \mathrm{SO}_{4}$ is added and shaken for 1 minute. After separation ( $\sim 1$ minute), $1 \mathrm{ml}$ of the blue iso-butanol layer is removed and the rest of the liquid is discarded. The $1 \mathrm{ml}$ of Isobutanol is then diluted with $3 \mathrm{ml}$ of pure (200 proof) ethyl alcohol and allowed to develop in darkness for 2 hours. The absorbance is read on a spectrophotometer at a path length of $1 \mathrm{~cm}$ and a wavelength of $725 \mathrm{~nm}$.

Each analysis was compared against a standard series of concentrations that were adjusted for both $\mathrm{pH}$ and concentration of supernatants post-dilution. 


\section{$\underline{\text { Results: }}$}

Solid Phases:

In this section, I will present the results of the SEDEX analysis on the selected sediment cores. I will also introduce other solid-phase data that is relevant to phosphate cycling in the sediments. The results of the SEDEX analysis on the sediment cores are presented in Figures $1-3$ and in Tables 1 and 2. Additional solid phase data for Hingham Bay and Massachusetts Bay is presented in Figures $4-5$.

Reproducibility: Due to the time investment that the SEDEX method requires, only a few samples were analyzed multiple times to establish the reproducibility of the results obtained in the study. Two samples from the Buzzards Bay (March 2003) site were run under the SEDEX procedure in either quadruplicate or triplicate and the resulting values are compared in Table 3. Step I is the most variable. This is likely a consequence of the poorly defined nature of the "loosely sorbed" phase, which is strictly operationally defined as any $\mathrm{PO}_{4}$ released by either dissolution or ion exchange with the $\mathrm{Cl}^{-}$ion in the $\mathrm{MgCl}_{2}$ wash solution. It is likely that $\mathrm{PO}_{4}$ from other phases is removed during this extraction, particularly from the organic-P fraction. (Ruttenberg 1992) As this amount may differ from extraction to extraction, a higher variance in this step is to be expected. This phase typically constitutes a small portion of the total solid-phase $\mathrm{PO}_{4}$ and thus it does not distort the $\mathrm{PO}_{4}$-content profiles of other phases. The variability in the Step II results may be caused by relatively poor reproducibility in the $\mathrm{PO}_{4}$ analysis of the $\mathrm{CDB}$ fraction. Ruttenberg notes that the Watanabe and Olsen Method (including the modified version utilized during this study) generally exhibits variance between $10 \%$ and $20 \%$, which is in line with the results from this study (Ruttenberg 1992). The Ca-bound 
fraction measured in Step III exhibits less variance than the Fe-bound fraction, but is still prone to interferences from other sediment components, particularly clay Al-bearing minerals, per Ruttenberg. A primary component of the Ca-fraction is apatite, which is also the principal component of fish bones. Detrital material homogenized in the samples can have a sizeable effect on this value. The other fractions exhibit a fairly reliable reproducibility, consistent with values presented in Ruttenberg.

\section{SEDEX vs. Total Phosphorus:}

A check of the SEDEX Method is to compare the SEDEX-derived totals with a "Total Phosphorus" measurement. After collection, samples of cores from Hingham Bay and Massachusetts Bay were completely digested and were analyzed on an InductivelyCoupled Plasma Mass Spectrometer (ICP-MS) to generate a Total P profile. (data from M. Bothner, personal communication; Briggs 1999). In Mass Bay, there is a very good agreement between the Total $\mathrm{P}$ and SEDEX Total profiles (Figure 6). In contrast, the profiles for Hingham Bay exhibit a significant difference. In both the January and September cores, the Total P values are $\sim 1.75$ times larger than the SEDEX Totals at the surface and $\sim 1.3$ times larger downcore. Thus, it would appear that there is a considerable addition to the pool of measurable phosphorus during the Total $\mathrm{P}$ analysis which may be explained by differences in the analysis methods and the reactions from the different sites. The SEDEX method utilizes chemical extraction techniques to liberate phosphate ion $\left(\mathrm{PO}_{4}^{-3}\right)$ which is then measured with a colorimetric process. The ICP-MS method uses total sediment dissolution and atom counting, which includes $\mathrm{P}$ that is not measured by the five SEDEX extractions. Hingham Bay and Mass Bay sediments vary mineralogically in ways which could generate the differences in the measurements. 
Almost twice as much iron is present in the sediments at Hingham Bay as there is Mass Bay. Different mineral phases that contain P are not thought to be measured by the SEDEX process, including reduced-metal minerals such as vivianite $\left(\mathrm{Fe}_{3}\left(\mathrm{PO}_{4}\right)_{2}: 8 \mathrm{H}_{2} \mathrm{O}\right)$ and struvite $\left(\mathrm{MnNH}_{4} \mathrm{PO}_{4}: 6 \mathrm{H}_{2} \mathrm{O}\right)$. As these minerals are based around an already reduced form of metal, it is possible that a significant fraction will survive the extraction process. The CDB/Dithoinite extraction utilized in the SEDEX method are primarily targeted at "easily-reduced ferric minerals" such as goethite, lepidocrocite, and hematite. (Ruttenberg 1992) Additionally, the SEDEX method is not designed to quantify Albound $\mathrm{PO}_{4}$, which would also be included in the Total $\mathrm{P}$ value. Finally, Fe has also been suggested to interfere with the colorimetric method of phosphate analysis, so the presence of Fe in sample solutions may act to lower the SRP measured. This is due to $\mathrm{Fe}^{2+}$ oxidizing to $\mathrm{Fe}^{3+}$ in the presence of oxygen, producing ferric oxyhydroxides (Fe-OOH) which precipitate out and sorb SRP onto surface binding sites during the analytical process. This may have occurred during storage of the $\mathrm{CDB}$ extractions, as they were not acidified during storage, as per Ruttenburg. Instead, the reducing potential of the dithionite and the chelating properties of the citrate were relied upon to keep the Fe in the $(2+)$ state and soluble. It is possible that during this time, as the dithionite began to neutralize, that some Fe-precipitation may have occurred, especially due to the addition of the ferric chloride $\left(\mathrm{FeCl}_{3}\right)$ to the solution. During the analysis performed on the solution, acidic reagents are added while the dithionite is neutralized, which should prevent ferric precipitation. 


\section{Phosphate Distribution In Solid Phases}

The proportions of the SRP between the extracted phases exhibit similar characteristics at all three locations. (Table 1 and 2) The dominant phase at the sediment-water interface (SWI) is the Fe-bound phase and occasionally Ca-bound.

Downcore, this phase decreases and is exceeded by others. In Buzzards Bay, the organic$\mathrm{P}$ and Ca-bound $\mathrm{PO}_{4}$ are the majority phases at depth (Figure 7), while in Mass Bay, the Ca-bound $\mathrm{PO}_{4}$ and the refractory $\mathrm{PO}_{4}$ become the majority phases (Figure 8). In Hingham Bay (Figure 9), Ca-bound $\mathrm{PO}_{4}$, refractory $\mathrm{PO}_{4}$ and organic- $\mathrm{PO}_{4}$ all exceed the Fe-bound fraction downcore in January. However, in September, the Fe-bound fraction decreases but remains the dominant solid phase. Hingham Bay possesses a very high Fe content in the sediments, reaching up to $5 \%$ by mass in the downcore regions in question. This could give the Fe-bound phase a much higher "holding capacity" for the Fe-bound $\mathrm{PO}_{4}$ at this site than at the other two.

There is a definite seasonal variation to the SEDEX Total $\mathrm{PO}_{4}$. At two of the sites, solid-phase-associated $\mathrm{PO}_{4}$ increases from the winter samples to the fall samples near the SWI. The largest change of this manner occurs at Buzzards Bay (Figure 1), with a smaller one in Hingham Bay (Figure 2). At Mass Bay (Figure 3), the total $\mathrm{PO}_{4}$ decreases in the October core, but a broader feature of constant solid-phase $\mathrm{PO}_{4}$ below the SWI develops with a decrease below $1 \mathrm{~cm}$. This is in contrast to every other core analyzed, which exhibited either an immediate increase to a peak or a decrease below the surface. The phases of refractory- $\mathrm{PO}_{4}, \mathrm{Ca}$-bound $\mathrm{PO}_{4}$ and organic $\mathrm{PO}_{4}$ show little seasonal variance, with one exception, the Ca-bound $\mathrm{PO}_{4}$ in Hingham Bay. There is a massive increase in Ca-bound $\mathrm{PO}_{4}$ at around $2 \mathrm{~cm}$ depth in January that is not seen in the 
September core or at any other site. This may potentially be a result of core to core variability, reflecting perhaps a switch in type of incoming sediments, as will be investigated further in the next section.

With a few exceptions, the Ca-bound, organic- $\mathrm{PO}_{4}$ and refractory $\mathrm{PO}_{4}$ do not exhibit significant changes in downcore concentrations. Loosely-sorbed $\mathrm{PO}_{4}$ and Febound $\mathrm{PO}_{4}$ demonstrate consistent features across the selected samples. It follows that the shape of the profile of these two phases, primarily that of Fe-bound $\mathrm{PO}_{4}$, determines the structure of the Total $\mathrm{PO}_{4}$ curve. These phases therefore have the most potential for generating a dynamic cycling reservoir.

Features of Principle Phases (Loosely-sorbed and Fe-bound):

The Fe-bound $\mathrm{PO}_{4}$ profile peaks shift in core depth depending on the time of the year. In Buzzards Bay (Figure 1) the Fe-bound profile maximum value occurs at or immediately below the SWI during the late winter/early spring. These peaks shift downwards by less than a centimeter in the late summer/fall cores. In Hingham Bay (Figure 2) and Mass Bay (Figure 3), this trend is reversed, with a sub-surface peak observed in January and a maximum observed at the SWI during September. The profile at Mass Bay is smeared down, which may be a consequence of mixing in the upper $2 \mathrm{~cm}$ or of the beginning of a seasonal shift. Due to the nature of the collection methods employed during recovery of the cores, there is a high certainty of the upper sediments near the SWI being relatively intact.

The shape of the loosely-sorbed fraction profile mimics that of the Fe-bound phase. This may indicate that the loosely-sorbed fraction reflects some exchange between the porewaters and the Fe-bound phase. As Fe-bound $\mathrm{PO}_{4}$ is cycled, the newly 
liberated $\mathrm{PO}_{4}$ can become associated with binding sites on the mineral particles, becoming briefly re-associated with the solid phase. The time scale for this exchange between the porewaters and the loosely-sorbed phase is unknown. Hyacinthe has proposed that a portion of the Fe-bound phase is highly reactive. (Hyacinthe 2004) That study utilized an ascorbate extraction (sodium citrate $(50 \mathrm{~g} / 1)$, sodium bicarbonate $(50 \mathrm{~g} / \mathrm{l})$ and $\mathrm{L}(+)$ Ascorbic Acid $(10 \mathrm{~g} / \mathrm{l}), \mathrm{pH}=7.5)$ for determination of the Fe-bound $\mathrm{PO}_{4}$, a method which has been shown to selectively target poorly-crystallized oxy-hydroxides, while leaving well-crystallized oxides, such as hematite and lepidocrocite, relatively intact (extraction of $25 \%$ or less). (C. Hyacinthe 2004) This measurement technique also would include what Ruttenberg has defined as the "loosely sorbed" phase. Considering the complications with the SEDEX method of determining the exact nature of this phase, suggestions have been made to simply merge it with the Fe-bound phase as an "active $\mathrm{PO}_{4}$ " phase. (C. Hyacinthe 2004) This would yield a profile of a higher concentration (umol $\mathrm{PO}_{4} / \mathrm{g}$ sediment) but it would not significantly change the shape of our generated profiles or the model of linked Fe-P cycling that we develop below.

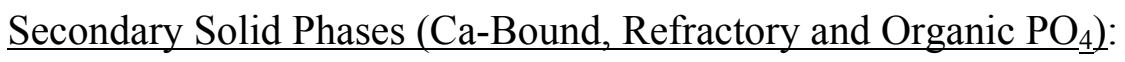

The secondary solid phases show little downcore variation with the exception of $\mathrm{P}_{\text {org }}$ in Mass Bay. With a few exceptions, solid-phase concentrations decrease slightly downcore. An increase in Ca-bound $\mathrm{PO}_{4}$ in Hingham Bay in January is not believed to be a diagenetic feature (Figure 2). This feature disappears when $\mathrm{P}$ is normalized to $\mathrm{Al}$ (Figure 10) indicating that it may reflect a change in type of deposited sediments for an unknown reason. This does not appear to be a mineral precipitation curve, as there is no 
corresponding feature in the pore-water $\mathrm{PO}_{4}$ profile to suggest the precipitation of apatite (Figure 11).

Calculating the phosphate inventory of the sediments (umol $\mathrm{PO}_{4} / \mathrm{cm}^{2}$ sediment) (Table 4) confirms that the Ca-bound, "refractory" and $\mathrm{P}_{\text {org }}$ phases are the primary reservoirs downcore contributing to phosphate burial and subsequent removal from the coastal ecosystem. (Figure 13) My results differ from those of Hyacinthe, which suggested that the Fe-bound phase acted as major sink in freshwater sections of an estuarine environment. (C. Hyacinthe 2004) This does not appear to be the case at our coastal saltwater sites.

Potential complications arise from the organic $\mathrm{PO}_{4}$ measurement. It is known that some of the organic $\mathrm{PO}_{4}$ dissolves in the initial extraction and becomes part of the "loosely sorbed" measurement, although the total size of the "loosely sorbed" pool is small relative to the $\mathrm{P}_{\text {org }}$ pool. (Ruttenberg 1992) Consequently, the organic $\mathrm{PO}_{4}$ measured in Step V reflects a minimum amount depending on the type of organic matter being deposited at the site. Studies have shown that in coastal regions, the C:P ratio in $\mathrm{C}_{\text {org }}$ can vary widely due to the input of continental $\mathrm{C}_{\text {org }}$. C:P ratios can vary from 800 to 2050, in contrast to the 106 taken as the general oceanic value per Redfield (Ingall and Van Capellen 1990). In the nearby Long Island Sound, Ingall found a C:P ratio of 371 in the upper $10 \mathrm{~cm}$ of the sediment column. Our sediments seem to reflect this variability as well. (Table 5) These values were calculated by comparing the measured amounts of $P_{\text {org }}$ from the SEDEX analysis and $\mathrm{P}_{\text {org }}$ calculated by multiplying measured $\mathrm{C}_{\text {org }}$ by (C:P) Redfield values (106:1). Ingall explains high C:P values by a combination of contributions of terrigenous $\mathrm{C}_{\text {org }}$ into the coastal waters and preferential remineralization 
of $\mathrm{PO}_{4}$ relative to $\mathrm{C}$. Although no major rivers discharge into Buzzards Bay, terrestrial inputs are likely to be significant and both Mass Bay and Hingham Bay have historically had significant anthropogenic input of $\mathrm{C}_{\text {org }}$ via sewage discharge and organic pollutants in the overlying seawater. (Morford, Martin et al. 2007) These results show that the oceanic Redfield ratio of 106:1 is an overestimation of the amount of organic- $\mathrm{PO}_{4}$ contained in $\mathrm{C}_{\text {org }}$ in the sediment column, in agreement with Ingall's findings.

Table 6 presents solid-phase Fe weight percentages and Fe/Al ratios (HB, MB from Martin, W., unpublished results, BB from Morford et al. (submitted)). The coretops are generally enriched with Fe relative to Al, with the exception of Hingham Bay, where there is no apparent shift in the average Fe:Al ratio down core. Also, the core-tops contain a higher percentage of Fe by weight, except for Hingham Bay. This would make sense as Fe, reduced and released from the lower sediment column, diffuses upwards and precipitates out at the oxic/anoxic boundary layer, very near the SWI. In Hingham Bay, there is little difference between the average SWI and downcore values of both $\% \mathrm{Fe}$ and Fe/Al. An increase in the solid phase Fe coincides with porewater $\mathrm{H}_{2} \mathrm{~S}$ rising above zero and porewater $\mathrm{Fe}^{2+}$ dropping below detectable levels. (Figure 4, Figure 11) The sulfide can act as a check on the Fe cycling of the sediment column by reacting with the porewater $\mathrm{Fe}^{2+}$, generated by $\mathrm{C}_{\text {org }}$ diagenesis, and forming insoluble $\mathrm{Fe}-\mathrm{S}$ compounds. Such compounds would not release reduced Fe at depth, limiting the supply of Fe returning towards the SWI.

Solid Phase Fluxes:

Utilizing sediment mixing data generated from radioisotope analysis of the study sites allows us to calculate the mixing rates of sediments generated by bioturbation of the 
upper sediment column. (personal communication, Martin, W,)(Morford et al, submitted) (Morford, Martin et al. 2007) A bioturbation mixing coefficient was calculated for each site and combined with our SEDEX data to determine the apparent flux of solid-bound $\mathrm{PO}_{4}$ as a result of this biological activity (Table 7). (Parameters and equations for flux calculations can be found in the Appendix). With one exception at Mass Bay (October 2002), the Fe-bound phase accounts for a high percentage of solid-phase $\mathrm{PO}_{4}$ being mixed down into the sediment column. A significant amount of $\mathrm{PO}_{4}$ is being transported down into the sediment column as an Fe-bound solid-phase component.

\section{Summary}

Fe-bound $\mathrm{PO}_{4}$ appears to be the most active of all the solid-phase phosphate in the sediment. $\mathrm{Fe} / \mathrm{Al}$ ratios indicate a strong iron cycle in both Buzzards Bay and Mass Bay, but a muted cycle in Hingham Bay. The SEDEX profiles indicate that the most active region of solid-phase cycling is located around the oxic/anoxic boundary layer in the upper 1-2 cm of the sediment column. The fraction of Fe-bound $\mathrm{PO}_{4}$, relative to other solid-phases, is highest at the core tops and diminishes deeper into the sediments. The largest burial of $\mathrm{PO}_{4}$ seems to be associated with the Ca-bound phase and $\mathrm{P}_{\text {org }}$. 


\section{Results:}

Porewaters

Porewater Profiles:

Porewater profiles of several chemical species relevant to phosphate cycling were compiled to investigate aqueous-phase processes. These species included total dissolved carbon $\left(\mathrm{tCO}_{2}\right)$, total dissolved $\mathrm{Fe}^{2+}$, dissolved $\mathrm{PO}_{4}$, dissolved oxygen and dissolved $\mathrm{H}_{2} \mathrm{~S}$ (Figures $11-12,14-17$ ). The sites exhibited typical sediment profile structures for many of these species. For instance, every core exhibited a subsurface $\mathrm{PO}_{4}$ peak. All dissolved component profiles indicate production in situ and subsequent flux out of the sediments into the overlying waters, except for oxygen, which is consumed in the upper centimeter. Dissolved oxygen was measured in situ via electrode probe inserted into the sediments. All other profiles were determined after extraction and chemical analysis of porewaters.

Hingham Bay:

In Hingham Bay, during January, there is a gradual increase in porewater $\mathrm{PO}_{4}$ downcore from the SWI until reaching a peak of $325 \mathrm{umol} / 1$ at $\sim 7 \mathrm{~cm}$ (Figure 11). From this depth to $16 \mathrm{~cm}$, the concentration remains roughly constant. Below this section, there is a final increase of $200 \mathrm{umol} / 1$ to $23 \mathrm{~cm}$, the deepest depth measured. This is in contrast to the September core (Figure 12), in which porewater $\mathrm{PO}_{4}$ increases much more rapidly, with a decrease in slope between 2 to $5 \mathrm{~cm}$, and a peak at $\sim 450 \mathrm{umol} / 1$ around 7 $\mathrm{cm}$. The $\mathrm{tCO}_{2}$ profile in September is almost twice as steep as the profile from January. In January, the Fe concentration increases from 0 to $\sim 300 \mathrm{umol} / \mathrm{kg}$ at approx. $1.5 \mathrm{~cm}$. In 
the September core, the Fe peak is half the size of the January peak, and is located above $1 \mathrm{~cm}$.

Buzzards Bay:

Total $\mathrm{CO}_{2}\left(\mathrm{tCO}_{2}\right)$ in March (Figure 114) increases downcore in the upper $2 \mathrm{~cm}$ and holds a steady value below, while in August (Figure 15), the $\mathrm{tCO}_{2}$ levels increase by almost $1500 \mathrm{umol} / \mathrm{kg}$. Fe porewater values during March increase from 0 at the SWI to a peak of about $\sim 150 \mathrm{umol} / \mathrm{kg}$ at around $2.5 \mathrm{~cm}$. This value decreases back to $\sim 80 \mathrm{uM}$ around $10 \mathrm{~cm}$. The Fe values in the August core increase from 0 at the surface to a peak of $\sim 250 \mathrm{umol} / \mathrm{kg}$ at $\sim 1 \mathrm{~cm}$ with a marked decline back to a near-zero level by $\sim 10 \mathrm{~cm}$. Oxygen penetrates to $1 \mathrm{~cm}$ during March. In August, the oxygen penetration depth (OPD) is about $0.3 \mathrm{~cm}$. (Morford et al, submitted)

Massachusetts Bay:

In the February core (Figure 16), $\mathrm{PO}_{4}$ increases downcore with a reduced slope between 2 and $4 \mathrm{~cm} . \mathrm{PO}_{4}$ increases to a peak of $\sim 125 \mathrm{umol} / 1$ at around $9 \mathrm{~cm}$ depth followed by a decrease downcore through the sampling range. In October, the porewater $\mathrm{PO}_{4}$ increases to about $60 \mathrm{umol} / 1$ around $5 \mathrm{~cm}$ depth (Figure 17). This profile also exhibits the decrease in slope between $2-4 \mathrm{~cm}$. Unlike the February profile, there is no marked decrease in $\mathrm{PO}_{4}$ below the peak values, but rather a noisy static value till the base of the analyzed depth range. Oxygen penetration at this site was $0.6 \mathrm{~cm}$ in February decreasing to $0.3 \mathrm{~cm}$ during October (Sayles and Goudreau 2007).

\section{Porewater Ratios}

A consequence of the hypothesized $\mathrm{PO}_{4}$ cycling described in the Introduction would be the enrichment of $\mathrm{PO}_{4}$ values in the porewaters beyond what would normally be 
predicted by $\mathrm{C}_{\text {org }}$ decomposition alone, as shown by calculating the porewater ratios for dissolved species relative to the established ratios produced by $\mathrm{C}_{\text {org }}$ remineralization. I determined that it would be most useful to examine the $\mathrm{tCO}_{2}: \mathrm{PO}_{4}$ ratios for this procedure, as opposed to dissolved oxygen or nitrate. Significant dissolution of carbonate minerals is unlikely to occur in this near-shore environment, and is therefore unlikely to affect our $\mathrm{tCO}_{2}: \mathrm{PO}_{4}$ ratios.

An examination of Hingham Bay illustrates this well. In the September 2002 site, a plot of $\mathrm{PO}_{4}$ vs. $\mathrm{tCO}_{2}$ is compared to the plot predicted for the Redfield values. (Figure 14) $\mathrm{The} \mathrm{PO}_{4}$ plot shows deviation above the expected Redfield values. This is a strong indicator that the principal factor causing this enrichment is from a cycle in the sediments that is independent of other remineralization products, such as the hypothesized Fe-P cycle. Massachusetts Bay pore waters exhibited similar enrichment (Figure 18). Buzzards Bay porewaters are not plotted because removal of $\mathrm{PO}_{4}$ and $\mathrm{tCO}_{2}$ at depth from proposed mineral precipitation skew the plots into showing depletion at depth.

\section{Porewater $\mathrm{PO}_{4} / \mathrm{Fe}$ Interactions}

Comparing the porewater profiles of $\mathrm{PO}_{4}$ and dissolved $\mathrm{Fe}^{+2}$ reveals a common structure across the sediment profiles. An example of this is illustrated in the combined profiles in Hingham Bay, January (Figure 11). Between 2 and $4 \mathrm{~cm}$ depth, there is a decline in the $\mathrm{PO}_{4}$ gradient. At the peak of the $\mathrm{Fe}^{+2}$ profile, which occurs at around $\sim 2$ $\mathrm{cm}$, there is a noticeable increase in the $\mathrm{PO}_{4}$ gradient. This trend continues upcore until the measurable $\mathrm{Fe}^{+2}$ goes to zero at around $0.75 \mathrm{~cm}$. $\mathrm{PO}_{4}$ then returns to its previous gradient. This supports a dynamic between the precipitation of Fe in the sediments and removal of $\mathrm{PO}_{4}$ from the porewaters, as the removal of Fe from the porewaters via 
precipitation correlates with increased rates of $\mathrm{PO}_{4}$ removal. Also, changes in the porewater $\mathrm{PO}_{4}$ gradients correspond with changes in the dissolved Fe profile, which indicates connected removal processes.

Another typical instance of this linking behavior between dissolved $\mathrm{Fe}$ and $\mathrm{PO}_{4}$ is evident in the Buzzards Bay site (Figure 14 and 15). In the profiles, one notes that both the dissolved $\mathrm{Fe}$ and $\mathrm{PO}_{4}$ both go to zero at the OPD; in March, this is around $1 \mathrm{~cm}$ while in August it is at the SWI. This pattern of generation and removal holds even though far more dissolved Fe and $\mathrm{P}$ are generated in the summer, with dissolved peaks more than double the March concentrations. This is strong evidence for a process that simultaneously removes both components from the porewaters, such as coupled Feprecipitation and P-adsorption. A similar behavior is observed at Mass Bay. Porewater $\mathrm{tCO}_{2}$

An increase in $\mathrm{C}_{\text {org }}$ respiration during the summer months leads to a large increase in $\mathrm{tCO}_{2}$ porewater values. As the region of $\mathrm{C}_{\text {org }}$ oxidation in the sediment profiles does not shift significantly between seasons, summer porewater profiles show a much higher $\mathrm{tCO}_{2}$ gradient than winter profiles, but overall profile shape remains the same (compare Figures 11 and 12,14 and 15, 16 and 17). The $\mathrm{tCO}_{2}$ profiles also show a sizeable step difference between the porewater values immediately below the SWI and the bottom water concentrations. In contrast with porewater $\mathrm{PO}_{4}$, whose values at the $\mathrm{SWI}$ are almost identical to the bottom water values, the $\mathrm{tCO}_{2}$ concentrations are elevated relative to the overlying water. This is potentially the result of the oxidation of a highly labile portion of the incoming $\mathrm{C}_{\mathrm{org}}$ immediately at the SWI. 


\section{$\underline{\text { Porewater Fluxes }}$}

With the available porewater data, diffusive fluxes were calculated using Fick's First Law for diffusive flux through a porous medium. (Berner 1980) To correct for the effects of the sedimentary environment, standard diffusion coefficients were adjusted for sediment tortuousity using porosity and formation factor data (personal communication, Martin, W.)(Morford, Martin et al. 2007). Visual identification and a trial and error approach located the regions of highest slope for the flux determinations. Further discussion of flux calculations is located in the Appendix.

Tables 8 through 11 contain porewater flux data for both $\mathrm{PO}_{4}$ and $\mathrm{tCO}_{2}$, with flux rates calculated both at maximum downcore gradient $(8,9)$ and across the SWI $(10)$ and tCO2:PO4 ratios of these fluxes $(10,11)$. The maximum porewater gradient flux represents production of the dissolved species in the sediments, while the SWI flux measures actual flux of species up into the overlying water column. Both sets of $\mathrm{PO}_{4}$ and $\mathrm{tCO}_{2}$ fluxes increase from winter to summer. The $\mathrm{PO}_{4}$ flux calculated from the maximum gradient is the flux upwards into the oxic/anoxic boundary layer, while the SWI flux is the amount of $\mathrm{PO}_{4}$ that diffuses from this layer into the water column. The shifts in magnitude between winter and summer are expected as both higher production in the water column and warmer temperatures in the bottom waters during the summer contribute to much higher levels of remineralization within the sediments. The ratio of $\mathrm{tCO}_{2}$ to $\mathrm{PO}_{4}$ fluxes across the SWI greatly decreases during the summer/late fall. (Table 10) At Buzzards Bay and Hingham Bay, the shift is on the scale of two orders of magnitude. This reflects the increased release of $\mathrm{PO}_{4}$ from Fe-reducing respiration and its subsequent escape from the sediments into the overlying waters. The $\mathrm{tCO}_{2}$ fluxes 
change only modestly, while the $\mathrm{PO}_{4}$ fluxes increase dramatically. These increased fluxes also correspond with a decrease in the thickness of the oxic layer in the sediment column. Thinner oxic layers generate less effective removal of $\mathrm{PO}_{4}$ upwardly diffusing through the sediments, by decreasing the region where fresh Fe-OOH is likely to be present for phosphate sorption. 


\section{Benthic Flux Chamber Data}

Overview:

In order to obtain additional data about the sediment's role in coastal cycling processes, benthic flux chambers were deployed at the research sites at locations similar to those from which cores were taken. There are numerous complications involved with utilizing this data. These chambers generate a micro-environment over the SWI, which alters the conditions in the upper section of the sediment column, most dramatically with regards to the dissolved $\mathrm{O}_{2}$ levels. Also altered is the effect that bottom water circulation has on the exchange rates between the bottom waters and the sediment column. In order to overcome these complications, some of the chambers were fitted with a gas-permeable tube that circulated bottom water through in order to prevent $\mathrm{O}_{2}$ levels from dropping to zero. This caused the chamber to equilibrate with the rate of exchange across the tubing, resulting in a lower $\mathrm{O}_{2}$ concentration but preventing an anoxic environment from developing. This kept chamber conditions closer to ambient, and prevented "enhanced" fluxes potentially generated by anoxic conditions, but changes in the OPD were still possible from the decreased overlying $\mathrm{O}_{2}$ concentrations. Additionally, all chambers were equipped with a paddle stirrer device to approximate the diffusive sublayer above the SWI. Table 12 contains the fluxes calculated from each site from the chamber data.

The chambers deployed in Buzzards Bay both had oxygen additions from bottom water diffusion. For the chambers deployed in Mass Bay, the February chamber was not equipped with the $\mathrm{O}_{2}$ tubing, while the October chamber was. For Hingham Bay, data is available from two chambers, one equipped with $\mathrm{O}_{2}$ tubing and one without. The flux values for these chambers were averaged together. $\mathrm{PO}_{4}$ released from reducing $\mathrm{Fe}^{+3}$ 
bearing minerals increased as anoxia overtakes the SWI in the non-ventilated chambers, another link between $\mathrm{Fe}$ and $\mathrm{PO}_{4}$, but this did not affect the flux calculations.

Flux values were calculated from species concentration in the chamber and its change over time. In the time sequence plots from the chambers, the majority of $\mathrm{PO}_{4}$ flux out of the sediments appears to occur immediately, slowing considerably beyond 20-30 hours.

The same enrichment of $\mathrm{PO}_{4}$ relative to $\mathrm{tCO}_{2}$ during the progression from winter to summer/fall that was observed in the porewater fluxes, both in the max gradient and SWI values, is also apparent in these fluxes. This trend is clearest in Mass Bay and Hingham Bay. Buzzards Bay does not seem to experience this shift, but one possibility is that this is a reflection of increased $\mathrm{PO}_{4}$ sequestration in the upper sediments. 


\section{Discussion:}

This study suggests a definite connection between the sedimentary iron and phosphorus cycles. Figure 19 gives a cartoon visualization of this intertwined $\mathrm{Fe}-\mathrm{P}$ cycling.

Support for the correlation between Fe and P cycling is illustrated by graphing the porewater $\mathrm{PO}_{4}$ and Fe-bound $\mathrm{PO}_{4}$ profiles on the same depth scale. (Figures 20, 21, 22) An inverse pattern between the shapes of the Fe-bound and porewater $\mathrm{PO}_{4}$ is noticeable across the sites. This indicates that there is simultaneous removal of porewater $\mathrm{PO}_{4}$ and generation of Fe-bound $\mathrm{PO}_{4}$ in the upper $\sim 2-3 \mathrm{~cm}$ of the sediment column. Changes in the gradient of the porewater profiles also reflect $\mathrm{PO}_{4}$ sorbing/desorbing onto the Febearing minerals in the region around the redox-cline. This provides a strong qualitative case for the formation of the proposed "trapping" Fe-binding layer.

The fluxes of solid-phase $\mathrm{PO}_{4}$ mixed down into the sediments by bioturbation and the flux of porewater $\mathrm{PO}_{4}$ heading up into the overlying bottom waters are presented in Table 13 and Figure 23. As illustrated in Table 7, Fe-bound $\mathrm{PO}_{4}$ makes up the majority of the solid-phase $\mathrm{PO}_{4}$ mixed down into the sediment column. This links the $\mathrm{P}$ and $\mathrm{Fe}$ cycles, by establishing the $\mathrm{Fe}^{3+}$ returned through downcore mixing as a carrier for $\mathrm{PO}_{4}$ input back into the sediments. This downward mixing of Fe-bound $\mathrm{PO}_{4}$ appears to be the source for the very large $\mathrm{PO}_{4}$ enrichment of the porewaters (see Figure 14).

Potential difficulty in further constraining this portion of the overall cycle stems from the apparent imbalance between the diffusive $\mathrm{PO}_{4}$ flux into the oxic layer, and the calculated transport of Fe-bound $\mathrm{PO}_{4}$ down into the sediments via bioturbation. (Table 13) A major concern is the validity of a steady-state assumption for the system. In 
steady-state, the downward flux of Fe-bound $\mathrm{PO}_{4}$ and the upward flux of dissolved $\mathrm{PO}_{4}$ should balance. The apparent discrepancy may be explained by the fact that the bioturbation mixing coefficients calculated for a study site are prone to a wide range of spatial and temporal variability. In addition, as the time scales of mixing are on the order of a month $\left(\mathrm{t}_{1 / 2}\right.$ of ${ }^{234} \mathrm{Th}=24$ days $)$, while the equilibrium time for the $\mathrm{Fe}$ bound/porewater $\mathrm{PO}_{4}$ exchange is likely far shorter, a discrepancy between the solidphase and porewater fluxes seems likely to occur. Further temporal sampling may help resolve such apparent discrepancies between the solid and dissolved phase fluxes. Nevertheless, there is a clear link between porewater removal and $\mathrm{Fe}$-uptake of $\mathrm{PO}_{4}$ occurring at the redox-cline.

Another indication of Fe-P coupling is the simultaneous removal of both $\mathrm{PO}_{4}$ and $\mathrm{Fe}^{2+}$ from the porewaters at around the OPD. (Figures $11-15$ ) The shape of the profiles exhibits similar removal features, including going to a near-zero value below the SWI. This is observable in all the cores with data available, but is most easily seen in Buzzard Bay, March 2003. (Figure 14)

At every site, there are peaks in both the "Fe-bound" and "Loosely Sorbed" $\mathrm{PO}_{4}$ profiles that mimic the shape of the Total $\mathrm{PO}_{4}$ profile almost precisely (Figures $1-3$ ). Since the loosely-sorbed phase is much smaller than the Fe-bound phase, this establishes the Fe-bound phase as the primary driver of porewater/mineral interactions in $\mathrm{P}$ cycling. Porewater $\mathrm{O}_{2}$ profiles, where available, show that the maximum value of the Fe-bound phase concentration occurs at the apparent OPD. There is an accompanying enrichment of Fe in this layer in Buzzards Bay and Mass Bay, as well as a much smaller enrichment in Hingham Bay. (Figure 4, 5) Buzzards Bay and Mass Bay both exhibit higher weight 
percentages of $\mathrm{Fe}$ in the core tops than in the downcore regions, while Hingham Bay has the highest overall Fe content, but only a small shift in weight $\%$ as observed in the other cores (Table 6).

The Fe/Al ratios (Figure 10) from the cores reveal functions of the Fe cycle that explain these features. In Mass Bay, $\mathrm{Fe}$ is enriched relative to $\mathrm{Al}$ in the upper $2 \mathrm{~cm}$ of the core and depleted relative to the surface $\mathrm{Fe} / \mathrm{Al}$ ratio downcore, where an asymptotic value of both $\mathrm{Fe}$ and $\mathrm{Fe} / \mathrm{Al}$ is reached. However, Hingham Bay's Fe/Al profiles show a much smaller enrichment value at the surface and a large enrichment downcore, between $6 \mathrm{~cm}$ during January and $9 \mathrm{~cm}$ during September. A reason for this is suggested by the relationship between porewater $\mathrm{Fe}$ and $\mathrm{H}_{2} \mathrm{~S}$ in the Hingham Bay cores (Figure 11). There is a very shallow incidence of $\mathrm{H}_{2} \mathrm{~S}$ in the porewaters, beginning at around $5 \mathrm{~cm}$. This is coupled with a drawdown of the porewater $\mathrm{Fe}$, which exhibits a removal feature in its profile between $2.5 \mathrm{~cm}$ and $5 \mathrm{~cm}$, eventually going to zero concentration by $6 \mathrm{~cm}$. This indicates that $\mathrm{Fe}$ and $\mathrm{S}$ are reacting in the $5-6 \mathrm{~cm}$ range to form ferrous sulfides, which are insoluble and precipitate out. The formation of these sulfides removes Fe from the porewaters before it has a chance to diffuse upwards to the OPD. This short-circuits the Fe cycle, by removing mobilized Fe away from the regions where oxidation and precipitation, with associated $\mathrm{PO}_{4}$ scavenging, may occur. Such processes may account for the lack of a seasonal variation in the Fe-bound P phase at Hingham Bay.

Therefore, I propose that the short-circuited Fe cycle present in Hingham Bay limits the trapping effect of the "iron curtain" at the oxic/anoxic boundary layer. One way to support this is to look at the porewater fluxes in the sediments. During the late summer/fall time periods, every core exhibits higher fluxes upward from porewater 
concentration maxima of both $\mathrm{PO}_{4}$ and $\mathrm{tCO}_{2}$ (Tables 8 and 9). This is an obvious consequence of increased respiration occurring in situ. Barring the dissolution of carbonate minerals, the $\mathrm{tCO}_{2}$ value can be taken as a rough estimate of $\mathrm{C}_{\text {org }}$ remineralization in the sediment column. Every core shows an enrichment of its $\mathrm{PO}_{4}$ fluxes upwards into the oxic/anoxic boundary layer relative to this $\mathrm{tCO}_{2}$ and its expected Redfield value. Indeed, as noted in the porewater section of the results, $\mathrm{C}_{\text {org }}$ is likely to possess even higher $\mathrm{C}: \mathrm{P}$ ratios in coastal settings. A comparison of $\mathrm{tCO}_{2}: \mathrm{PO}_{4}$ ratios of the fluxes across the sites reveals an immediate distinction between Hingham Bay and the other sites. In Buzzards Bay and Mass Bay, the ratio remains relatively constant, whereas in Hingham Bay, the ratio value decreases from 18 in January to 7 in September, a $2.5 \mathrm{x}$ increase in the amount of $\mathrm{PO}_{4}$ flux relative to the $\mathrm{tCO}_{2}$ produced. (Table 11) All of this occurs without any major shifts in the solid-phase $\mathrm{PO}_{4}$ concentrations. Therefore, the dampened $\mathrm{Fe}$ cycle in Hingham Bay leads to a greater release of $\mathrm{PO}_{4}$ back into the overlying waters compared to the other two sites, where dissolved $\mathrm{H}_{2} \mathrm{~S}$ was not found.. However, the flux across the SWI is still much lower than the flux calculated from the maximum gradient (20x in winter, $3 \mathrm{x}$ in summer), indicating that the Fe-associated trapping effect is still an important factor (Table 15).

\section{Impact on Benthic Fluxes}

The return of $\mathrm{PO}_{4}$ to the overlying waters is perhaps the most crucial part of this investigation because this is what ultimately affects coastal nutrient availability and production rates. The different conditions at each site alter the expected return of $\mathrm{P}$ to the water column. Table 14 presents all the returning $\mathrm{PO}_{4}$ fluxes, from both porewater SWI and benthic flux chamber (BFC) measurements (Figure 24). With the exception of the 
BFC flux in Buzzards Bay, there is a very consistent trend of fluxes depleted or nearly depleted in $\mathrm{PO}_{4}$ relative to $\mathrm{tCO}_{2}$ in the cold months, countered with moderate enrichment of $\mathrm{PO}_{4}$ during the summer/fall, relative to Redfield values. (Tables 11 and 12, Figure 25) This trend may be a result of increased Fe-reducing remineralization during the summer and a thinner oxic layer at the SWI. As respiration ramps up during the warmer months, increased bioturbation supplies more Fe-OOH $* \mathrm{PO}_{4}$ downcore, which is then consumed as the electron acceptor for microbial diagenetic processes. This removal of $\mathrm{Fe}-\mathrm{OOH}$ from the surface and the subsequent reduction downcore release $\mathrm{PO}_{4}$ that had been previously bound on these Fe-bearing minerals. This enriches the porewaters in $\mathrm{P}$ relative to $\mathrm{tCO}_{2}$ and drives accelerated fluxes out of the sediments, which in turn reflect this $\mathrm{PO}_{4}$ enrichment with steep decreases in the $\mathrm{tCO}_{2}: \mathrm{PO}_{4}$ ratio (Tables 10 - 12). The thinner oxic layer reduces the volume of unsaturated $\mathrm{Fe}-\mathrm{OOH}$-containing sediment that the upwards fluxing $\mathrm{PO}_{4}$ must pass through before returning to the overlying waters. As the temperature and incoming $\mathrm{C}_{\mathrm{org}}$ drop, the remineralization rate in the sediment column decreases. This means that less $\mathrm{Fe}^{3+}$ from the $\mathrm{Fe}-\mathrm{OOH}$ minerals is reduced for respiration, releasing a lesser amount of $\mathrm{Fe}-$ bound $\mathrm{PO}_{4}$ in the process. Also, decreased bioturbation lowers the rate at which Fe-bound $\mathrm{PO}_{4}$ is mixed downcore. Decreased respiration moves the OPD downcore, increasing the thickness of the oxic layer, in turn increasing the volume of Fe-OOH-containing sediments that $\mathrm{PO}_{4}$ fluxing upwards must pass through. Thus, porewater $\mathrm{PO}_{4}$ once again becomes trapped on the Fe-bearing minerals at the oxic/anoxic boundary layer, but with a diminished return rate back downcore. This retards the return rates of $\mathrm{PO}_{4}$ back into the overlying waters, and leads to a depletion of $\mathrm{PO}_{4}$ relative to $\mathrm{tCO}_{2}$ in the fluxes into the water column, as seen in 
Table 11 and 12. In the next year, this cycle will start back up again, with cycling down of Fe-bound $\mathrm{PO}_{4}$ to be released, raising porewater $\mathrm{PO}_{4}$ concentrations and producing an enriched $\mathrm{PO}_{4}$ flux to the overlying waters. Additional evidence for this behavior is illustrated in Figure 13, which shows that for the majority of the sites, the Fe-bound $\mathrm{PO}_{4}$ inventory during the winter is higher than in the summer/fall, indicating increased storage of $\mathrm{PO}_{4}$ during that time.

This picture is supported by examining the reduction in the porewater $\mathrm{PO}_{4}$ calculated fluxes as the $\mathrm{PO}_{4}$ passes through the oxic/anoxic boundary layer on its way out of the sediments. Table 15 shows that, generally, over $90 \%$ of the porewater $\mathrm{PO}_{4}$ does not make it past the oxic/anoxic boundary layer during winter. In the summer/fall, this amount is reduced to between $\sim 40-60 \%$. This provides evidence for the increased trapping effect formed by the thickening of the oxic layer during winter. Note also that Hingham Bay has the highest trapping efficiency of the three sites, with $95 \%$ trapped in winter and $61 \%$ trapped during the summer. This is connected to its relatively high amount of total Fe in the sediment column.

\section{$\underline{\text { Potential Consequences: Mineral Precipitation and P Burial }}$}

Another potential removal mechanism for pore-water phosphate is the precipitation of phosphate-type minerals. This is a proposed consequence of the elevated $\mathrm{P}$ ratios in the pore-waters formed by the solid-phase cycling trap. Such minerals include struvite $\left(\mathrm{MnNH}_{4} \mathrm{PO}_{4}: 6 \mathrm{H}_{2} \mathrm{O}\right)$, apatite $\left(\mathrm{Ca}_{10}(\mathrm{PO} 4)_{6}(\mathrm{~F}-\mathrm{OH})_{2}\right.$ and vivianite $\left(\mathrm{Fe}_{3}\left(\mathrm{PO}_{4}\right)_{2}: 8 \mathrm{H}_{2} \mathrm{O}\right)$. Several studies have indicated that coastal sediment settings have the potential to act as generation sites for these mineral types (Martens, Berner et al. 1978; Jahnke, Emerson et 
al. 1983; Van Der Zee, Slomp et al. 2002). Apatite formation is not indicated by the Cabound profiles from the SEDEX analysis.

The porewater profiles of $\mathrm{PO}_{4}$ at Buzzards Bay site exhibit loss of phosphate at depth. During March, this removal seems to be located in the region between $2 \mathrm{~cm}$ and $20 \mathrm{~cm}$ (Figure 14). A shift in this region occurs during the transition to August (Figure 15). During that time, the return to previous $\mathrm{PO}_{4}$ levels is not observed. Instead, phosphate decrease begins at $3.8 \mathrm{~cm}$ and approaches a value of $\sim 15 \mathrm{uM}$ around $21.9 \mathrm{~cm}$. Porewater $\mathrm{Fe}^{2+}$ levels exhibit removal at depth at these times as well, with a very strong removal during August. These regions of removal do not correspond with known areas of FeS formation and must be the work of a different removal process.

To investigate whether the precipitation of phosphate-type minerals is occurring, we determine if the pore-waters achieve super-saturation with respect to the solid phases in question. Here we examine vivianite, the only mineral with sufficient data for solubility analysis.

Porewater concentrations from the August 2004 Buzzards Bay cores were analyzed by the algorithm described in Martens and laid out in the Appendix. (Martens, Berner et al. 1978) The generated solubility profiles (Figure 26) indicate that the porewaters are supersaturated with respect to vivianite from a depth range of $\sim 0.4 \mathrm{~cm}$ to around $\sim 8.0 \mathrm{~cm}$. When plotted as Ion Activity Product (IAP) vs. Depth against Concentration vs. Depth, the peak of the IAP values appears to coincide with the peak of the dissolved iron curve and with the maximum of the pore-water phosphate profile. (Figure 26) The IAP curve then passes back under the solubility curve at $8.2 \mathrm{~cm}$, which is very close to the inflection point for the pore-water Fe curve, indicating that the switch 
from addition to removal of $\mathrm{Fe}^{2+}$ occurs at a similar depth. To test the model's reaction and sensitivity to changes in $\mathrm{pH}$, potentially resulting from inaccurate back calculation values from dissolved porewater concentrations, a lower value of $\mathrm{pH}=7.5$ was also fed into the calculations. The lower $\mathrm{pH}$ shifted the super-saturation region into a tighter range, but still a significant region of the core exhibited the potential for vivianite precipitation.

Vivianite formation would represent a solid-phase removal process for $\mathrm{P}$ in the lower reaches of the sediment column, made possible by the simultaneous occurrence of porewaters enriched in both $\mathrm{PO}_{4}$ and Fe. The $\mathrm{PO}_{4}$ profiles at the other research sites do not exhibit nearly as strong a $\mathrm{PO}_{4}$ removal at depth (Figures 9, 12, 16, 17). This may be attributed to the porewater Fe removal caused by sulfide. As iron sulfide minerals precipitate, they may lower the concentration of Fe below that required for vivianite precipitation. This is true at deep points in the sediments, and may limit potential areas of mineral precipitation to areas immediately adjacent to the dissolved $\mathrm{Fe}$ and $\mathrm{PO}_{4}$ maxima. 


\section{Conclusion:}

The phosphorus in Massachusetts coastal sediments exhibits a dynamic exchange cycle between porewaters, solid phases, and the overlying waters. By use of the SEDEX Method, $\mathrm{P}$-associated phases were separated and analyzed. Fe-bound $\mathrm{PO}_{4}$ is the primary actively cycling solid phase in this environment, which constitutes the majority of porewater/solid-phase $\mathrm{P}$ exchange. Fe-bound $\mathrm{PO}_{4}$ primarily determines the shape of the solid-phase $\mathrm{PO}_{4}$ profile, but was not necessarily its chief component. The Fe-bound phase is shown to peak in the near-surface sediments, near the depth of removal of porewater $\mathrm{Fe}^{2+}$, with a decline downcore where $\mathrm{Fe}$ is reduced by microbial diagenesis. While never going to a zero value, Fe-bound $\mathrm{PO}_{4}$ is not the principle solid-phase associated with burial at these sites.

Fe-associated minerals that form along the oxic/anoxic boundary layer act as a trapping feature, enriching porewaters greatly in $\mathrm{PO}_{4}$ with respect to the expected values from organic matter decomposition. It appears that the $\mathrm{PO}_{4}$ flux to the bottom waters is enhanced by a weakening of the Fe cycle due to precipitation and burial of Fe as iron sulfides, such as was observed in Hingham Bay. Benthic flux observations bear this out, displaying depletion in $\mathrm{P}$ relative to $\mathrm{C}$ in fluxes in the winter, and a significant enrichment of $\mathrm{P}$ in the summer/fall.

The principal phases that are associated with $\mathrm{PO}_{4}$ burial downcore in our sites are Ca-bound, "refractory" and $\mathrm{P}_{(\text {org) }}$. Thus, Fe-bound $\mathrm{PO}_{4}$ does not appear to be a major sink for $\mathrm{P}$ in these sediments. Also, in contrast to other studies of similar regions, this study does not note any significant formation of authigenic Ca-type minerals (apatite, chlorofluoro-apatite, etc.). 
In coastal environments, the sedimentary cycles of both Fe and $\mathrm{P}$ are intertwined. In order to properly constrain the return of bioavailabile $\mathrm{P}$ to the overlying waters, the particulars of the local Fe cycle must be known, especially the availability of sulfide in the sediments to form non-exchanging $\mathrm{Fe}(\mathrm{S})$ compounds. Exchanging Fe-bearing minerals, such as the ferric oxy-hydroxides (Fe-OOH), are capable of generating a substantial enrichment of $\mathrm{PO}_{4}$ in the porewaters, altering both the return rate of $\mathrm{P}$ to the water column and potentially generating conditions conducive to phosphate mineral precipitation capable of long-term burial in the sediments, depending on the rates of remineralization ongoing in the sediment column. The variations in the Fe cycle resonate in the $\mathrm{P}$ cycle, generating a seasonal pattern of depletion/enrichment of $\mathrm{P}$ in benthic fluxes. Future studies of nutrient cycling in this type of region must be sure to take these Fe-based interactions into account, if an accurate picture of $\mathrm{P}$ in a redox-driven world is to be created. This clarified picture of the coastal P cycle has numerous implications for other fields of inquiry, including coastal productivity models, "red-tide" predictions and general oceanic nutrient sinks. 


\section{Acknowledgements:}

This work was made possible by sponsorship and funding provided by NOAA, (U.S. Department of Commerce (Grant \# NA06OAR4170021, project \# R/G-29)); National Science Foundation (Grant \# OCE-0526389); WHOI / USGS Cooperative Agreement; and the WHOI Academic Programs Office

I would like to acknowledge the following people for their time and support in the creation of this thesis during my time in the Joint Program:

WHOI/MIT: Bill Martin, Joanne Goudreau, Ben Van Mooy, Dan McCorkle, Fred Sayles, Meg Tivey, Henry Dick, Ed Boyle, Ron Prinn, Jim Moffat, Bill Jenkins, Julia Westwater and Marsha Gomes.

Fellow Graduate Students: Paul Craddock, Christian Miller, Andrew McDonnell, Kelton McMahon, Alysia Cox, Desiree Plata, Matt Jackson, Patricia Gregg, Abigail Fusaro, Emily Roland, Erin Banning, Eoghan Reeves and Andrew Barton.

Family: Richard and Kathy Oates, Campbell Oates, Happy Kirkpatrick, Carl and Pam Kirkpatrick, Dusty and Zelda Oates, Caroline and Amanda Oates, Dr. Sam Gambrel, Dr. Bill Junkin, Dr. Harry Stille and my fiancée Sharon Hoffmann.

This thesis is dedicated to Sharon Hoffmann, my best friend and my love, and to the glory of God. 


\section{Appendix:}

Flux Calculations:

Fick's First Law describes fluxes of chemical species by diffusion:

$F=-\phi D_{i} \frac{\partial C_{i}}{\partial x}$ (Fick's First Law) (1.1)

where $\mathrm{F}=$ flux across a plane of reference, $\mathrm{phi}=$ porosity of the sediments, $\mathrm{D}_{\mathrm{i}}=$ diffusion coefficient of species (i), and the derivative $=$ concentration gradient of species (i). (Berner 1980) This equation was adapted for porous sediments via several modifications. First, the diffusion coefficient was calculated using data compiled by Boudreau for tortuousity and other sediment effects. (Boudreau 1997) This accounts for both temperature and salinity effects on the standard $\mathrm{D}_{(\mathrm{sw})}$ of the dissolved species. Then, the porosity of the sediments was taken into account by the following relationship (Morford, Martin et al. 2007):

$D_{(s e d)}=\frac{D_{(s w)}}{\phi F}($ where $\mathrm{phi}=$ porosity, $\mathrm{F}=$ formation factor $)(1.2)$

where:

$F=c \phi^{-v}($ where $\mathrm{c}$ and $\mathrm{v}=$ constants) (1.3)

Then (1.3) can be arranged into:

$\log \left(\frac{1}{F}\right)=c+v \log (\phi)(1.4)$

Incorporating (1.4) into (1.2), one arrives at:

$$
D_{(s e d)}=D_{(s w)} \phi^{(v-1)}(\mathbf{1 . 5})
$$

where $\mathrm{D}_{(\mathrm{sed})}$ is the diffusive coefficient in the sediment column. From the pore-water profiles, regions for flux calculations were selected to both reflect the hypothesized 
removal mechanism in the iron precipitation regions and the area of the curve with the steepest gradient. By using the region of highest gradient (delta $\mathrm{PO}_{4}$ vs. delta $\mathrm{z}$ ), a realistic value of the phosphate flux in the sediment column can be calculated. These regions were determined by visual examination of the profiles and a trial-and-error determination of the gradient location.

\section{Porewater Flux Calculation Parameters:}

The following are the depth ranges in the porewater profiles where the maximum downcore gradients were determined to be. In Buzzards Bay, the range for March 2003 was from 1.08 to $2.65 \mathrm{~cm}$. For August 2004, the range was from 0.16 to $1.27 \mathrm{~cm}$. Second, in Hingham Bay, the January 2002 range was from 1.23 to $1.88 \mathrm{~cm}$. In September 2002, the range was from 1.68 to $2.09 \mathrm{~cm}$. Finally, in Massachusetts Bay, the range for February 2002 was from 0.95 to $1.91 \mathrm{~cm}$. The range for October 2002 was from 1.83 to $2.23 \mathrm{~cm}$.

Tables 16 and 17 contain the sets of parameters utilized in flux calculations. All data was provided by W. Martin via personal communication.

\section{Solid Phase Fluxes:}

Table 18 contains the parameters utilized in calculating the solid phase fluxes. The following equation was used for this calculation:

$$
F_{(\text {solid }- \text { phase })}=-\rho(1-\phi) D_{b i o}\left(\frac{d C}{d z}\right)
$$

where rho $=$ density of sediments $\left(\mathrm{g} / \mathrm{cm}^{3}\right)$, phi $=$ porosity of sediments and $\mathrm{D}_{\text {bio }}=$ bioturbation mixing coefficient $\left(\mathrm{cm}^{2} / \mathrm{yr}\right)$. 
If additional terms were required, the porewater parameters for the corresponding site were employed. Density of coastal sediments was taken to be $\sim 2.6 \mathrm{~g} / \mathrm{cm}^{3}$ in all locations.

\section{Vivianite Solubility Calculations:}

Following the method outlined in Martens et al, 1978, I calculated the saturation state of the pore waters by substituting in the $\mathrm{K}_{\mathrm{a}}$ values adjusted for the seawater conditions and setting up a series of two equations. From the total SRP, the following equation is used to determine the $\mathrm{PO}_{4}{ }^{3+}$ ion concentration:

$$
m_{P O_{4}^{+3}}=\frac{\sum P}{1+a_{H+} / K_{3}{ }^{\prime}+a_{H+}^{2} / K_{2}{ }^{\prime} K_{3}{ }^{\prime}+a_{H+}^{3} / K_{1}^{\prime} K_{2}{ }^{\prime} K_{3}{ }^{\prime}}
$$

where $\mathrm{K}_{1}{ }^{\prime}, \mathrm{K}_{2}$ ' and $\mathrm{K}_{3}$ ' refer to the $1^{\text {st }}, 2^{\text {nd }}$ and $3^{\text {rd }}$ disassociation constants for phosphoric acid adjusted for a seawater solution and the activity of hydrogen ions in the solution (ie. the $\mathrm{pH}$ ). The $\mathrm{pH}$ of the solution was back-calculated from the measured values of $\mathrm{tCO}_{2}$, Alkalinity and other measured dissolved charged species. The values for the phosphoric constants were obtained from Kester and Pytkowicz 1968 for values indicated for the salinity and temperature averages from the Buzzards Bay site. (Kester and Pytkowicz 1967) The values utilized were $2.96 \times 10^{2}$ for $K_{1}{ }^{\prime}, 0.74 \times 10^{6}$ for $K_{2}$ ' and $0.82 \times 10^{9}$ for $K_{3}$ '. The initial values for the Ka constants were taken from Principles and Applications of Aquatic Chemistry and are as follows: $\mathrm{K}_{1}=10^{-2.15}, \mathrm{~K}_{2}=10^{-7.2}, \mathrm{~K}_{3}=10^{-12.35}$.(Morel and Hering 1993) From there, I calculated the Ion Activity Product (IAP) for vivianite using the following formula:

$$
I A P=\gamma_{T^{3} \mathrm{Fe}^{+3}} \gamma_{T_{P_{4}^{-3}}^{2}} m_{T^{3} \mathrm{Fe}^{+3}} m_{T_{P_{4}^{-3}}^{2}}
$$


Gamma is the Total ion activity coefficient and $\mathrm{m}$ is the molality of the dissolved species. Following per Martens 1978, I took a total ion activity (TIA) of 0.25 for iron. The total ion activity for phosphate was determined per Martens with the following formula:

$$
\gamma_{T_{P O 4}}=\frac{K_{1} K_{2} K_{3}}{K_{1}{ }^{\prime} K_{2}^{\prime} K_{3}^{\prime}} \gamma_{H_{3} P O_{4}}
$$

where TIA of $\mathrm{H}_{3} \mathrm{PO}_{4}$ is assumed to equal 1. After the IAP is calculated, the value is compared to the precipitation constant for vivianite, which is taken to be $10^{-36}$, again, per Martens. If the IAP is found to be larger than the solubility constant, then the solution can be considered supersaturated, making precipitation of vivianite a realistic possibility. 


\section{References:}

Anschutz, P., S. Zhong, et al. (1998). "Burial Efficiency of Phosphorus and the Geochemistry of Iron in Continental Margin Sediments." Limnology and Oceanography 43(1): 53-64.

Berner, R. A. (1980). Early Diagenesis: A Theoretical Approach, Princeton University Press.

Boudreau, B. P. (1997). Diagenetic Models and Their Implementation: Modelling Transport and Reactions in Aquatic Sediments, Springer.

Briggs, P. M., A. (1999). The determination of forty-two elements in geological materials by inductively-coupled mas spectrometry. USGS Open File Report 1999-166, US Geological Survey.

Burdige, D. J. (2006). Geochemistry of marine sediments, Princeton University Press.

C. Hyacinthe, P. V. C. (2004). "An Authogenic iron phosphate phase in estuarine sediments: composition, formation and chemical reactivity." Marine Chemistry 91: 227 251.

Druffel, E. R. M., P. M. Williams, et al. (1992). "Cycling of Dissolved and Particulate Organic Matter in the Open Ocean." Journal of Geophysical Research 97(C10): 1563915659.

Ingall, E. D. and P. Van Cappellen (1990). "Relation between sedimentation rate and burial of organic phosphorus and organic carbon in marine sediments." Geochim. Cosmochim. Acta 54(2): 373-383.

Jahnke, R. A., S. R. Emerson, et al. (1983). "The present day formation of apatite in Mexican continental margin sediments." Geochimica et Cosmochimica Acta 47(2): 259266.

Kalnejais, L. H. (2005). Mechanisms of Metal Release from Contaminated Coastal Sediments. Dept. of Marine Chemistry and Geochemistry. Woods Hole, MA, MIT/WHOI Joint Program. Ph.D.

Kalnejais, L. H., W. R. Martin, et al. (2007). "Role of Sediment Resuspension in the Remobilization of Particulate-Phase Metals from Coastal Sediments." Environmental science \& technology 41(7): 2282-2288.

Kester, D. R. and R. M. Pytkowicz (1967). "Determination of the Apparent Dissociation Constants of Phosphoric Acid in Seawater." Limnology and Oceanography 12(2): 243252. 
Krom, M. D. and R. A. Berner (1980). "Adsorption of Phosphate in Anoxic Marine Sediments." Limnology and Oceanography 25(5): 797-806.

Lehtoranta, J. and H. Pitkänen (2003). "Binding of phosphate in sediment accumulation areas of the eastern Gulf of Finland, Baltic Sea." Hydrobiologia 492(1): 55-67.

Martens, C. S., R. A. Berner, et al. (1978). "Interstitial Water Chemistry of Anoxic Long Island Sound Sediments. 2. Nutrient Regeneration and Phosphate Removal." Limnology and Oceanography 23(4): 605-617.

Morel, F. M. M. and J. G. Hering (1993). Principles and Applications of Aquatic Chemistry, Wiley-Interscience.

Morford, J. L., W. R. Martin, et al. (2007). "Insights on geochemical cycling of U, Re and Mo from seasonal sampling in Boston Harbor, Massachusetts, USA." Geochimica et Cosmochimica Acta 71(4): 895-917.

Rozan, T. F., M. Taillefert, et al. (2002). "Iron-Sulfur-Phosphorus Cycling in the Sediments of a Shallow Coastal Bay: Implications for Sediment Nutrient Release and Benthic Macroalgal Blooms." Limnology and Oceanography 47(5): 1346-1354.

Ruttenberg, K. (1992). "Development of a sequential extraction method for different forms of phosphorus in marine sediments." Limnology and Oceanography 37(7): 1460 1482.

Ruttenberg, K. C. (2003). The Global Phosphorus Cycle. Treatise on Geochemistry. W. H. Schlesinger, Elsevier. 8: 585 - 643.

Sayles, F. a. G., Joanne (2007). Sediment Oxygen Profiles and Fluxes as a Constraint on the Delivery of Organic Matter to Sediments. Processes Influencing The Transport and Fate of Contaminated Sediments in the Coastal Ocean ---- Boston Harbor and Massachusetts Bay. M. a. B. Bothner, B, US Geological Survey: 56 -61.

Schuffert, J. D., M. Kastner, et al. (1998). "CARBON AND PHOSPHORUS BURIAL ASSOCIATED WITH MODERN PHOSPHORITE FORMATION." Marine geology 146(1-4): 21-31.

Slomp, C. P., J. F. P. Malschaert, et al. (1998). "The Role of Adsorption in SedimentWater Exchange of Phosphate in North Sea Continental Margin Sediments." Limnology and Oceanography 43(5): 832-846.

Strickland, J. D. H. and T. R. Parsons (1960). A Manual of Sea Water Analysis: With Special Reference to the More Common Micronutrients and to Particulate Organic Material, Fisheries Research Board of Canada. 
Van Der Zee, C., C. P. Slomp, et al. (2002). "Authigenic P formation and reactive P burial in sediments of the Nazaré canyon on the Iberian margin(NE Atlantic)." Marine geology 185(3-4): 379-392.

Watanabe, F. S. and S. R. Olsen (1962). "COLORIMETRIC DETERMINATION OF PHOSPHORUS IN WATER EXTRACTS OF SOIL." Soil Science 93: 183 - 188. 


\section{TABLES:}

\section{SEDEX-generated Solid $\mathrm{Phase}^{\mathrm{PO}_{4}}$ Values}

\begin{tabular}{|c|c|c|c|c|c|c|c|c|}
\hline $\begin{array}{c}\mathrm{PO}_{4} \\
\text { Concentration } \\
\text { (umol/g sed) }\end{array}$ & & & $\begin{array}{l}\text { Loosely- } \\
\text { sorbed }\end{array}$ & $\begin{array}{c}\text { Fe- } \\
\text { Bound }\end{array}$ & $\begin{array}{c}\text { Ca- } \\
\text { Bound }\end{array}$ & Refractory & $\begin{array}{c}\text { Organic } \\
\mathrm{P}\end{array}$ & $\begin{array}{l}\text { Total } \\
\mathrm{PO}_{4}\end{array}$ \\
\hline Buzzards & Mar-03 & SWI & 3.08 & 11.86 & 6.38 & 2.97 & 6.94 & 31.22 \\
\hline \multirow[t]{4}{*}{ Bay } & & $20 \mathrm{~cm}$ & 2.16 & 3.64 & 6.80 & 2.79 & 6.99 & 22.37 \\
\hline & & & & & & & & \\
\hline & Aug-04 & SWI & 3.90 & 15.39 & 7.81 & 3.18 & 7.84 & 38.12 \\
\hline & & $22 \mathrm{~cm}$ & 1.18 & 3.27 & 7.75 & 3.49 & 5.90 & 21.58 \\
\hline Hingham & Jan-03 & SWI & 4.88 & 11.16 & 9.83 & 6.97 & 6.09 & 38.93 \\
\hline \multirow[t]{3}{*}{ Bay } & & $15.5 \mathrm{~cm}$ & 0.70 & 4.69 & 17.41 & 8.19 & 6.74 & 37.73 \\
\hline & Sep-03 & SWI & 4.20 & 17.21 & 6.27 & 7.91 & 8.83 & 44.42 \\
\hline & & $10.2 \mathrm{~cm}$ & 0.44 & 7.31 & 6.54 & 7.66 & 9.15 & 31.10 \\
\hline Mass. & Feb-02 & SWI & 3.94 & 12.04 & 10.39 & 8.64 & 6.20 & 41.20 \\
\hline \multirow[t]{3}{*}{ Bay } & & $21 \mathrm{~cm}$ & 0.61 & 2.59 & 9.67 & 10.26 & 2.94 & 26.07 \\
\hline & Oct-02 & SWI & 4.33 & 8.31 & 11.44 & 8.46 & 5.15 & 37.68 \\
\hline & & $9.2 \mathrm{~cm}$ & 0.69 & 1.90 & 9.93 & 10.44 & 2.51 & 25.47 \\
\hline
\end{tabular}

(units of umol $\mathrm{PO}_{4} / g$ sediment)

(Table 1)

Percent Totals of SEDEX $\mathrm{PO}_{4}$ Solid Phases

\begin{tabular}{|c|c|c|c|c|c|c|c|c|}
\hline \multicolumn{2}{|c|}{ Phase Fractions (\%total) } & $\begin{array}{c}\text { Loosely- } \\
\text { sorbed }\end{array}$ & $\begin{array}{c}\text { Fe- } \\
\text { Bound }\end{array}$ & $\begin{array}{c}\text { Ca- } \\
\text { Bound }\end{array}$ & Refractory & $\begin{array}{c}\text { Organic } \\
\mathrm{P}\end{array}$ & $\begin{array}{c}\text { Total } \\
\mathrm{PO}_{4}\end{array}$ \\
\hline Buzzards & Mar-03 & SWI & 9.86 & 37.98 & 20.42 & 9.50 & 22.23 & 100.00 \\
\hline Bay & & $20 \mathrm{~cm}$ & 9.64 & 16.28 & 30.37 & 12.45 & 31.26 & 100.00 \\
\hline & & & & & & & & \\
\hline & Aug-04 & SWI & 10.24 & 40.38 & 20.49 & 8.33 & 20.57 & 100.00 \\
\hline & & $22 \mathrm{~cm}$ & 5.45 & 15.15 & 35.91 & 16.16 & 27.34 & 100.00 \\
\hline & & & & & & & \\
\hline Hingham & Jan-03 & SWI & 12.54 & 28.67 & 25.24 & 17.91 & 15.64 & 100.00 \\
\hline Bay & & $15.5 \mathrm{~cm}$ & 1.85 & 12.44 & 46.13 & 21.71 & 17.86 & 100.00 \\
\hline & & & & & & & & \\
\hline & Sep-03 & SWI & 9.45 & 38.74 & 14.10 & 17.81 & 19.89 & 100.00 \\
\hline & & $10.2 \mathrm{~cm}$ & 1.41 & 23.51 & 21.02 & 24.62 & 29.44 & 100.00 \\
\hline & & & & & & & & \\
\hline Mass. & Feb-02 & SWI & 9.56 & 29.22 & 25.20 & 20.96 & 15.06 & 100.00 \\
\hline Bay & & $21 \mathrm{~cm}$ & 2.33 & 9.93 & 37.10 & 39.37 & 11.26 & 100.00 \\
\hline & & & & & & & & \\
\hline & Oct-02 & SWI & 11.49 & 22.06 & 30.35 & 22.44 & 13.65 & 100.00 \\
\hline & & $9.2 \mathrm{~cm}$ & 2.71 & 7.46 & 38.98 & 40.99 & 9.85 & 100.00 \\
\hline
\end{tabular}

$\left(\right.$ Phase fraction $=\left(\right.$ phase $/$ Total $\left.\left.\mathrm{PO}_{4}\right) * 100\right)$

(Table 2) 
Determination of Variability in the SEDEX Method

\begin{tabular}{|c|c|c|c|c|c|c|}
\hline \multicolumn{2}{|c|}{ Buzzards Bay (March 2003) } & & & & & \\
\hline \# 2-2 Depth $=0.23 \mathrm{~cm}$ & Step I & Step II & Step III & Step IV & Step V & $\begin{array}{l}\text { Total } \\
\mathrm{PO}_{4}\end{array}$ \\
\hline Average & 1.765 & 11.37 & 6.263333 & 2.835 & 7.4825 & 29.07333 \\
\hline Std. Dev & 0.421861 & 1.708469 & 0.737111 & 0.130767 & 0.122848 & 1.287646 \\
\hline$\% \mathrm{CV}$ & 23.90147 & 15.02611 & 11.76868 & 4.612591 & 1.641806 & 4.42896 \\
\hline \multicolumn{7}{|l|}{ \#2-23 Depth $=20.03 \mathrm{~cm}$} \\
\hline Average & 1.373333 & 3.17 & 6.183333 & 2.786667 & 6.933333 & 20.49 \\
\hline Std. Dev & 0.880814 & 0.527162 & 1.245325 & 0.130128 & 0.152753 & 1.738649 \\
\hline$\% \mathrm{CV}$ & 64.13694 & 16.62972 & 20.14002 & 4.66967 & 2.203161 & 8.485353 \\
\hline
\end{tabular}

(where $\% C V=$ Std. Dev/Average $* 100)(\# 2-2=$ quadruplicate, $\# 2-23=$ triplicate)

(Table 3)

Inventories of Solid-Phase $\mathrm{PO}_{4}$ in Sediments

\begin{tabular}{|c|c|c|c|c|c|c|c|c|}
\hline \multicolumn{2}{|c|}{$\begin{array}{l}\mathrm{PO}_{4} \text { Inventories } \\
\text { (umol } / \mathrm{cm}^{2} \text { ) }\end{array}$} & & $\begin{array}{l}\text { Loosely- } \\
\text { sorbed }\end{array}$ & $\begin{array}{l}\text { Fe- } \\
\text { Bound }\end{array}$ & $\begin{array}{l}\text { Ca- } \\
\text { Bound }\end{array}$ & Refractory & $\begin{array}{l}\text { Organic } \\
\mathrm{P}\end{array}$ & $\begin{array}{l}\text { Total } \\
\mathrm{PO}_{4}\end{array}$ \\
\hline Buzzards & Mar-03 & SWI & 0.14 & 0.53 & 0.29 & 0.13 & 0.31 & 1.41 \\
\hline \multirow[t]{4}{*}{ Bay } & & $21 \mathrm{~cm}$ & 26.69 & 55.17 & 85.76 & 35.25 & 90.48 & 293.35 \\
\hline & & & & & & & & \\
\hline & Aug-04 & SWI & 0.10 & 0.38 & 0.19 & 0.08 & 0.19 & 0.95 \\
\hline & & $22 \mathrm{~cm}$ & 14.52 & 44.72 & 94.93 & 40.99 & 74.78 & 269.94 \\
\hline Hingham & Jan-03 & SWI & 0.15 & 0.34 & 0.30 & 0.21 & 0.19 & 1.19 \\
\hline \multirow[t]{3}{*}{ Bay } & & $15.5 \mathrm{~cm}$ & 8.03 & 44.85 & 145.24 & 65.19 & 55.66 & 318.96 \\
\hline & Sep-03 & SWI & 0.19 & 0.77 & 0.28 & 0.35 & 0.39 & 1.98 \\
\hline & & $10.2 \mathrm{~cm}$ & 5.08 & 49.23 & 36.06 & 45.67 & 46.43 & 182.47 \\
\hline Mass. & Feb-02 & SWI & 0.25 & 0.77 & 0.66 & 0.55 & 0.40 & 2.63 \\
\hline \multirow[t]{3}{*}{ Bay } & & $21.3 \mathrm{~cm}$ & 17.98 & 67.85 & 189.66 & 198.21 & 67.26 & 540.96 \\
\hline & Oct-02 & SWI & 0.27 & 0.52 & 071 & 0.53 & 0.32 & 235 \\
\hline & & $9.2 \mathrm{~cm}$ & 9.14 & 23.43 & 87.37 & 83.46 & 24.73 & 228.13 \\
\hline
\end{tabular}

(inventory in units of (umol $\mathrm{PO}_{4} / \mathrm{cm}^{2}$ sediment)

(Table 4) 
Organic Carbon and $\mathrm{PO}_{4}$ in Sediments

\begin{tabular}{|c|c|c|c|c|c|}
\hline Organic C:P & & $\begin{array}{c}\text { Expected C:P } \\
\text { from [C }\end{array}$ & $\begin{array}{c}\text { Measured } \\
\mathrm{P}(\text { org })(\text { SEDEX) }\end{array}$ & $\begin{array}{c}\text { Expected C:P/ } \\
\text { SEDEX P }\end{array}$ & $\begin{array}{c}(\mathrm{C}: \mathrm{P})_{\text {org }} \text { from } \\
{\left[\mathrm{C}_{\text {org }}\right],\left[\mathrm{P}_{\text {org }}\right]}\end{array}$ \\
\hline Buzzards & SWI & 20 & 7.5 & 2.7 & 277 \\
\hline Bay & Deep & 13 & 6.5 & 2 & 218 \\
\hline & & & 8 & 3.3 & 333 \\
\hline Hingham & SWI & 25 & 7 & 3.1 & 332 \\
\hline Bay & Deep & 22 & & & 341 \\
\hline & & & $5.2-6.5$ & 3.2 & 403 \\
\hline Mass. & SWI & 19 & $2.5-3.0$ & 3.6 & \\
\hline Bay & Deep & 10 &
\end{tabular}

(where Expected $C: P=\left(\left[C_{\text {org }}\right] / 106\right)$, and $P($ org $)=$ SEDEX Step $V$, average values for both sampling times)

(Table 5)

Solid Phase Iron Amounts (\% weight) and Fe:Al Ratios

\begin{tabular}{|c|c|c|c|}
\hline & & $\% \mathrm{Fe}$ & Fe:Al \\
\hline Buzzards & SWI & 3.3 & 0.52 \\
\hline Bay & $\mathrm{z}>8 \mathrm{~cm}$ & $2.8-3.2$ & $0.45-0.48$ \\
\hline & & & \\
\hline Hingham & SWI & $4.0-4.5$ & $0.55-0.60$ \\
\hline Bay & $\mathrm{z}>8 \mathrm{~cm}$ & $4.2-4.6$ & 0.55 \\
\hline & & & \\
\hline Mass. & SWI & $(2 / 02) 3.7$ & $0.5-0.56$ \\
\hline Bay & & $(10 / 02) 3.4$ & \\
\hline & $\mathrm{z}>5 \mathrm{~cm}$ & $(2 / 02) 2.8-3.5$ & $0.38-0.42$ \\
\hline & & $(9 / 02) 2.4-2.5$ & \\
\hline
\end{tabular}

(where $(\% \mathrm{Fe})$ is by weight)

(Table 6)

Solid Phase $\mathrm{PO}_{4}$ Downcore Fluxes from Oxic/Anoxic Boundary Layer

\begin{tabular}{|c|c|c|c|c|}
\hline $\begin{array}{c}\text { Solid Phase } \\
\text { Fluxes }\end{array}$ & & Downward & Downward & \\
\hline Buzzards & & Total PO 4 Flux & Fe-bound Flux & $\begin{array}{c}\text { \% of Flux as Fe- } \\
\text { Bound Fraction }\end{array}$ \\
\hline Bay & Mar-03 & -37 & -36 & 97 \\
\hline Fluxes & Aug-04 & -20 & -16 & 82 \\
\hline Hingham & & & & 94 \\
\hline Bay & Jan-03 & -10 & -9 & 70 \\
\hline Fluxes & Sep-03 & -125 & -88 & \\
\hline & & & & 85 \\
\hline Mass & & & & -14 \\
\hline Bay & Feb-02 & -16 & -13 & 39 \\
\hline Fluxes & Oct-02 & -33 & & \\
\hline
\end{tabular}

(flux in umol PO4/ cm2 yr, “-" sign indicates downward flux)

(Table 7) 


\section{Porewater $\mathrm{PO}_{4}$ Fluxes (derived from maximum porewater gradient)}

\begin{tabular}{|c|c|c|c|}
\hline \multicolumn{2}{|c|}{$\mathrm{PO}_{4}$ Fluxes (max gradient) } & \multirow[b]{2}{*}{ Flux Up } & \multirow[b]{2}{*}{ Flux Down } \\
\hline Buzzards & & & \\
\hline Bay & Mar-03 & 1.50 & 0.01 \\
\hline Fluxes & Aug-04 & 8.78 & 0.84 \\
\hline Hingham & & Flux Up & \\
\hline Bay & Jan-03 & 7.45 & $\mathrm{~N} / \mathrm{A}$ \\
\hline Fluxes & Sep-03 & 38.24 & $\mathrm{~N} / \mathrm{A}$ \\
\hline Mass & & Flux Up & \\
\hline Bay & Feb-02 & 2.21 & $\mathrm{~N} / \mathrm{A}$ \\
\hline Fluxes & Oct-02 & 5.32 & N/A \\
\hline
\end{tabular}

(Table 8)

\section{Porewater $\mathrm{tCO}_{2}$ Fluxes (derived from maximum porewater gradient)}

\begin{tabular}{|c|c|c|c|}
\hline \multicolumn{2}{|c|}{$\mathrm{tCO}_{2}$ Fluxes (max gradient) } & & \\
\hline Buzzards & & Flux Up & Flux Down \\
\hline Bay & Mar-03 & 23.00 & -6.07 \\
\hline Fluxes & Aug-04 & 160.68 & -10.18 \\
\hline & & & \\
\hline Hingham & & Flux Up & \\
\hline Bay & Jan-03 & 134.44 & N/A \\
\hline Fluxes & Sep-03 & 270.93 & N/A \\
\hline \multicolumn{2}{|c|}{} & Flux Up & Flux Down \\
\hline Mass & & 27.84 & -18.63 \\
\hline Bay & Feb-02 & 110.39 & -10.71 \\
\hline Fluxes & Oct-02 & all fluxes in units of umol/cm & yr \\
\hline
\end{tabular}

(Table 9)

Porewater $\mathrm{PO}_{4}$ and $\mathrm{tCO}_{2}$ Fluxes (derived from SWI gradient) and $\mathrm{C}: \mathrm{P}$ Ratios

\begin{tabular}{|c|c|c|c|c|}
\hline \multicolumn{2}{|c|}{ SWI Porewater Fluxes } & & & \\
\hline Buzzards & & $\mathrm{PO}_{4}(\mathrm{SWI})$ & $\mathrm{tCO}_{2}(\mathrm{SWI})$ & $\mathrm{tCO}_{2}: \mathrm{PO}_{4}(\mathrm{SWI})$ \\
\hline Bay & Mar-03 & 0.05 & 270.81 & 5416.21 \\
\hline Fluxes & Aug-04 & 5.63 & 334.77 & 59.46 \\
\hline Hingham & & & & \\
\hline Bay & Jan-03 & 0.33 & 742.11 & 2248.80 \\
\hline Fluxes & Sep-03 & 14.7 & 803.27 & 54.64 \\
\hline Mass & & & & \\
\hline Bay & Feb-02 & 0.92 & 286.51 & 311.42 \\
\hline Fluxes & Oct-02 & 3.22 & 316.31 & 98.23 \\
\hline
\end{tabular}

(fluxes in units of umol $\mathrm{PO}_{4} / \mathrm{cm}^{2}$ yr)

(Table 10) 
Ratio of C:P in Porewater Fluxes (derived from maximum porewater gradient)

\begin{tabular}{|c|c|c|}
\hline \multicolumn{2}{|c|}{$\mathrm{tCO}_{2}: \mathrm{PO}_{4}$} & Redfield Ratio \\
\hline Buzzards Bay & & 106.00 \\
\hline March & & August \\
\hline 19.23 & & 17.75 \\
\hline & & \\
\hline Hingham Bay & & \\
\hline January & & September \\
\hline 18.04 & & 7.08 \\
\hline Mass Bay & & \\
\hline February & & \\
\hline 21.03 & & October \\
\hline
\end{tabular}

(Table 11)

Benthic Flux Chamber $\mathrm{PO}_{4}$ and $\mathrm{tCO}_{2}$ Fluxes (derived from chamber time series) and Ratios

\begin{tabular}{|c|c|c|c|c|}
\hline \multicolumn{2}{|c|}{ Benthic Flux Chamber } & $\mathrm{PO}_{4}$ Flux & $\mathrm{tCO}_{2}$ Flux & tCO2: $\mathrm{PO}_{4}$ (Chamber) \\
\hline Buzzards & Mar-03 & 0.67 & 307.97 & 459 \\
\hline Bay & Aug-04 & 0.9 & 471.65 & 524 \\
\hline Hingham & Jan-03 & 11.55 & 1186.32 & 102 \\
\hline Bay & Sep-03 & 12.55 & 928.28 & 73 \\
\hline Mass. & Feb-02 & 3.14 & 460.63 & 146 \\
\hline Bay & Oct-02 & 14.14 & 1056.8 & 74 \\
\hline
\end{tabular}

(Table 12)

Comparison of SWI and Benthic Chamber Fluxes Out and Solid-phase Fluxes Downcore

\begin{tabular}{|c|c|c|c|c|c|c|}
\hline $\begin{array}{c}\text { Solid Phase } \\
\text { Fluxes }\end{array}$ & & Total $\mathrm{PO}_{4}$ & Fe-bound & $\begin{array}{c}\text { Porewater } \\
\mathrm{PO}_{4}\end{array}$ & & $\mathrm{PO}_{4}$ Flux \\
\hline Buzzards & & Flux Down & Flux Down & Flux Up & $\begin{array}{c}\text { Flux } \\
\text { Down/Flux Up }\end{array}$ & $\begin{array}{c}\text { Benthic } \\
\text { Chamber }\end{array}$ \\
\hline Bay & Mar-03 & -37.33 & -36.31 & 1.51 & 24.69 & 0.67 \\
\hline Fluxes & Aug-04 & -20.54 & -16.83 & 9.63 & 2.13 & 0.9 \\
\hline & & & & & & \\
\hline Hingham & & Flux In & & & & \\
\hline Bay & Jan-03 & -10.53 & -9.84 & 7.45 & 1.41 & 11.55 \\
\hline Fluxes & Sep-03 & -125.65 & -87.59 & 38.25 & 3.29 & 12.15 \\
\hline & & & & & & \\
\hline Mass & & Flux In & & & & \\
\hline Bay & Feb-02 & -16.37 & -13.98 & 2.21 & 7.41 & 3.14 \\
\hline Fluxes & Oct-02 & -32.71 & -12.90 & 5.32 & 6.15 & 14.14 \\
\hline
\end{tabular}

(fluxes in units of umol/ $\mathrm{cm}^{2} \mathrm{yr}$ )

(Table 13) 
Comparison of SWI and BFC Fluxes w/ C:P Ratios

\begin{tabular}{|c|c|c|c|c|c|c|}
\hline & $\mathrm{PO}_{4}$ & & $\mathrm{tCO}_{2}$ & & & \\
\hline $\begin{array}{c}\text { Buzzards } \\
\text { Bay }\end{array}$ & $\begin{array}{c}\text { Porewater } \\
\text { SWI }\end{array}$ & BFC & $\begin{array}{c}\text { Porewater } \\
\text { SWI }\end{array}$ & BFC & $\begin{array}{c}\mathrm{tCO}_{2}: \mathrm{PO}_{4} \\
(\mathrm{SWI})\end{array}$ & $\begin{array}{c}\mathrm{tCO}_{2}: \mathrm{PO}_{4} \\
(\mathrm{BFC})\end{array}$ \\
\hline Mar-03 & 0.05 & 0.67 & 270.81 & 307.97 & 5416.21 & 459.66 \\
\hline Aug-04 & 5.63 & 0.90 & 334.77 & 471.65 & 59.46 & 524.06 \\
\hline \multicolumn{7}{|c|}{ Hingham Bay } \\
\hline Jan-02 & 0.33 & 11.55 & 742.11 & 1186.32 & 2248.80 & 102.71 \\
\hline Sep-02 & 14.70 & 12.15 & 803.27 & 928.28 & 54.64 & 76.40 \\
\hline \multicolumn{7}{|l|}{ Mass Bay } \\
\hline Feb-02 & 0.92 & 3.41 & 286.51 & 460.63 & 311.42 & 135.08 \\
\hline Oct-02 & 3.22 & 14.41 & 316.31 & 1056.80 & 98.23 & 73.34 \\
\hline
\end{tabular}

(fluxes in units of umol $\mathrm{PO}_{4} / \mathrm{cm}^{2}$ yr)

(Table 14)

Trapping Effects of Oxic/Anoxic Boundary Layer

\begin{tabular}{|c|c|c|c|c|c|}
\hline $\mathrm{PO}_{4}$ Trapping & & & & & \\
\hline Buzzards & & $\begin{array}{c}\text { Maximum } \\
\text { Gradient Flux }\end{array}$ & $\begin{array}{l}\text { SWI } \\
\text { Flux }\end{array}$ & $\begin{array}{l}\text { "Trapped" } \\
\mathrm{PO}_{4}\end{array}$ & $\begin{array}{c}\% \text { of Maximum } \\
\text { Gradient Trapped }\end{array}$ \\
\hline Bay & Mar-03 & 1.50 & 0.05 & 1.45 & 96 \\
\hline Fluxes & Aug-04 & 8.78 & 5.63 & 3.15 & 35 \\
\hline Hingham & & & & & \\
\hline Bay & Jan-03 & 7.45 & 0.33 & 7.12 & 96 \\
\hline Fluxes & Sep-03 & 38.24 & 14.7 & 23.54 & 62 \\
\hline Mass & & & & & \\
\hline Bay & Feb-02 & 2.21 & 0.92 & 1.29 & 58 \\
\hline Fluxes & Oct-02 & 5.32 & 3.22 & 2.10 & 39 \\
\hline
\end{tabular}

(units of flux in umol $\mathrm{PO}_{4} / \mathrm{cm}^{2}$ yr, "trapped $\mathrm{PO}_{4}$ " = difference between fluxes)

(Table 15) 
Flux Calculation Parameters: $\mathrm{PO}_{4}$

\begin{tabular}{|c|c|c|c|c|c|c|}
\hline Pore-Water Fluxes & & & & & & \\
\hline Upward Fluxes & & & & & & \\
\hline & & $\mathrm{T}(\mathrm{deg} \mathrm{C})$ & $\mathrm{D}(\mathrm{sw})$ & $\mathrm{v}$ & Average Porosity & $\mathrm{D}(\mathrm{sed})$ \\
\hline Buzzards & Mar-03 & 8 & 165 & 3.48 & 0.841477706 & 107.54 \\
\hline Bay & Aug-04 & 20 & 240.6 & 2.6 & 0.865529222 & 190 \\
\hline & & & & & & \\
\hline Hingham & Jan-02 & 5 & 146.2 & 1.86 & 0.786983777 & 118.9811 \\
\hline Bay & Sep-02 & 15 & 209.15 & 2.95 & 0.805594807 & 137.2099 \\
\hline & & & & & & \\
\hline Mass. & Feb-02 & 5 & 146.2 & 1.75 & 0.817714286 & 125.7183 \\
\hline Bay & Oct-02 & 10 & 177.6 & 1.75 & 0.8165 & 152.5493 \\
\hline
\end{tabular}

\begin{tabular}{|c|c|c|c|c|c|c|}
\hline Downward Fluxes & & & & & & \\
\hline & & $\mathrm{T}(\operatorname{deg} \mathrm{C})$ & $\mathrm{D}(\mathrm{sw})$ & $\mathrm{v}$ & Average Porosity & $\mathrm{D}(\mathrm{sed})$ \\
\hline Buzzards & Mar-03 & 8 & 165 & 3.48 & 0.805315938 & 96.44514 \\
\hline Bay & Aug-04 & 20 & 240.6 & 2.6 & 0.783948454 & 162.988 \\
\hline
\end{tabular}

(Table 16)

Flux Calculation Parameters: $\mathrm{tCO}_{2}$

\begin{tabular}{|c|c|c|c|c|c|c|c|}
\hline & & $\begin{array}{c}\mathrm{T}(\mathrm{deg} \\
\mathrm{C})\end{array}$ & Range $(\mathrm{cm})$ & $\mathrm{D}(\mathrm{sw})$ & $\mathrm{v}$ & $\begin{array}{c}\text { Average } \\
\text { Porosity }\end{array}$ & $\mathrm{D}(\mathrm{sed})$ \\
\hline Buzzards & Mar-03 & 8 & $0.11-1.07$ & 267.7 & 3.48 & 0.829566 & 168.4218 \\
\hline Bay & Aug-04 & 20 & $0.16-0.81$ & 332.6 & 2.6 & 0.888896 & 275.4759 \\
\hline & & & & & & & \\
\hline Hingham & Jan-03 & 5 & $0.13-1.22$ & 202.7 & 1.86 & 0.890554 & 183.4686 \\
\hline Bay & Sep-03 & 15 & $0.15-1.06$ & 289.3 & 2.95 & 0.814731 & 194.0107 \\
\hline & & & & & & & \\
\hline Mass. & Feb-02 & 5 & $0.13-0.68$ & 202.7 & 1.75 & 0.8218 & 174.9558 \\
\hline Bay & Oct-02 & 10 & $0.0-0.5$ & 246 & 1.75 & 0.84975 & 217.7226 \\
\hline & & & & & & & \\
\hline
\end{tabular}

(Table 17) 
Flux Calculation Parameters: Solid Phase $\mathrm{PO}_{4}$

\begin{tabular}{|c|c|c|c|c|c|}
\hline & & & Average & & \\
\hline Buzzards & & Range & Porosity & Gradient & Dbio \\
\hline Bay & Mar-03 & $0.23-0.7$ & 0.849916 & -9.47232 & 10.1 \\
\hline Fluxes & Aug-04 & $0.13-0.4$ & 0.90599 & 19.93631 & 3.3 \\
\hline & & & & & \\
\hline Hingham & & & & & \\
\hline Bay & Jan-03 & $0.415-1.23$ & 0.873033 & -6.01361 & 3 \\
\hline Fluxes & Sep-03 & $0.14-0.99$ & 0.851363 & -13.5471 & 24 \\
\hline & & & & & \\
\hline Mass & & & & & \\
\hline Bay & Feb-02 & $0.68-1.25$ & 0.834 & -7.58373 & 5 \\
\hline Fluxes & Oct-02 & $1.17-1.83$ & 0.8296 & -10.6987 & 6.9 \\
\hline
\end{tabular}

(units of gradient in delta(umol PO4/g sediment)/delta(cm))

(Table 18) 


\section{Figure 1: SEDEX Profiles - Buzzards Bay}

March 2003 SEDEX Phase Profile Conc. (umol $\mathrm{PO}_{4} / \mathrm{g}$ sed)

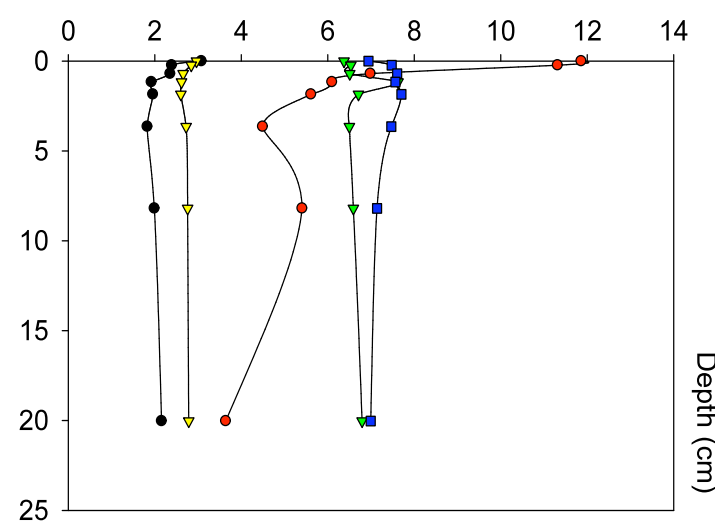

$$
\begin{aligned}
& \rightarrow \text { Loosely Sorbed } \\
& \rightarrow \text { Fe-bound } \\
& \rightarrow \text { Ca-bound } \\
& \rightarrow-\text { Refractory } \\
& \square \text { Organic P }
\end{aligned}
$$

SEDEX Total $\mathrm{PO}_{4}$

$\mathrm{PO}_{4}, \mathrm{uM} / \mathrm{g}$ sed

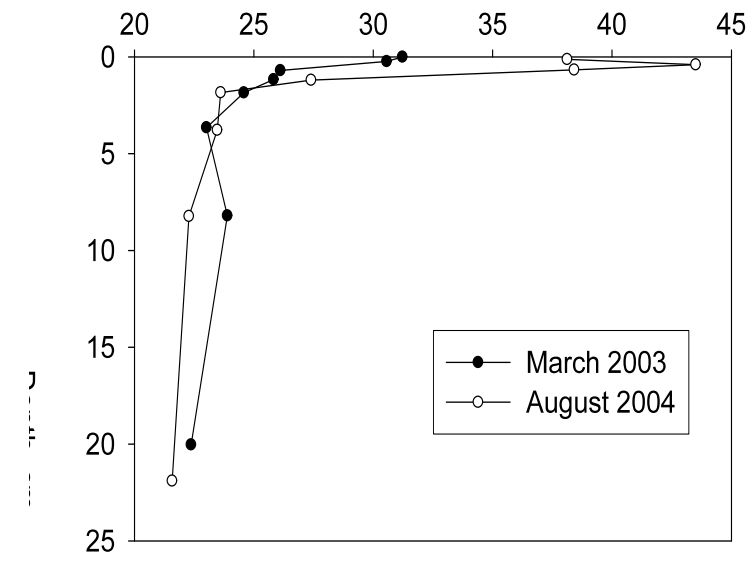

August 2004 SEDEX Phase Profile Conc. (umol $\mathrm{PO}_{4} / \mathrm{g}$ sed)

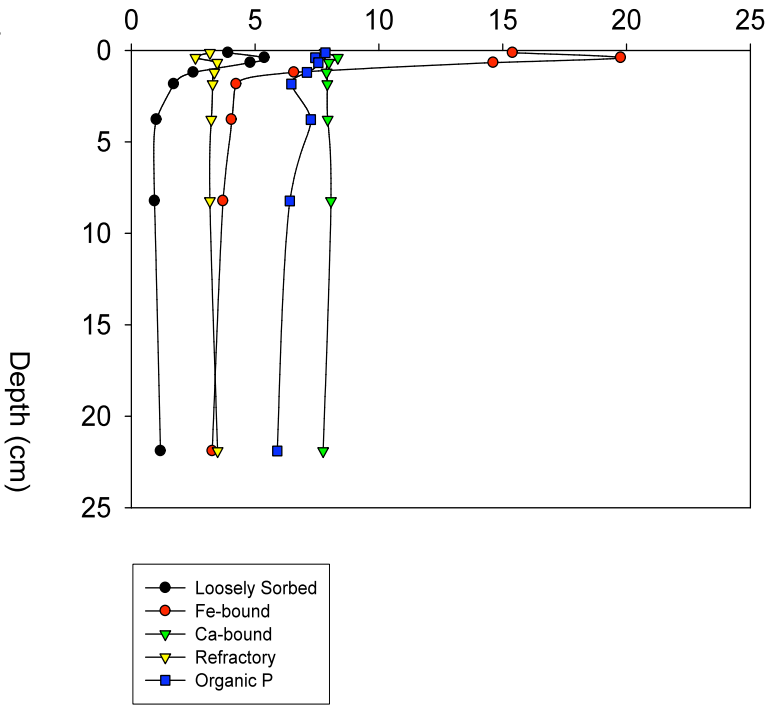




\section{Figure 2: SEDEX \\ Profiles - Hingham Bay}
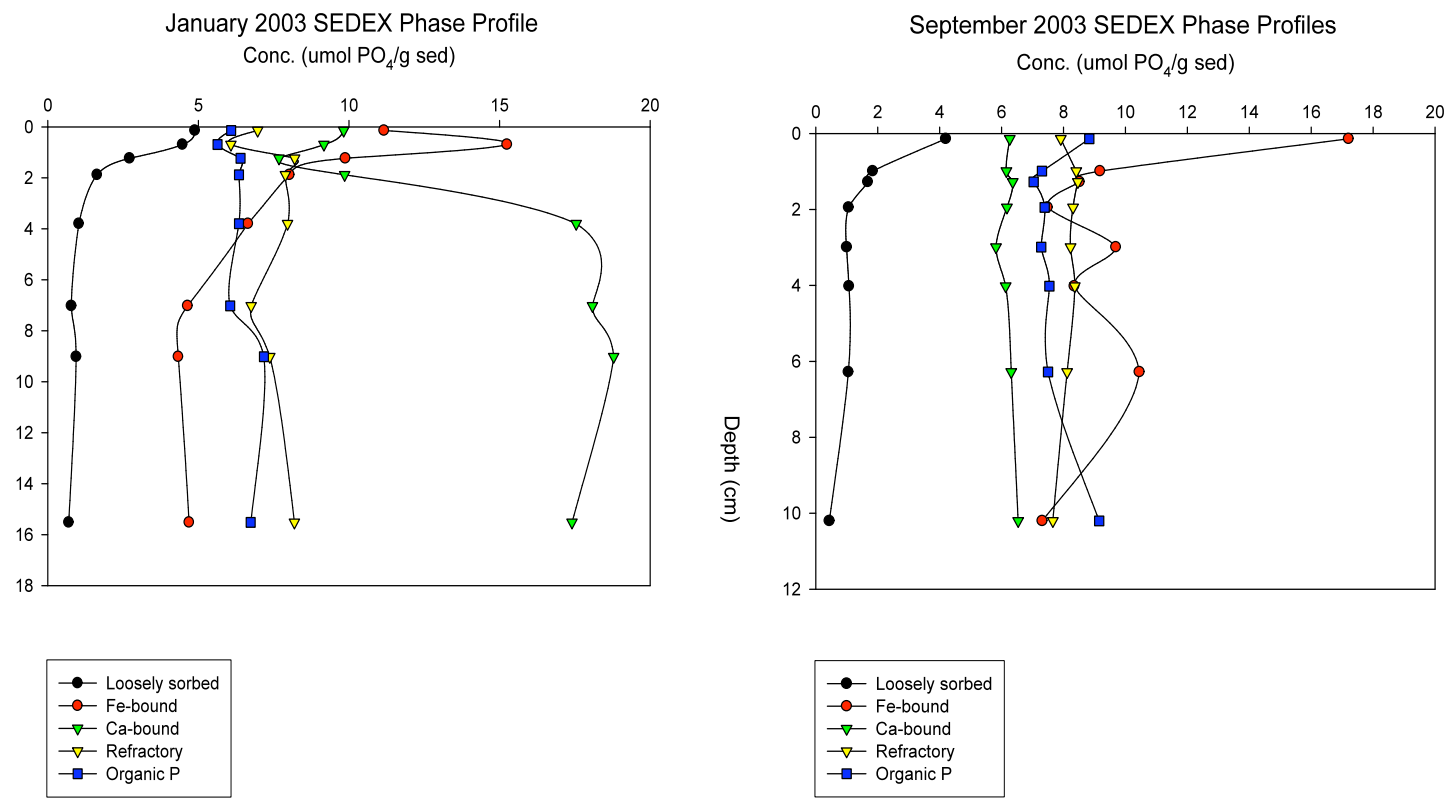

SEDEX Total $\mathrm{PO}_{4}$

$\mathrm{PO}_{4}, \mathrm{uM} / \mathrm{g}$ sed

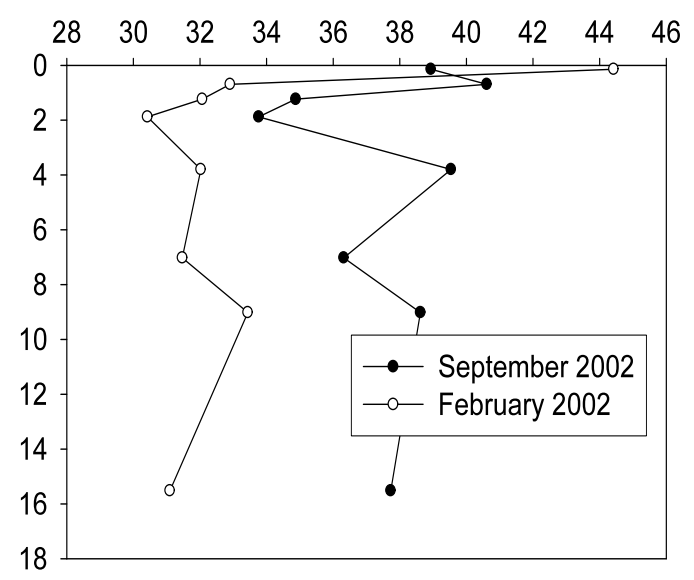




\section{Figure 3: SEDEX Profiles - Massachusetts Bay}
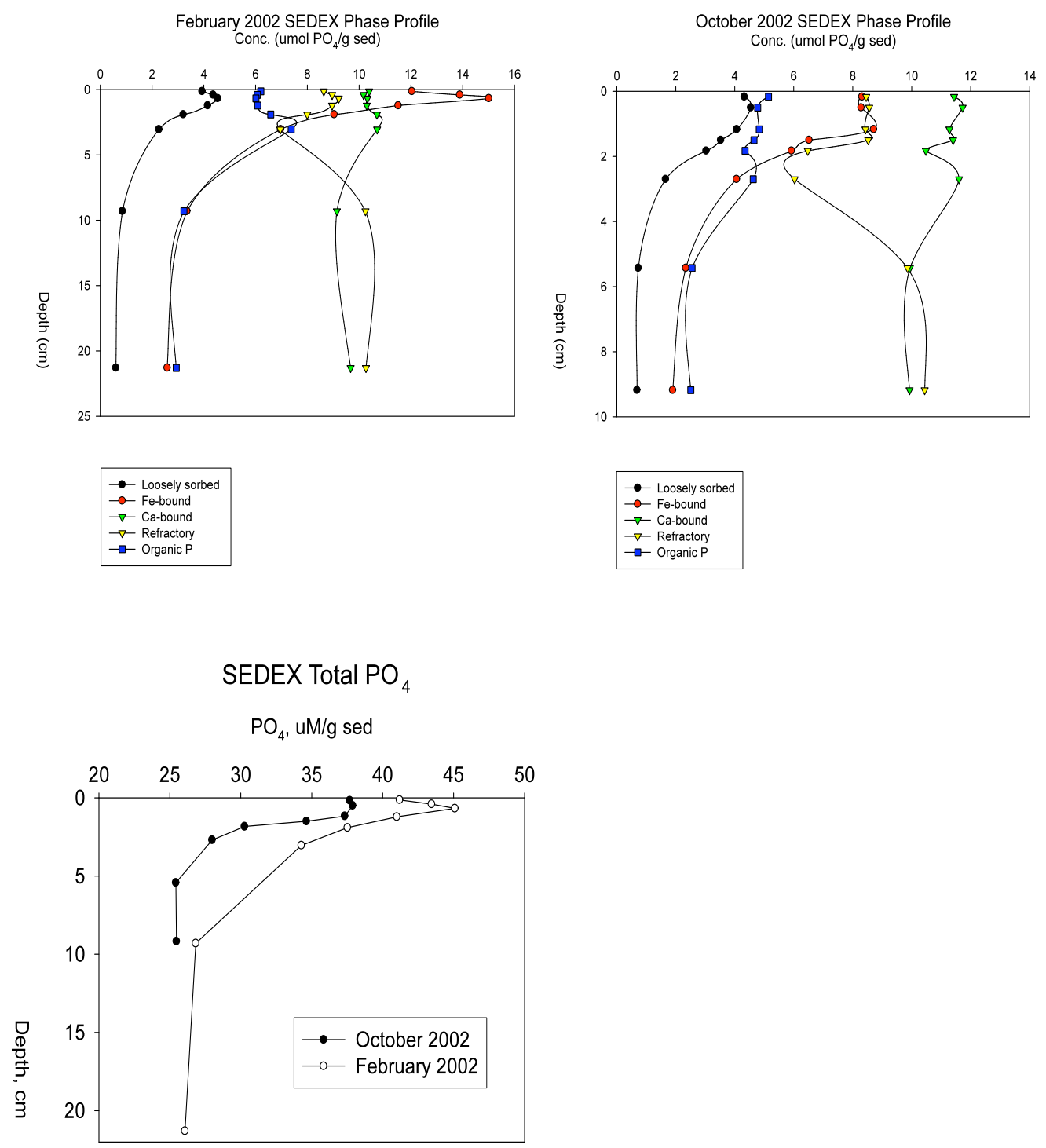


\section{Figure 4: Hingham Bay - Additional Profiles}
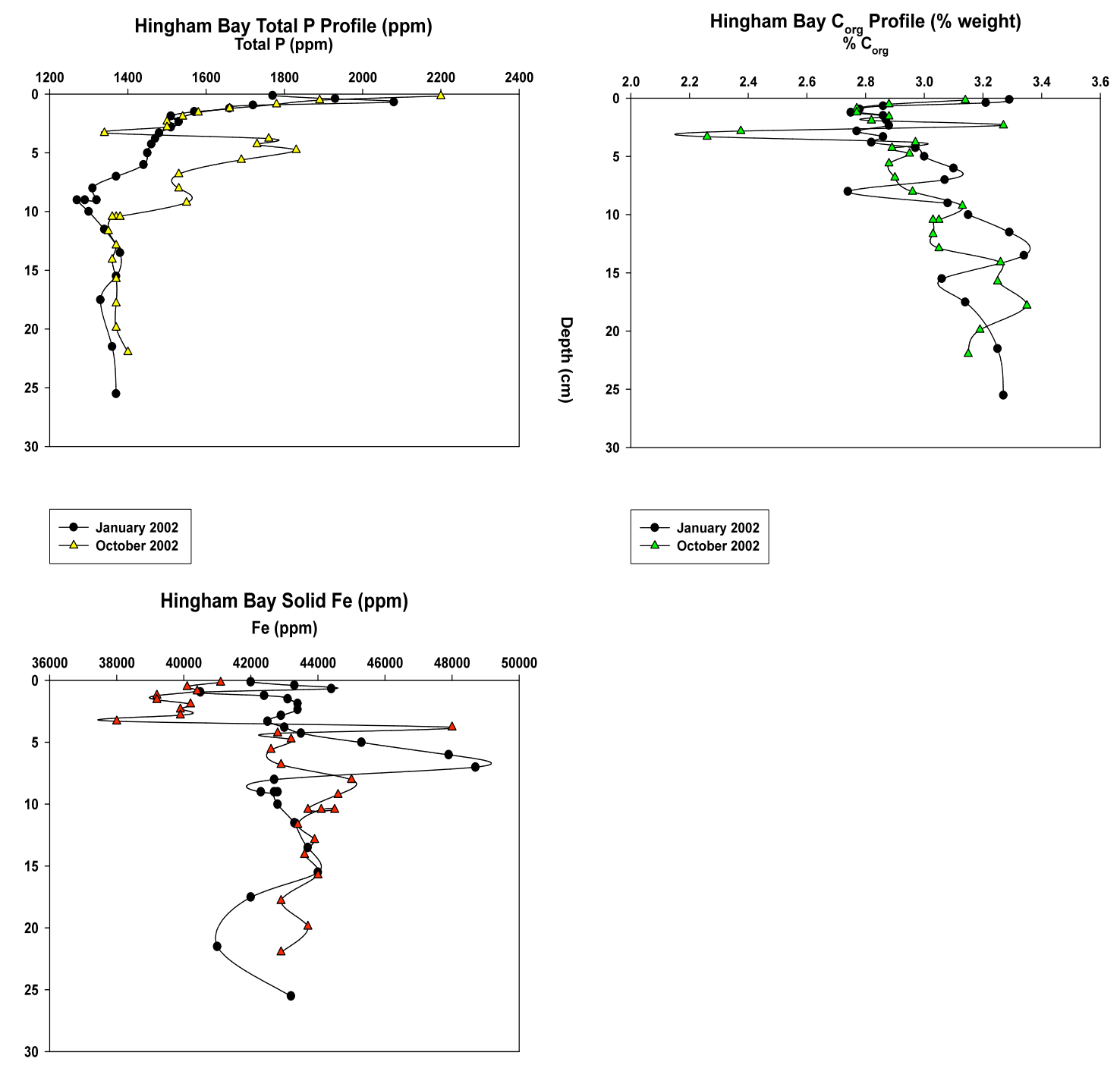

$\bullet$ January 2002
$-\triangle$ October 2002 


\section{Figure 5: Massachusetts Bay - Additional Profiles}

Massachusetts Bay Total P Profile (ppm) Total P (ppm)

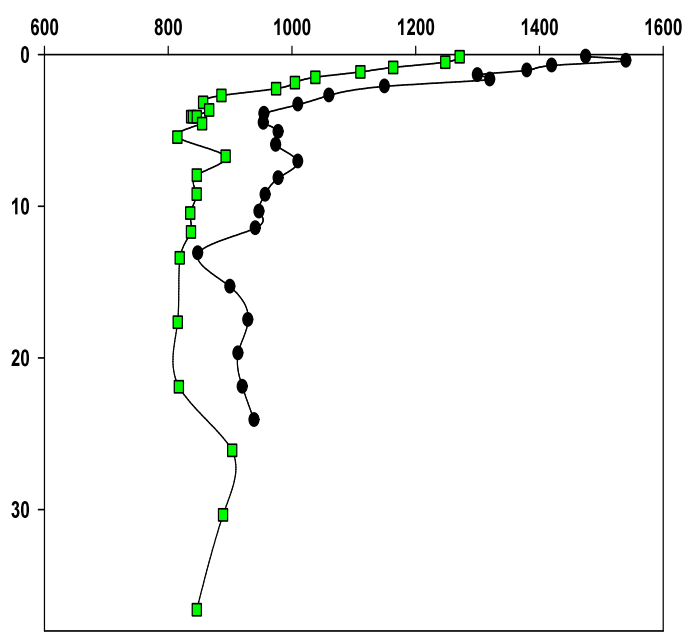

-- February 2002 $\rightarrow-$ October 2002
Massachusetts Bay Solid Fe Profile (ppm)

$\mathrm{Fe}$ (ppm)

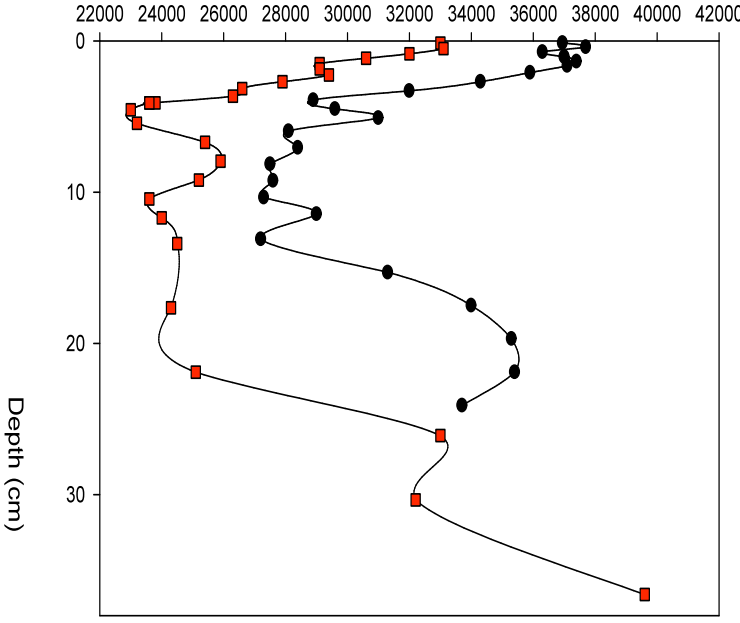

$\rightarrow$ February 2002

$\rightarrow-$ October 2002 


\section{Figure 6: Hingham and Mass Bay: Total P vs. SEDEX Total $\mathrm{PO}_{4}$}

Hingham Bay Total P vs. SEDEX Total $\mathrm{PO}_{4}$ (January 2002) Conc. (umol $\mathrm{PO}_{4} / \mathrm{g}$ sediment)

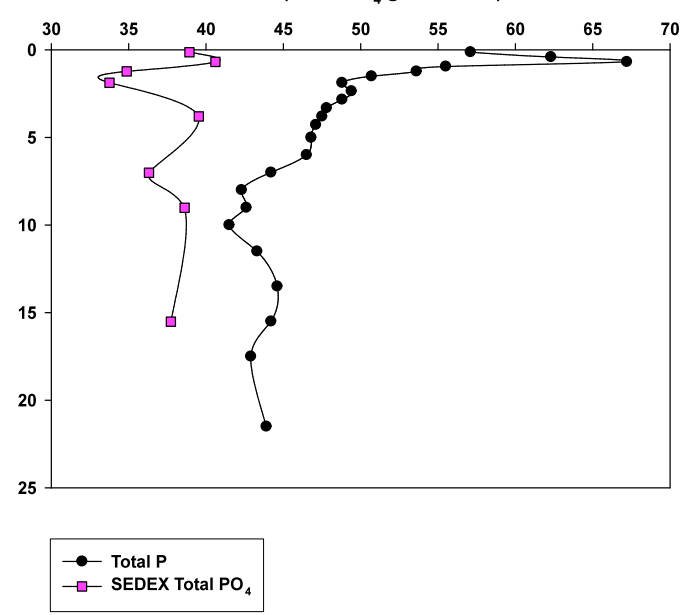

Hingham Bay Total P vs. SEDEX Total $\mathrm{PO}_{4}$ (September 2002) Conc. (umol $\mathrm{PO}_{4} / \mathrm{g}$ sediment)

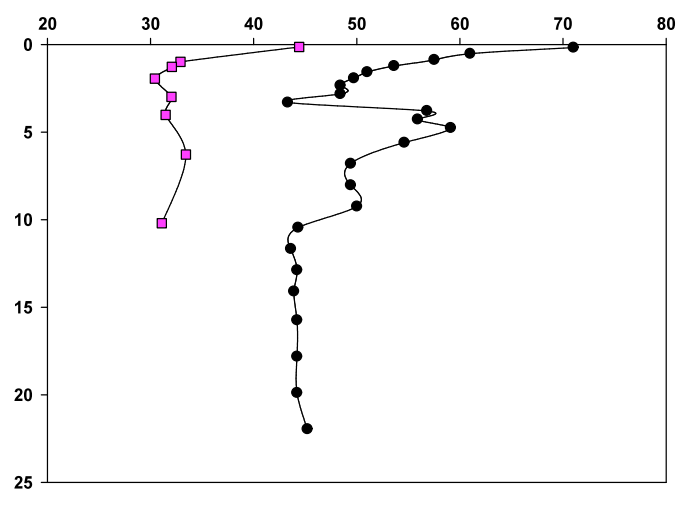

$\rightarrow$ Total P

$\rightarrow$ SEDEX Total PO $_{4}$

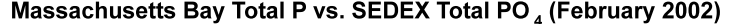
Conc. (umol $\mathrm{PO}_{4} / \mathrm{g}$ sediment)

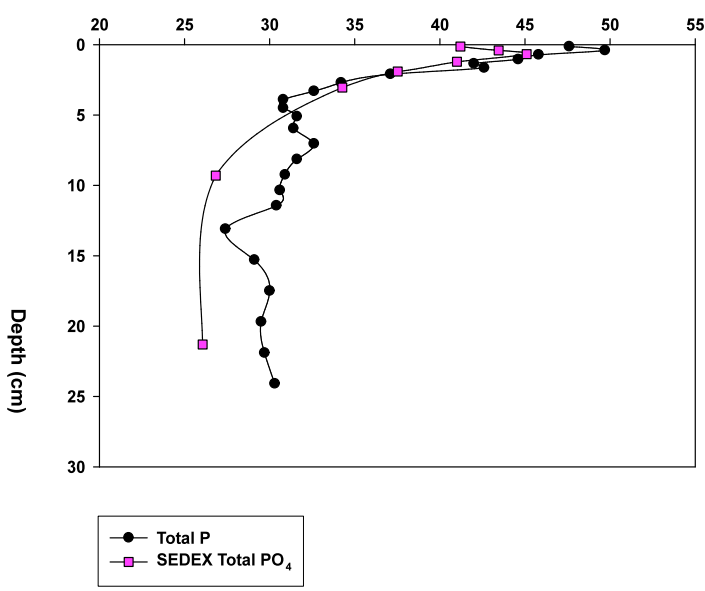

Massachusetts Bay Total P vs. SEDEX Total PO ${ }_{4}$ (October 2002) Conc. (umol $\mathrm{PO}_{4} / \mathrm{g}$ sediment)

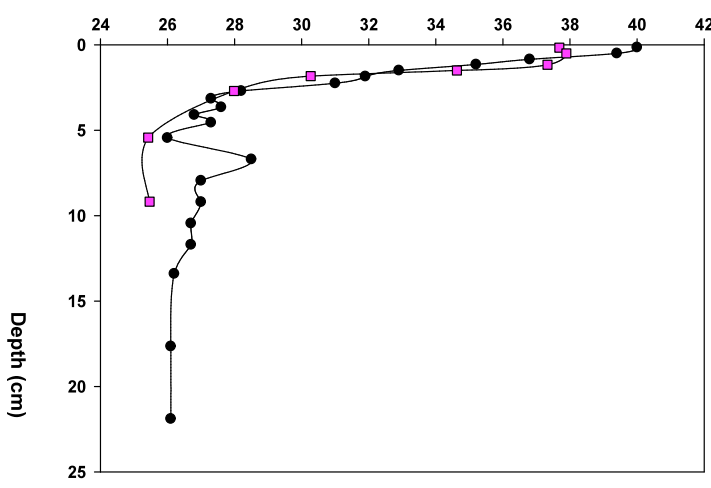

$\rightarrow$ Total P

$\neg$ SEDEX Total $\mathrm{PO}_{4}$ 


\section{Figure 7: Buzzards Bay Phase Fractions}

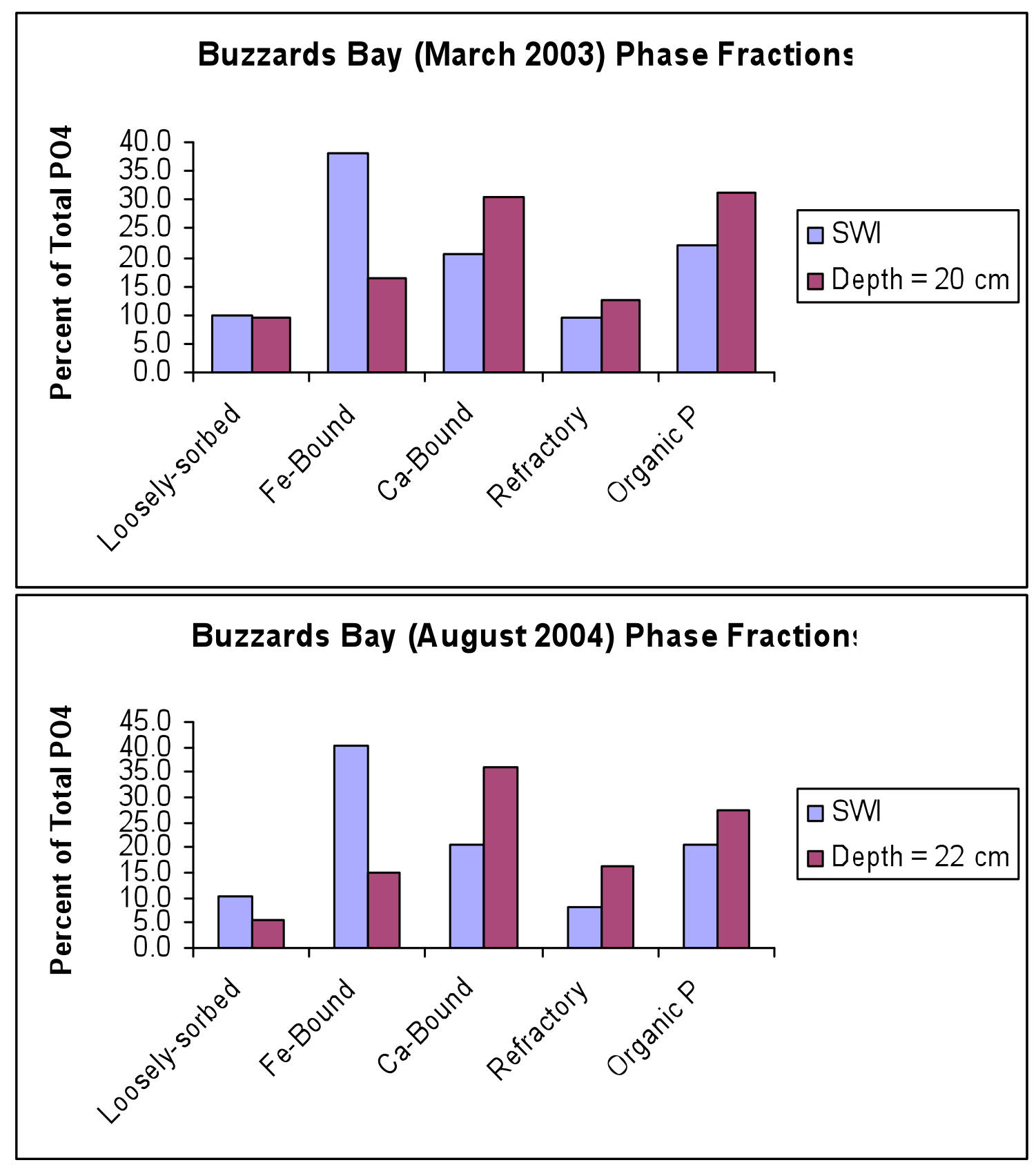




\section{Figure 8: Massachusetts Bay Phase Fractions}
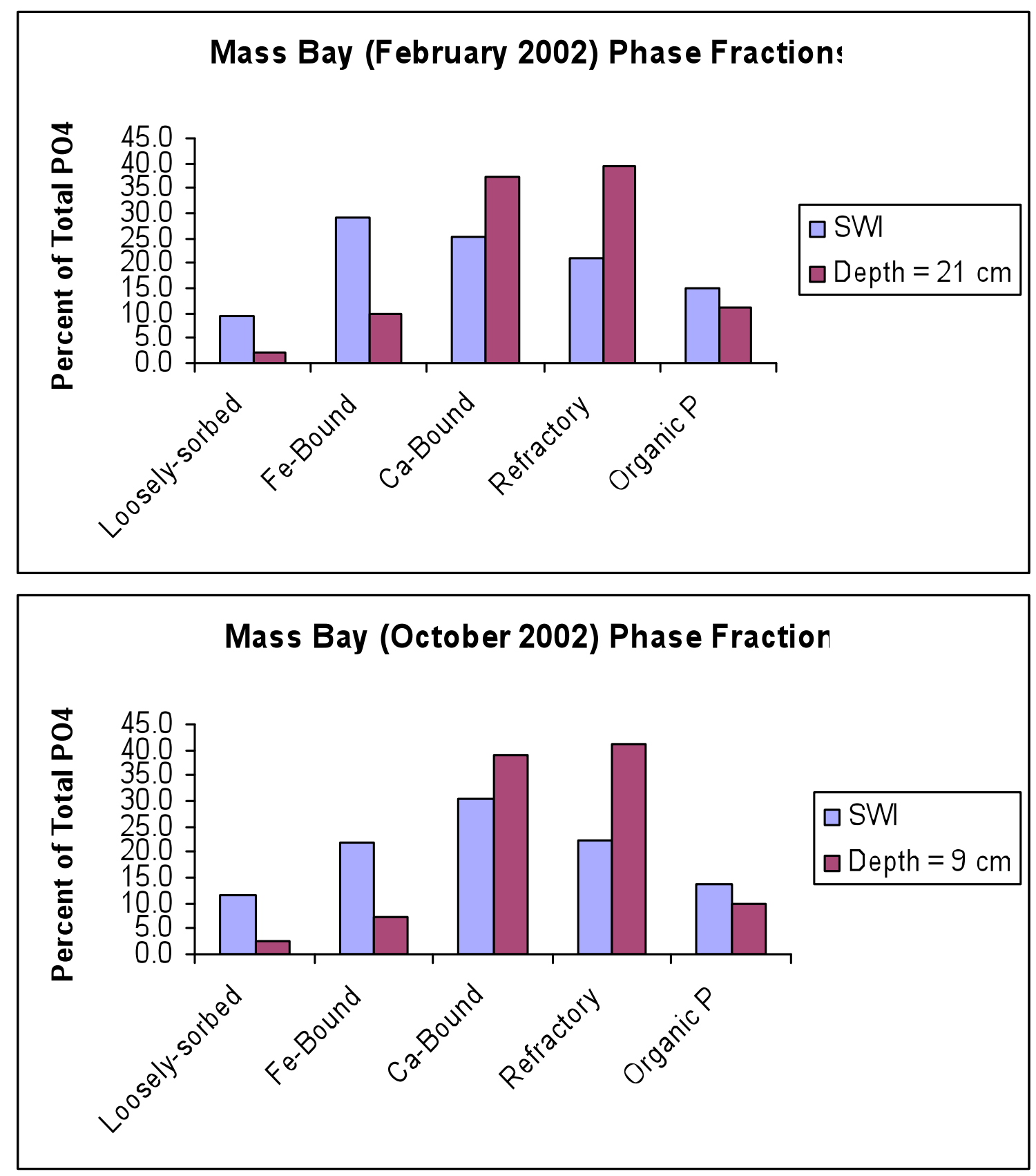


\section{Figure 9: Hingham Bay Phase Fractions}
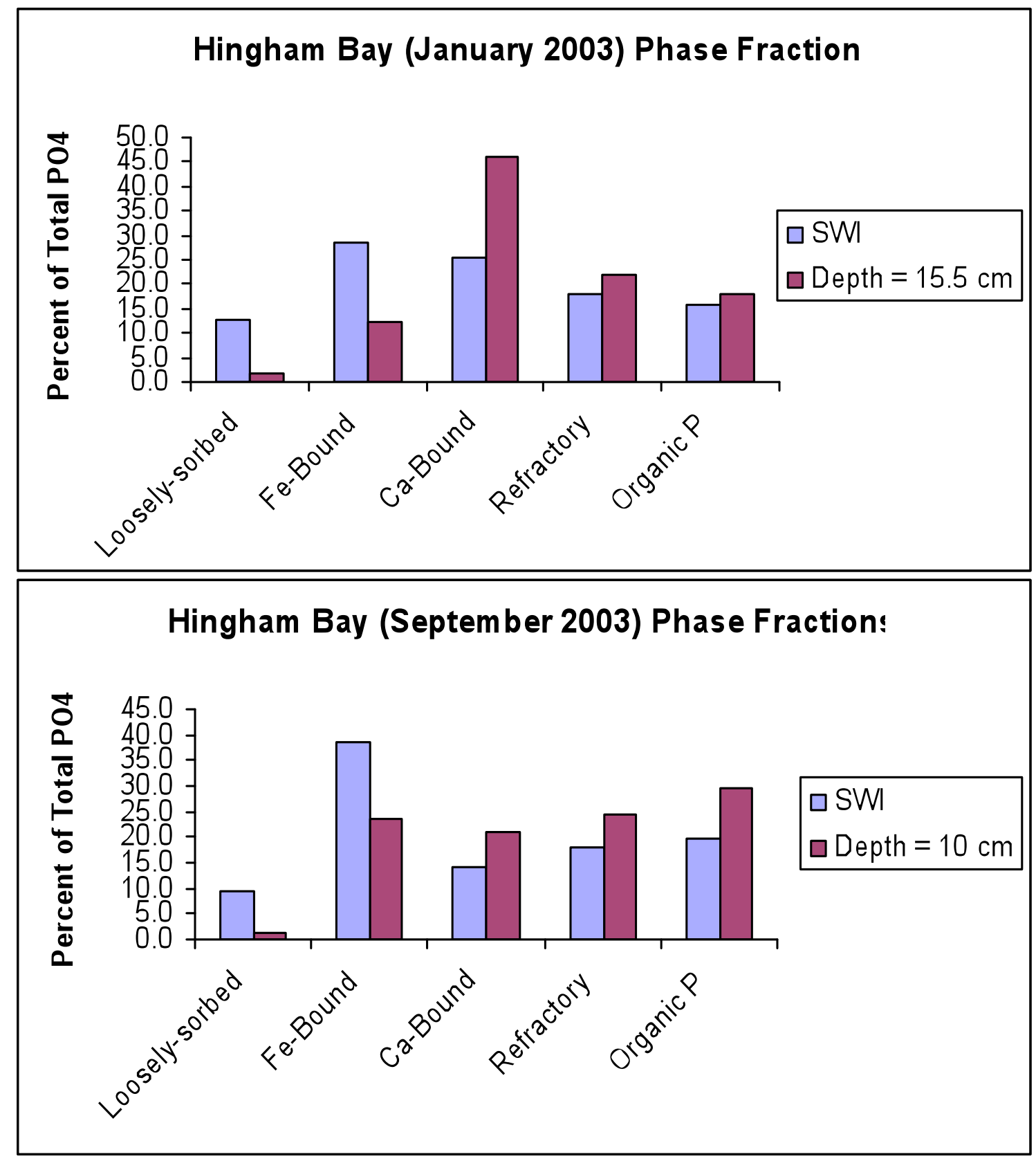


\section{Figure 10: Fe/Al and P/Al ratio profiles}

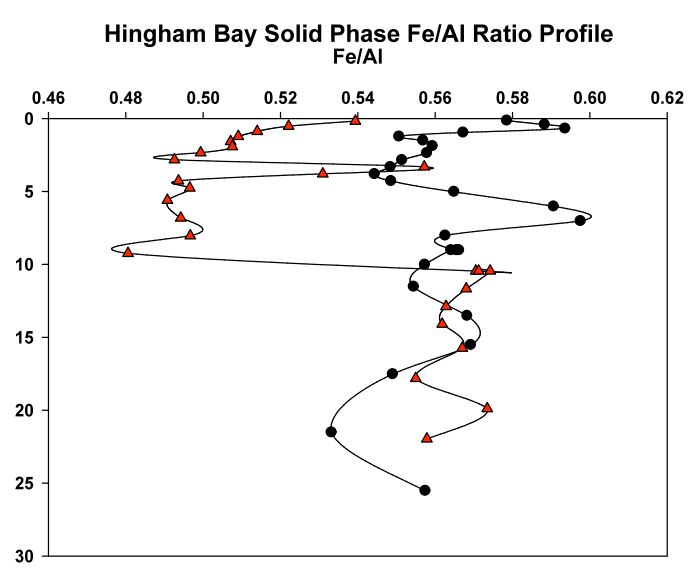

\section{$\longrightarrow$ January 2002}

Hingham Bay Solid Phase P/AI Ratio Profile

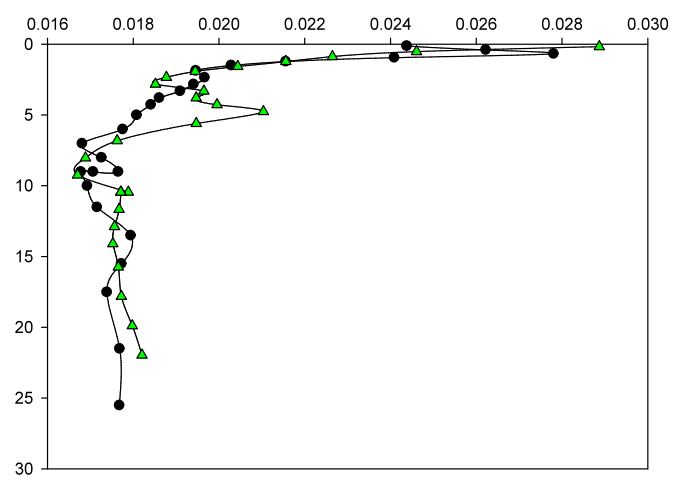

$\rightarrow$ January 2002

October 2002
Massachusetts Bay Solid Phase Fe/AI Ratio Profile FelAl

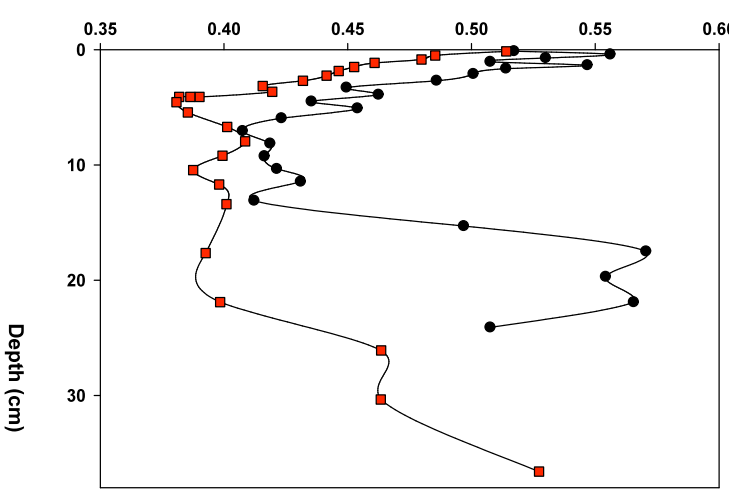

$\rightarrow$ February 2002

October 2002

Massachusetts Bay Solid, Phase P/AI Ratio Profiles

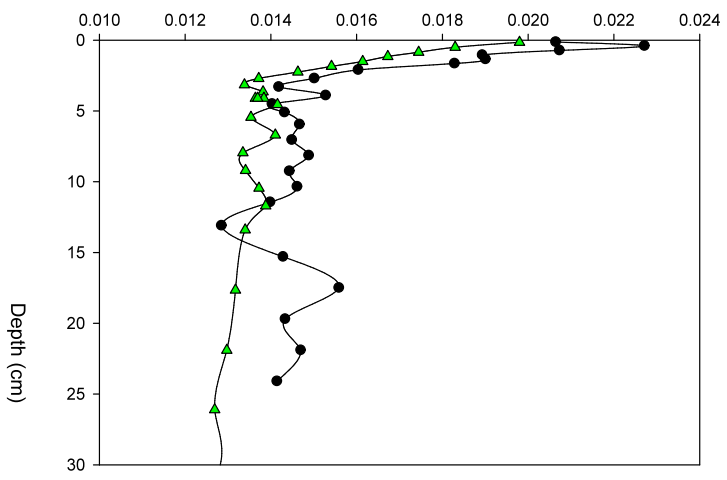

- February 2002 $\triangle-$ October 2002 


\section{Figure 11: Hingham Bay (January 2003) Porewater Profiles}
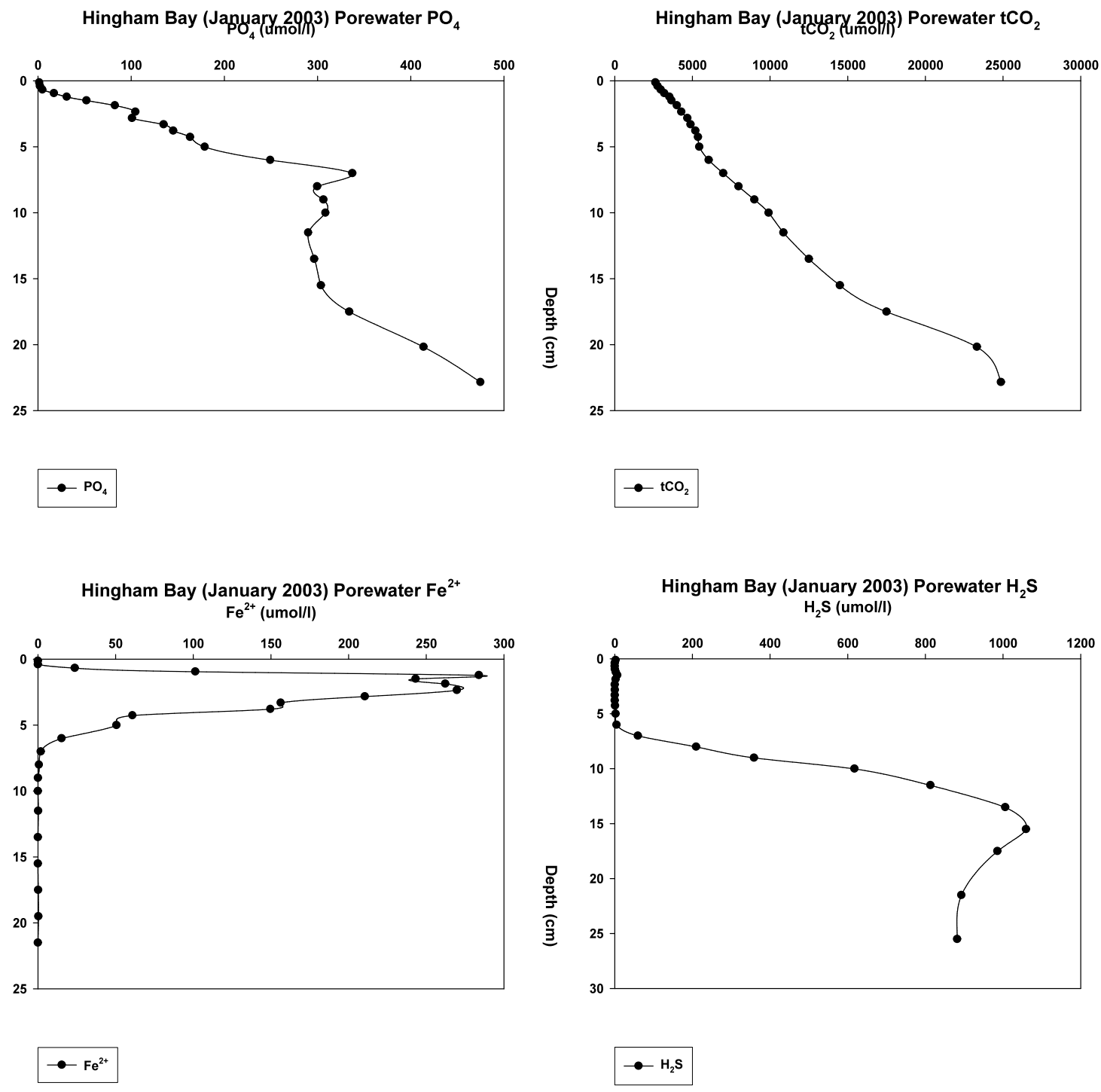


\section{Figure 12: Hingham Bay (September 2002) Porewater Profiles}

Hingham Bay (September 2p03) Porewater $\mathrm{PO}_{4}$

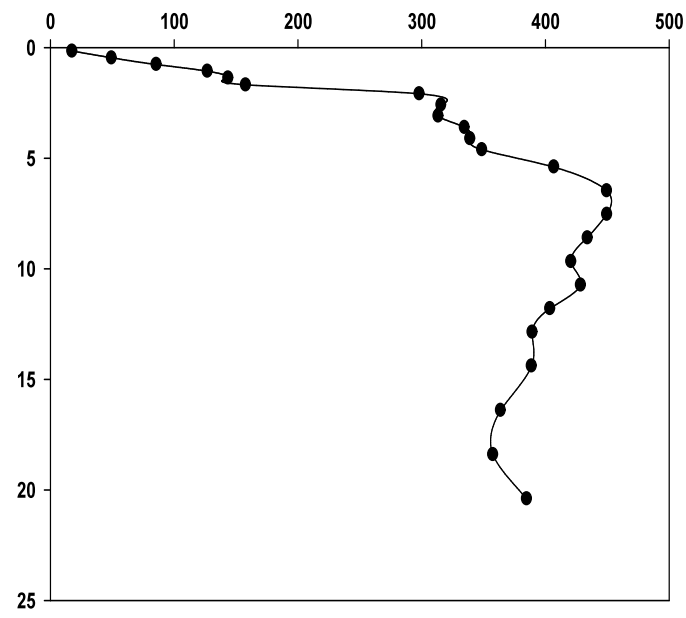

$$
\rightarrow \mathrm{PO}_{4}
$$

Hingham Bay (September 2003) Porewater $\mathrm{tCO}_{2}$ $\mathrm{tCO}_{2}$ (umol/I)

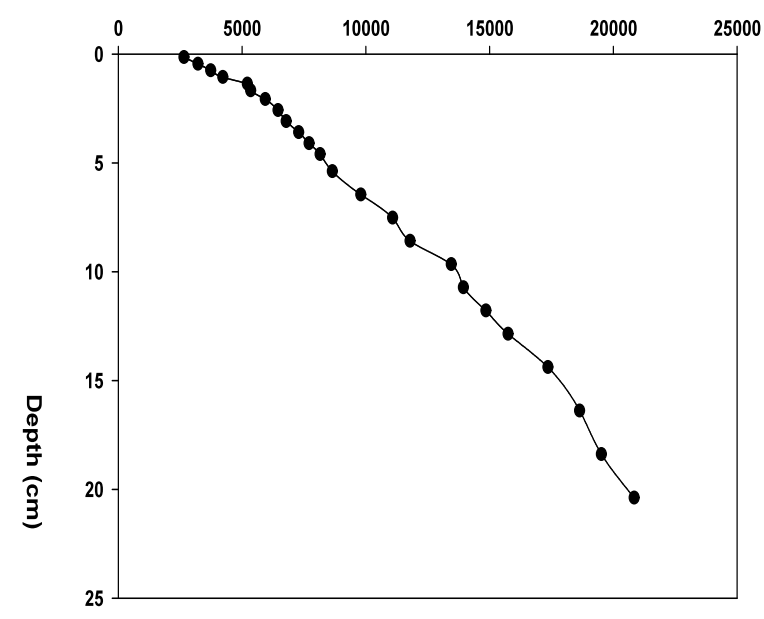

$$
\rightarrow \mathrm{tCO}_{2}
$$




\section{Figure 13: Surface Fe- Bound $\mathrm{PO}_{4}$ Inventories}

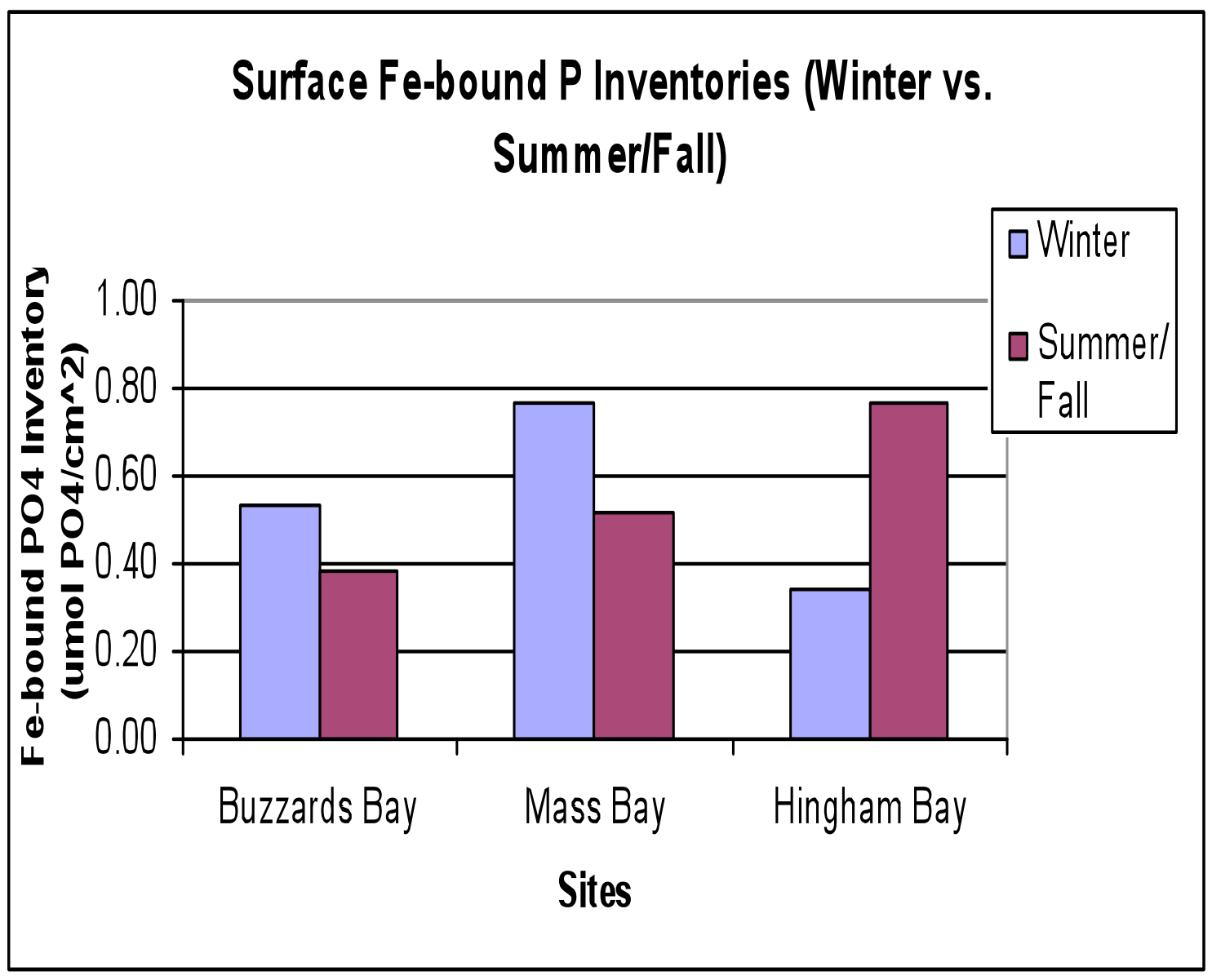




\section{Figure 14: Buzzards Bay (March 2003) Porewater Profiles}
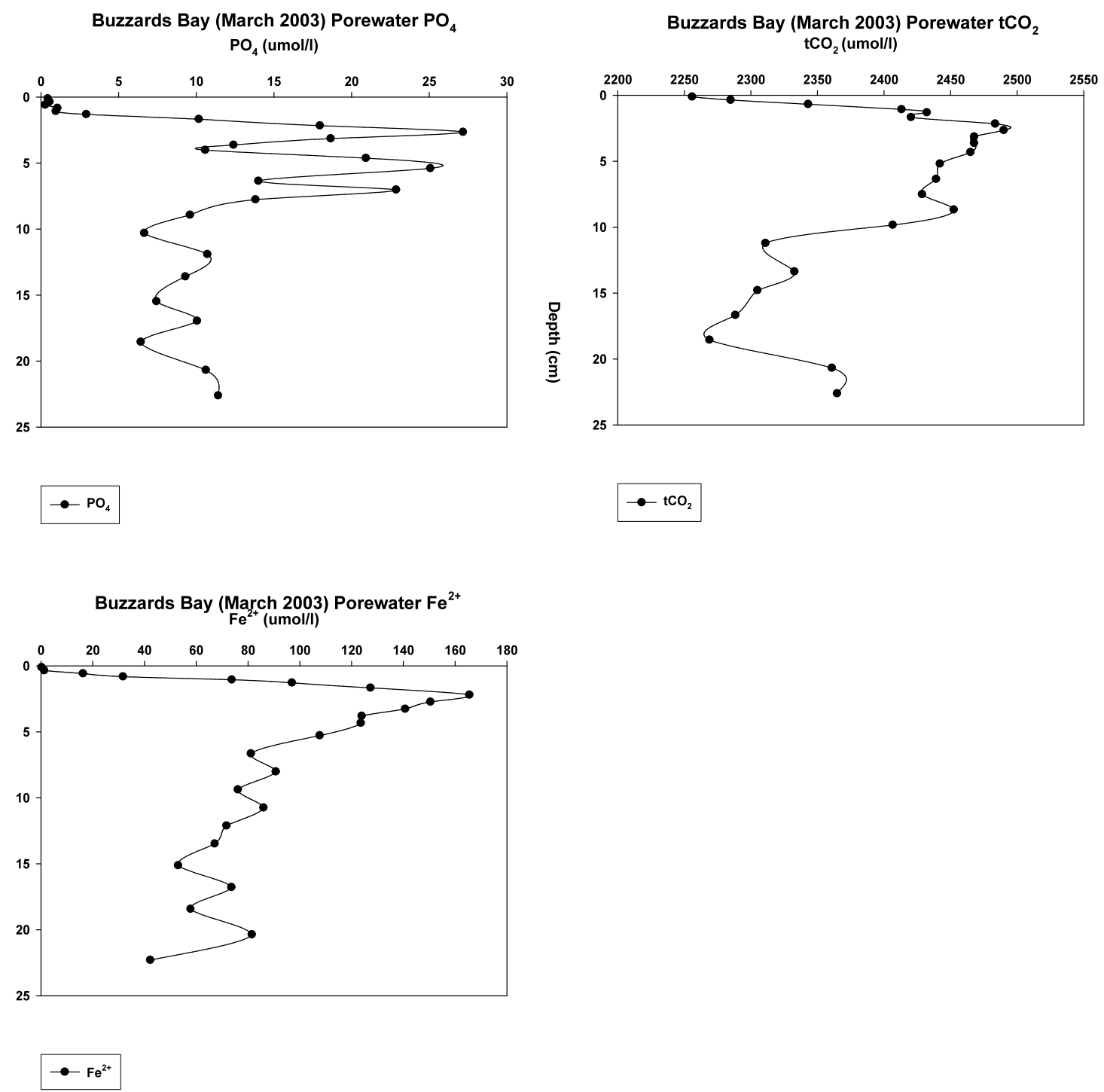


\section{Figure 15: Buzzards Bay (August 2004) Porewater Profiles}
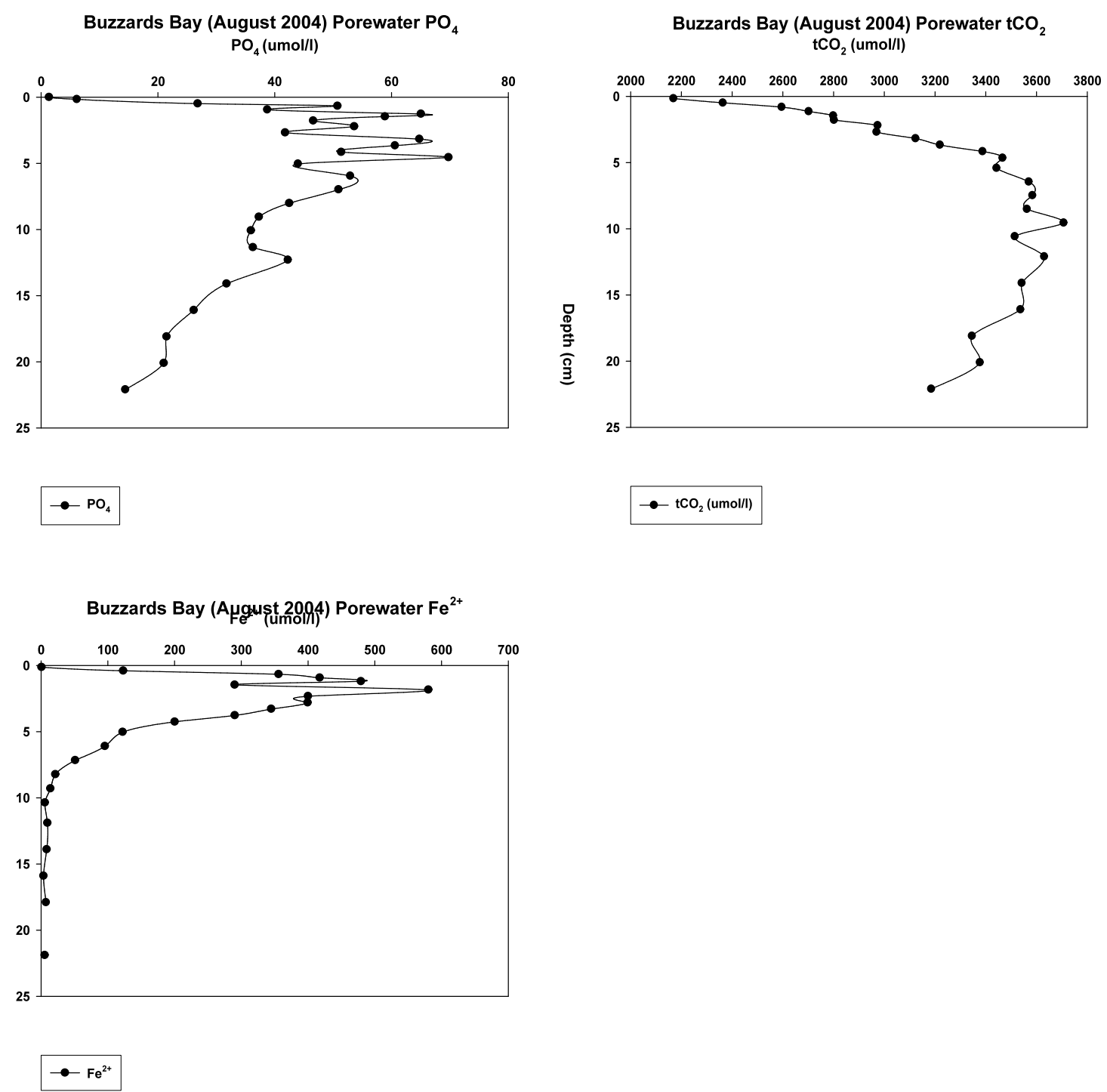


\section{Figure 16: Massachusetts Bay (February 2002) Porewater Profiles}

Massachusetts Bay (Feburary 2002) Porewater $\mathrm{PO}_{4}$

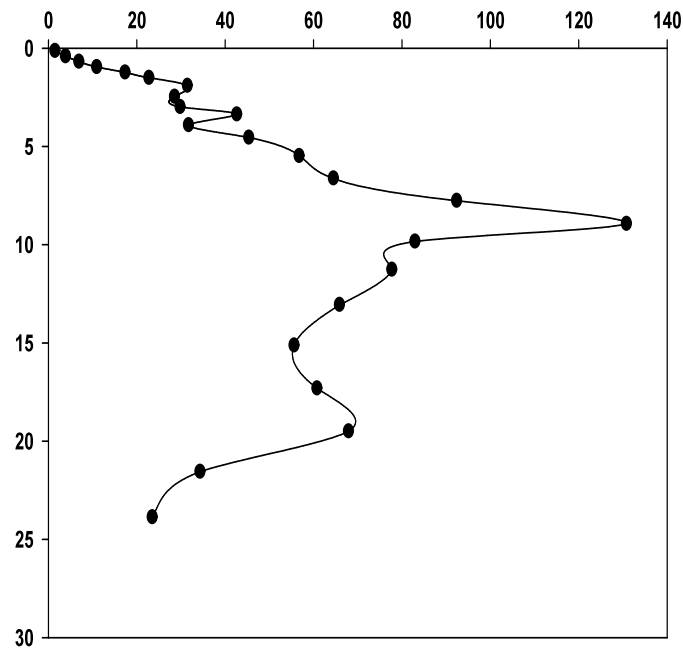

$\rightarrow-\mathrm{PO}_{4}$
Massachusetts Bay (February 2003) Porewater $\mathrm{tCO}_{2}$ $\mathrm{tCO}_{2}$ (umoll)

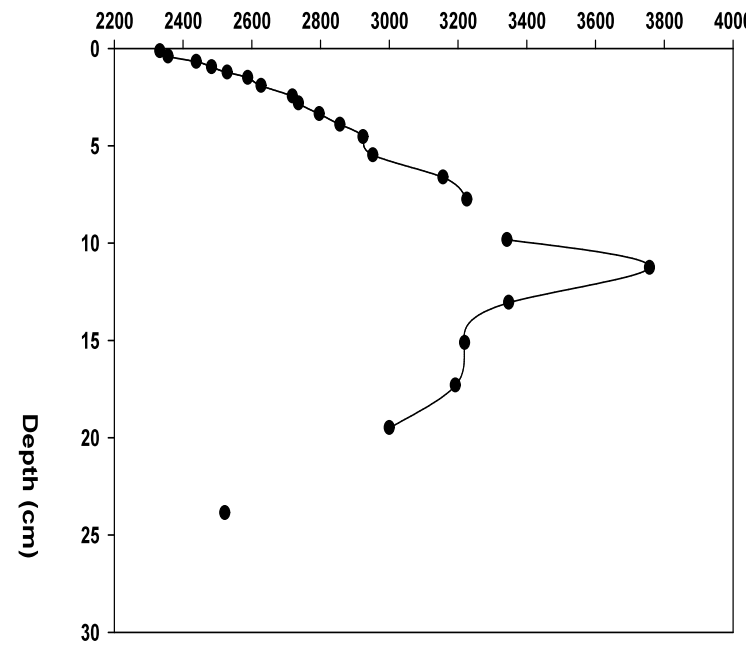

$\rightarrow-\mathrm{tCO}_{2}$ 


\section{Figure 17: Massachusetts Bay (October 2002) Porewater Profiles}

Massachusetts Bay (October 2002) Porewater $\mathrm{PO}_{2}$ PO4 (umolll)

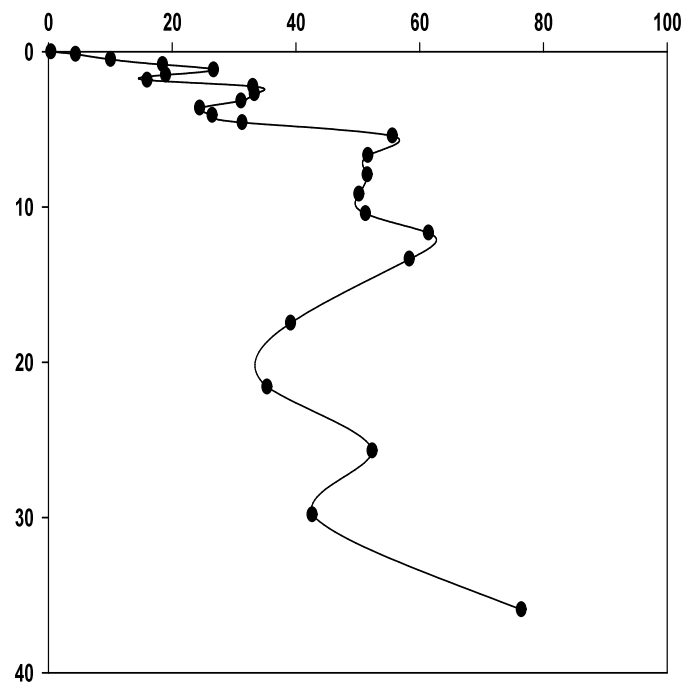

$\rightarrow-\mathrm{PO}_{4}$
Massachusetts Bay (October 2002) Porewater $\mathrm{tCO}_{2}$ $\mathrm{tCO}_{2}$ (umolli)

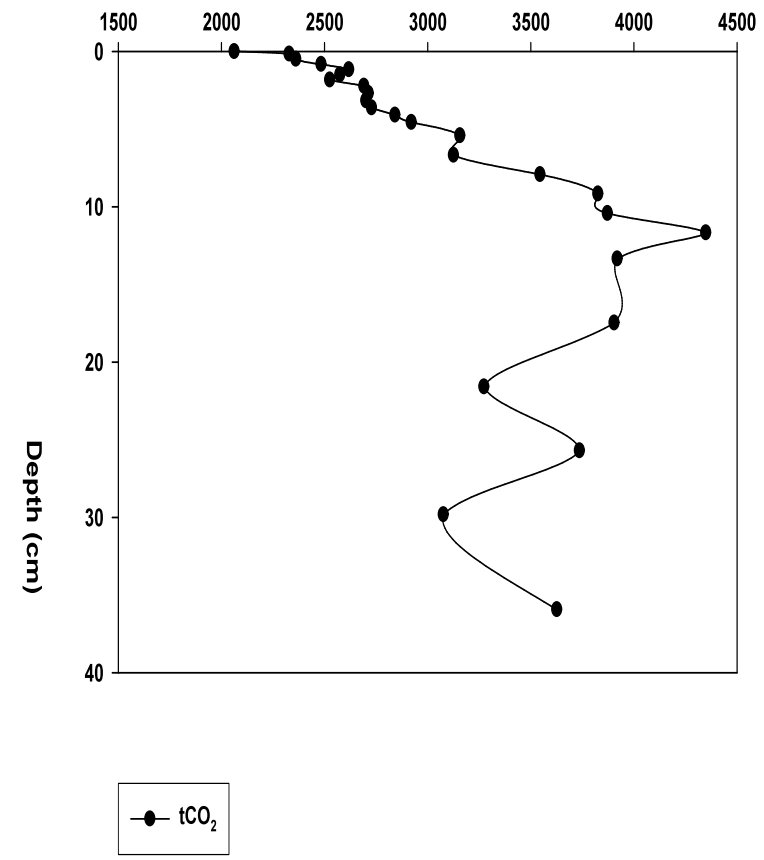




\section{Figure 18: Hingham Bay and Mass Bay $\mathrm{PO}_{4}$ vs $\mathrm{tCO}_{2}$}

Hingham Bay (September 2002) Porewater $\mathrm{tCO}_{2}$ vs. $\mathrm{PO}_{4}$

Hingham Bay (January 2002) Porewater $\mathrm{tCO}_{2}$ vs. $\mathrm{PO}_{4}$
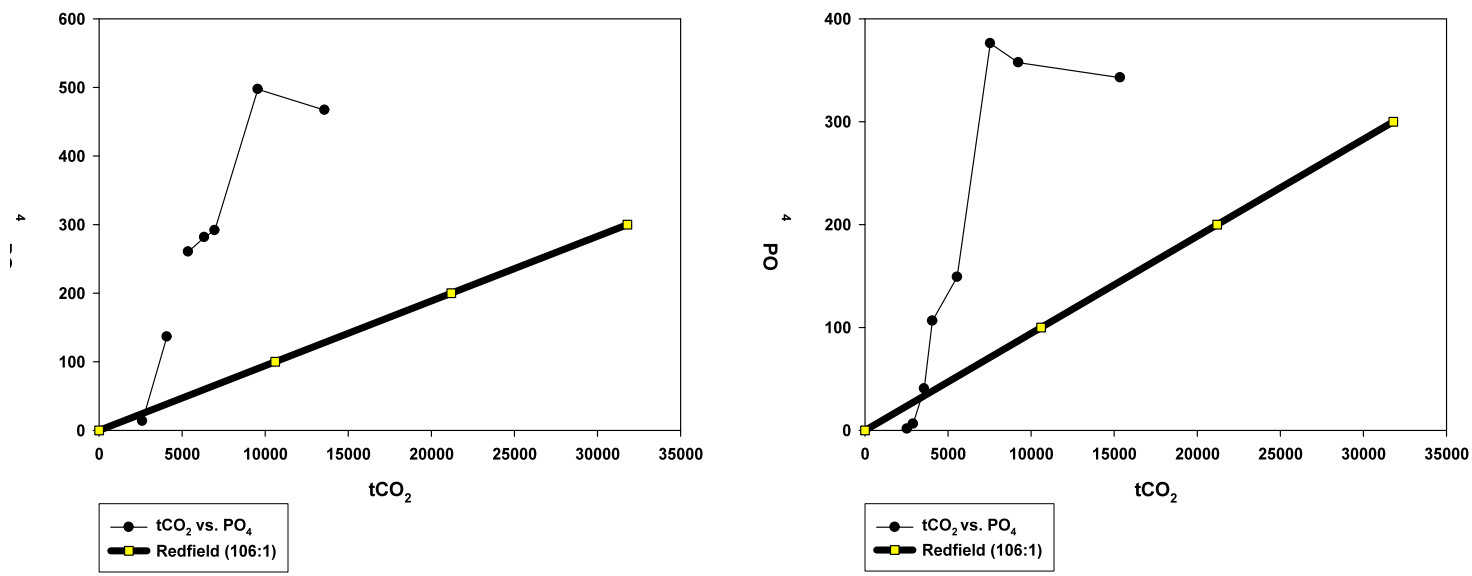

$\bullet-\mathrm{tCO}_{2}$ vs. $\mathrm{PO}_{4}$
- Redfield (106:1)

Massachusetts Bay (February 2002) Porewater $\mathrm{tCO}_{2}$ vs. $\mathrm{PO}_{4}$

Massachusetts Bay (October 2002) Porewater $\mathrm{tCO}_{2}$ vs. $\mathrm{PO}_{4}$
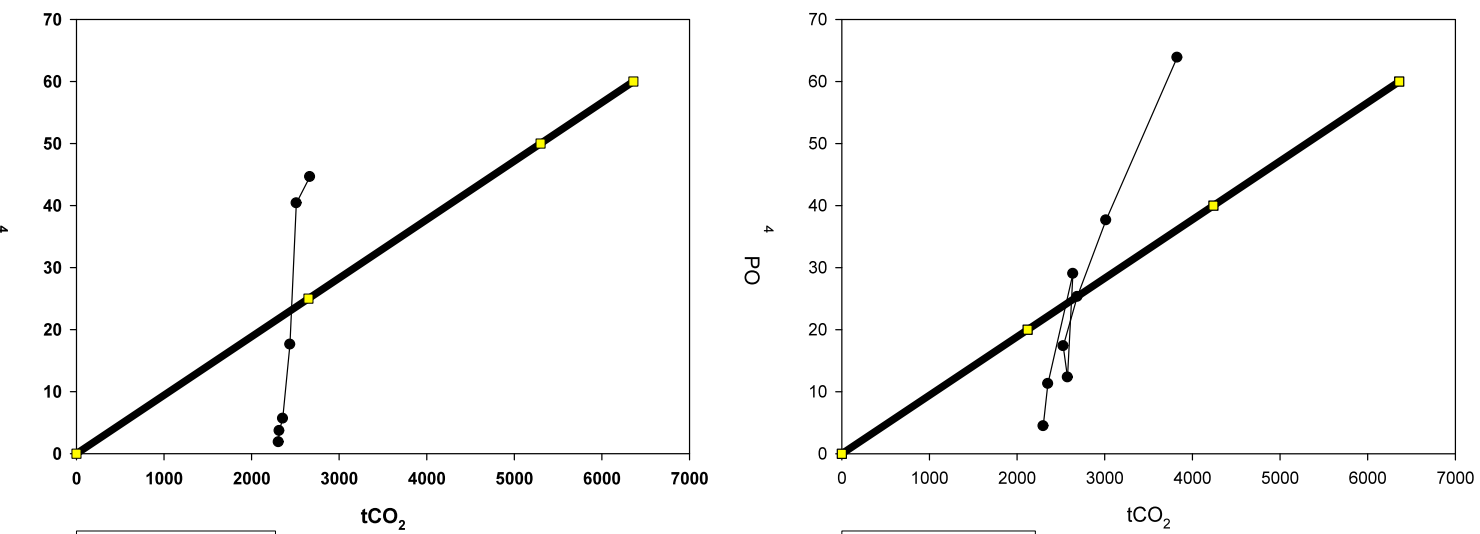

$\longrightarrow-\mathrm{tCO}_{2}$ vs. $\mathrm{PO}_{4}$
- Redfield $(106: 1)$

$\longrightarrow \mathrm{tCO}_{2}$ vs. $\mathrm{PO}_{4}$
$\longrightarrow$ Redfield $(106: 1)$ 


\section{Figure 19: The \\ Sedimentary Fe-P Cycle}

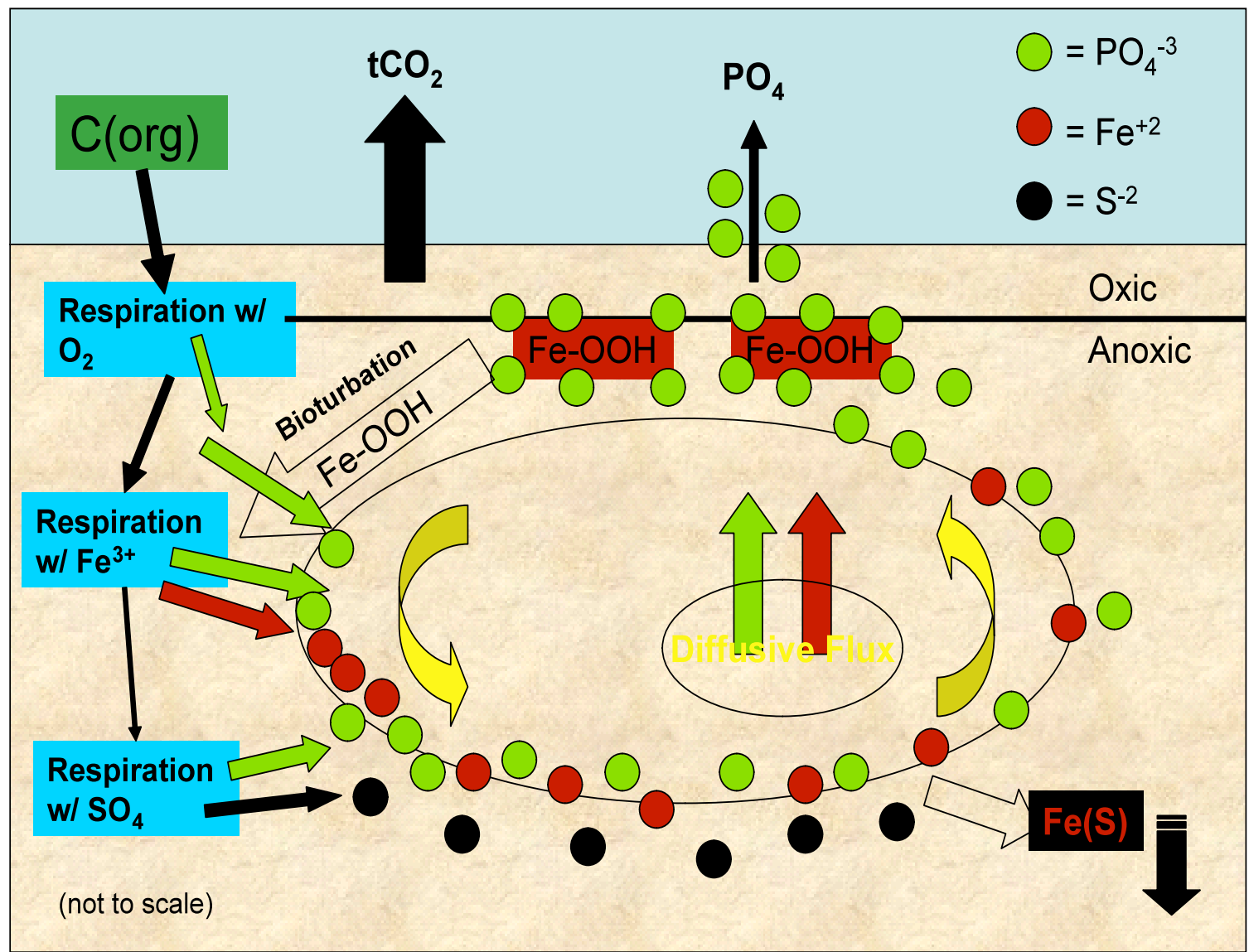

- $\mathrm{C}_{\text {org }}$ respiration releases $\mathrm{PO}_{4}$ into porewaters.

- $\mathrm{PO}_{4}$ diffuses upwards until oxic/anoxic layer.

- $\mathrm{PO}_{4}$ sorbs onto $\mathrm{Fe}-\mathrm{OOH}$

- $\mathrm{Fe}-\mathrm{OOH}^{*} \mathrm{P}$ is mixed downwards and/or oxic layer thickness decreases

- $\mathrm{Fe}-\mathrm{OOH}$ reduced $=>\mathrm{PO}_{4}$ released

- In certain sites, $\mathrm{S}^{-2}$ removes $\mathrm{Fe}^{2+}$ from depth, weakening Fe-trapping ability 


\section{Figure 20: Buzzards Bay Porewater and Fe-bound $\mathrm{PO}_{4}$}

Buzzards Bay (March 2003) Porewater $\mathrm{PO}_{4}$ vs Fe-bound $\mathrm{PO}_{4} \quad$ Buzzards Bay (August 2004) Porewater PO4 vs. Fe-bound PO4 $\mathrm{PO}_{4}$ (umollg sed)

$\mathrm{PO}_{4}$ (umollg sed)
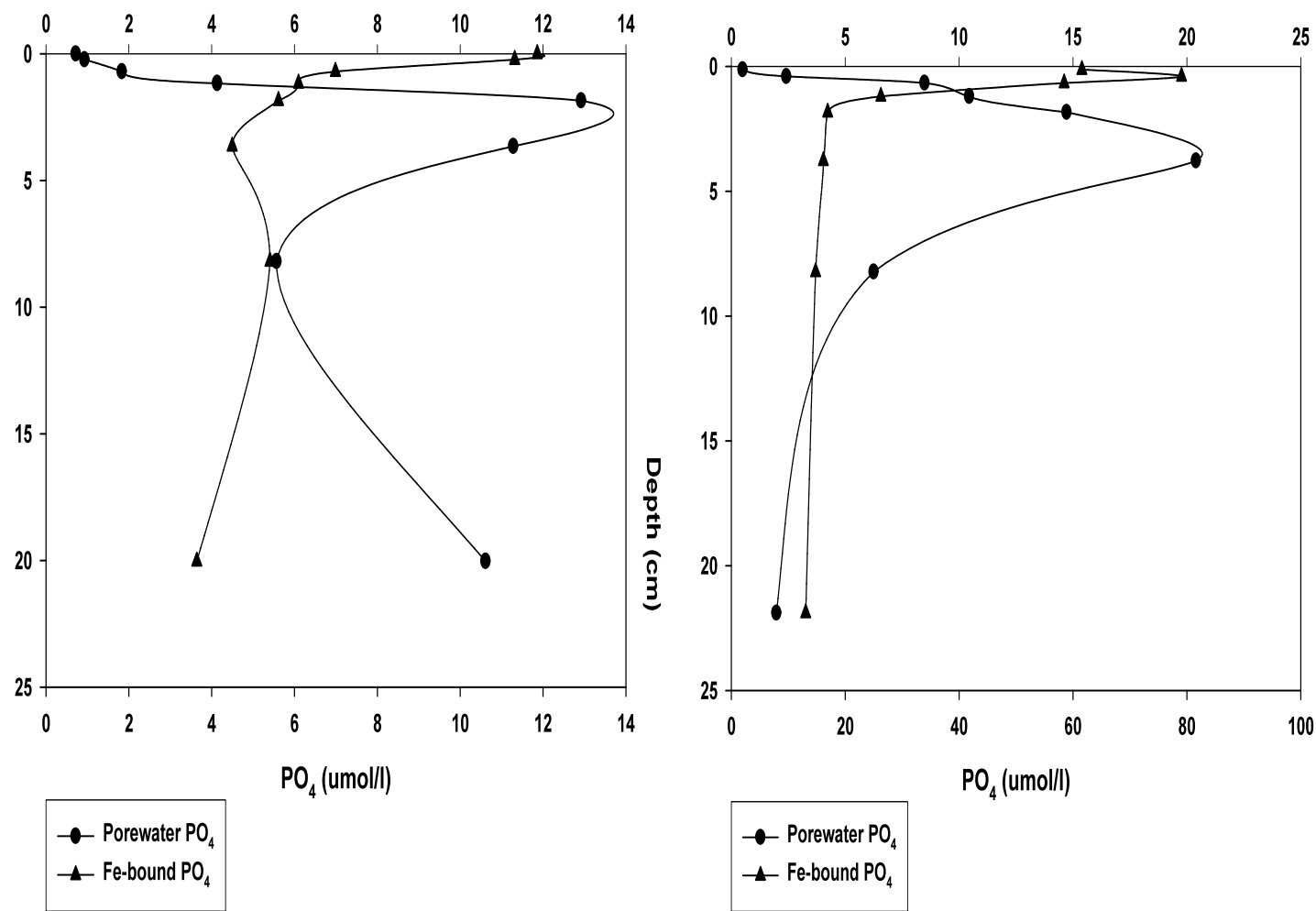


\section{Figure 21: Massachusetts Bay Porewater and Fe- Bound $\mathrm{PO}_{4}$}

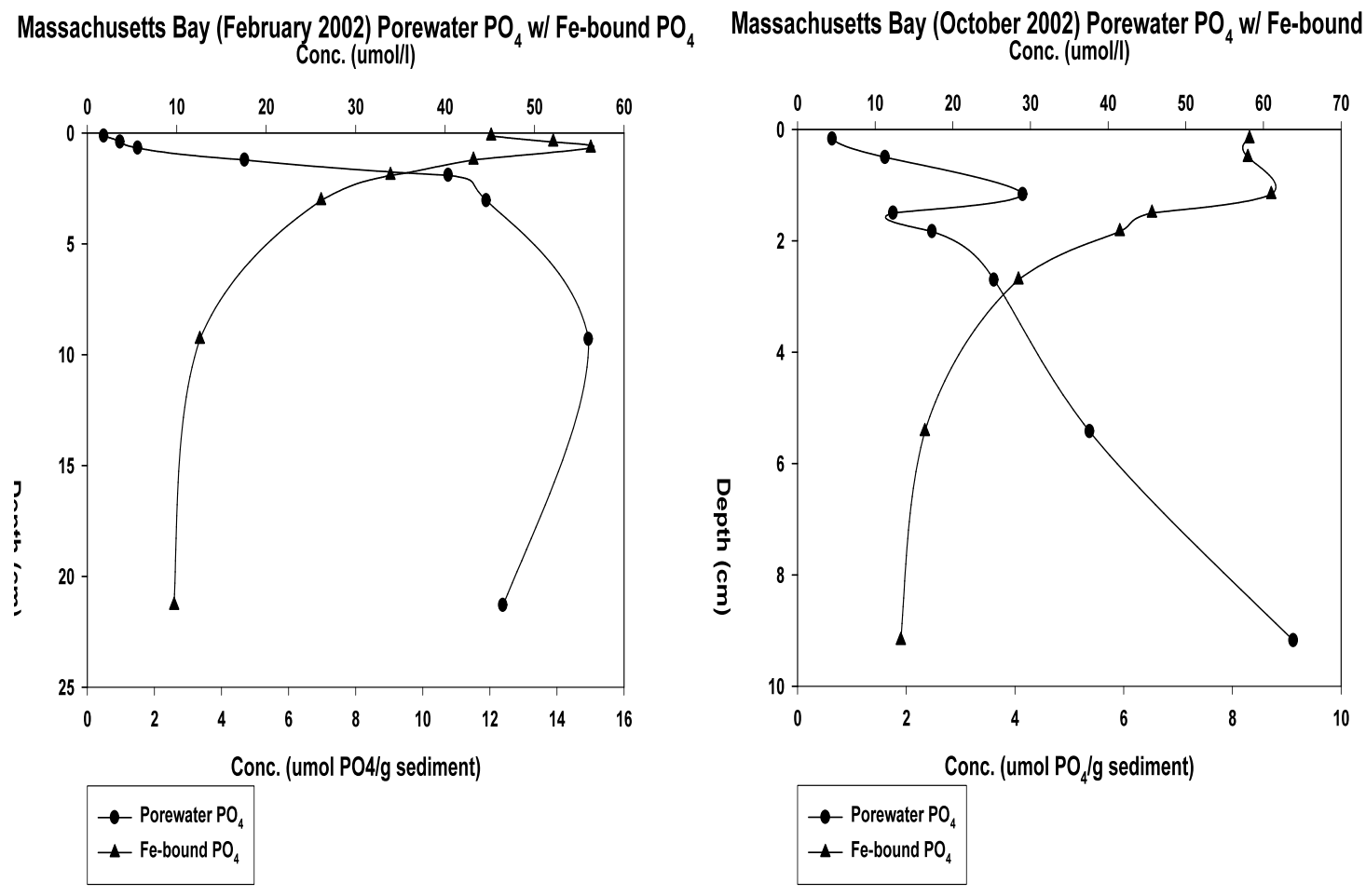




\section{Figure 22: Hingham Bay Porewater and Fe-bound $\mathrm{PO}_{4}$}

Hingham Bay (January 2003) Porewater $\mathrm{PO}_{4}$ w/ Fe-bound $\mathrm{PO}_{4}$ Conc. (umol/l)

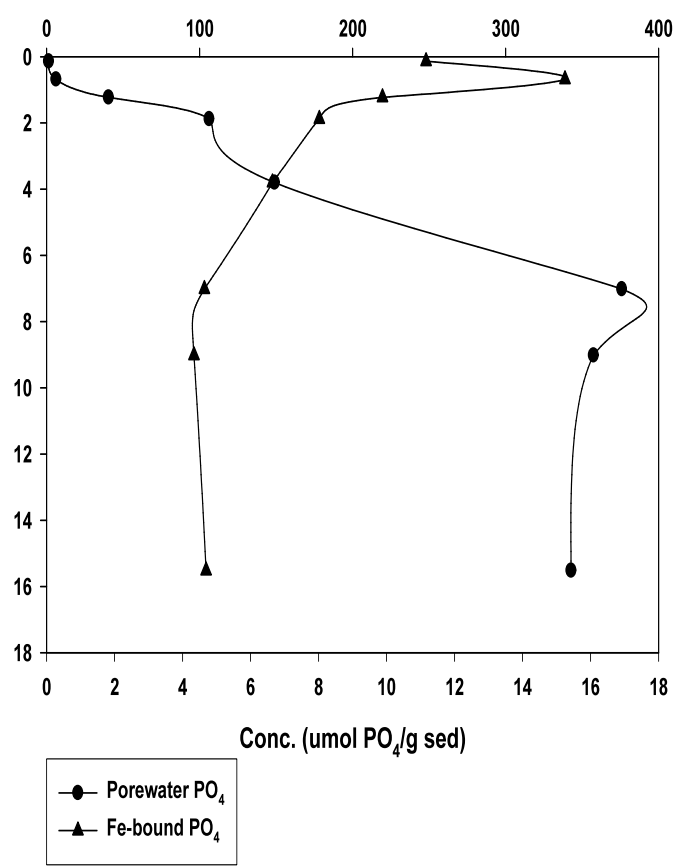

Hingham Bay (September 2002) Porewater $\mathrm{PO}_{4}$ w/ Fe-bound $\mathrm{PO}_{4}$ Conc. (umol/l)

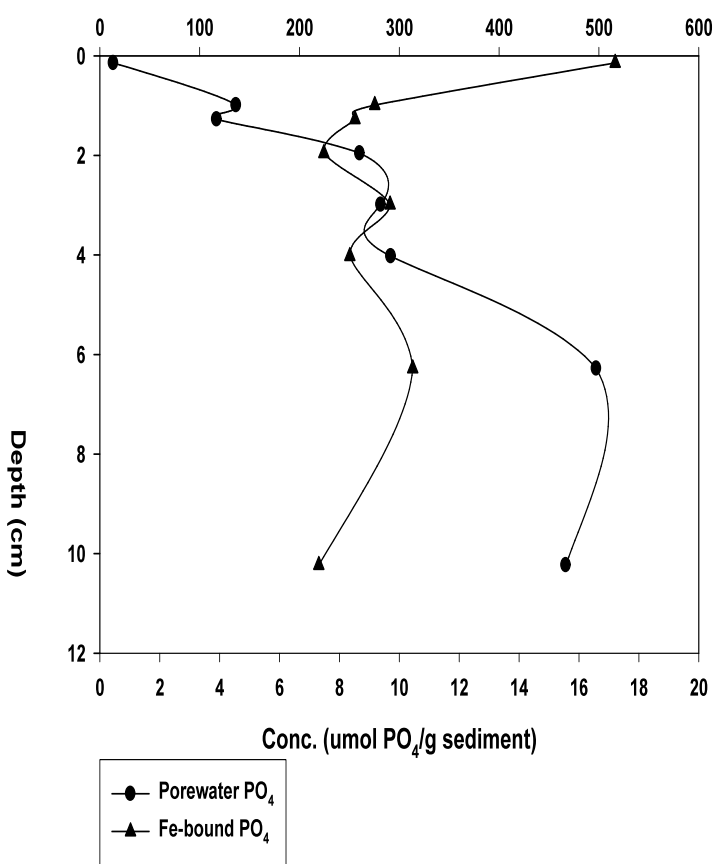




\section{Figure 23: Solid-bound $\mathrm{PO}_{4}$ Down Into Sediments}

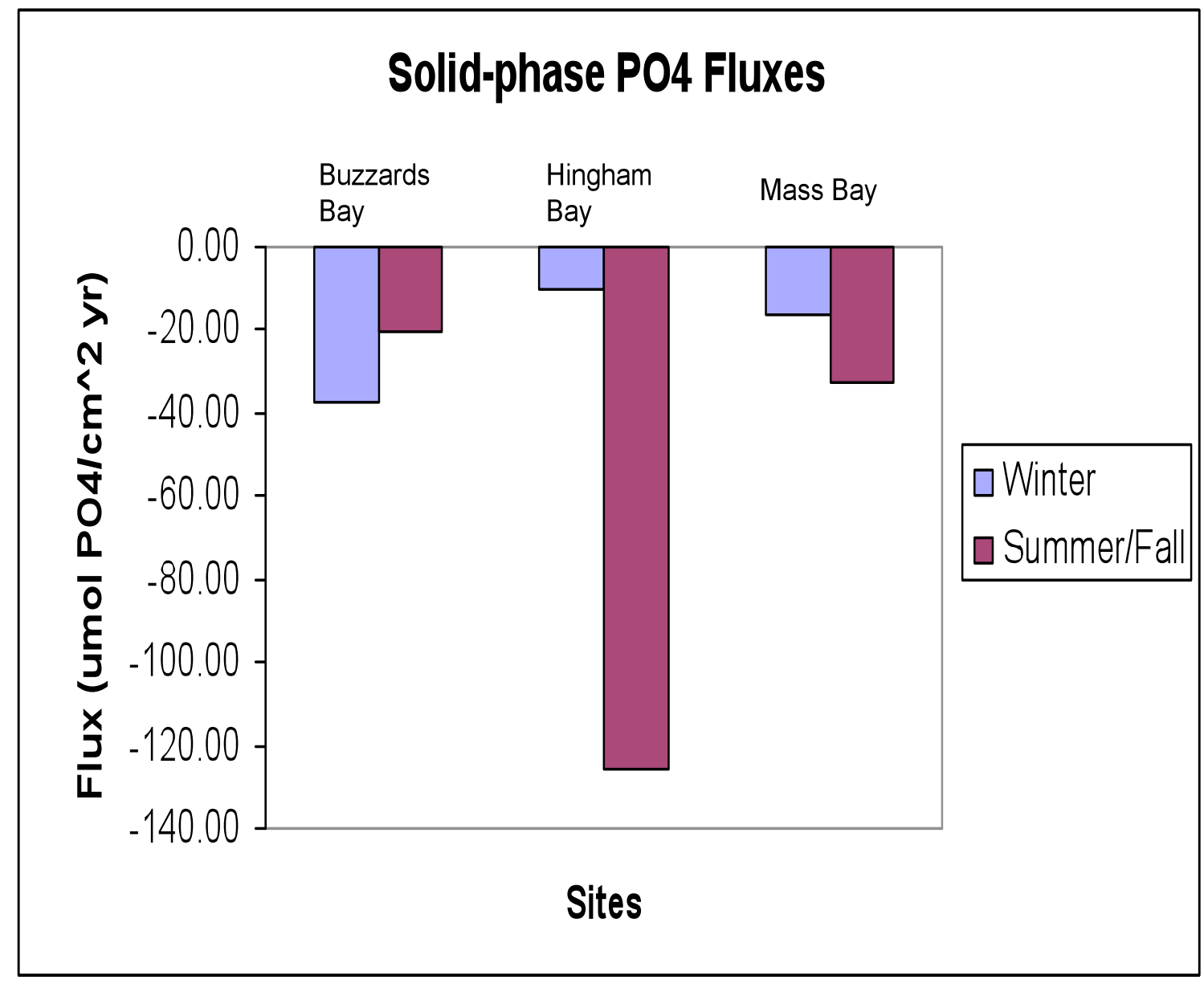




\section{Figure 24: Porewater Fluxes Out of Sediments}
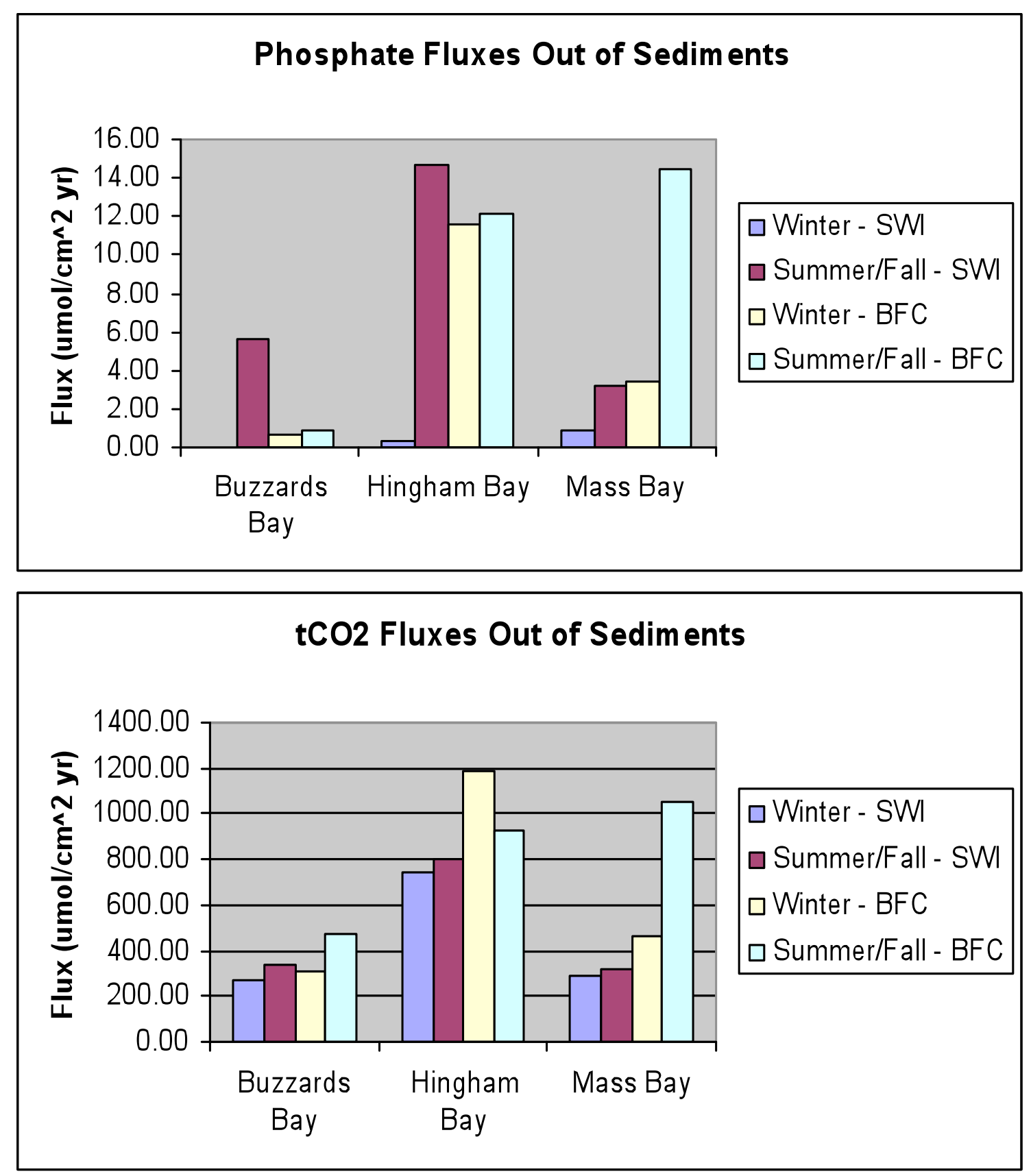


\section{Figure 25: C:P Ratios of $\mathrm{SWI}$ and BFC Fluxes}
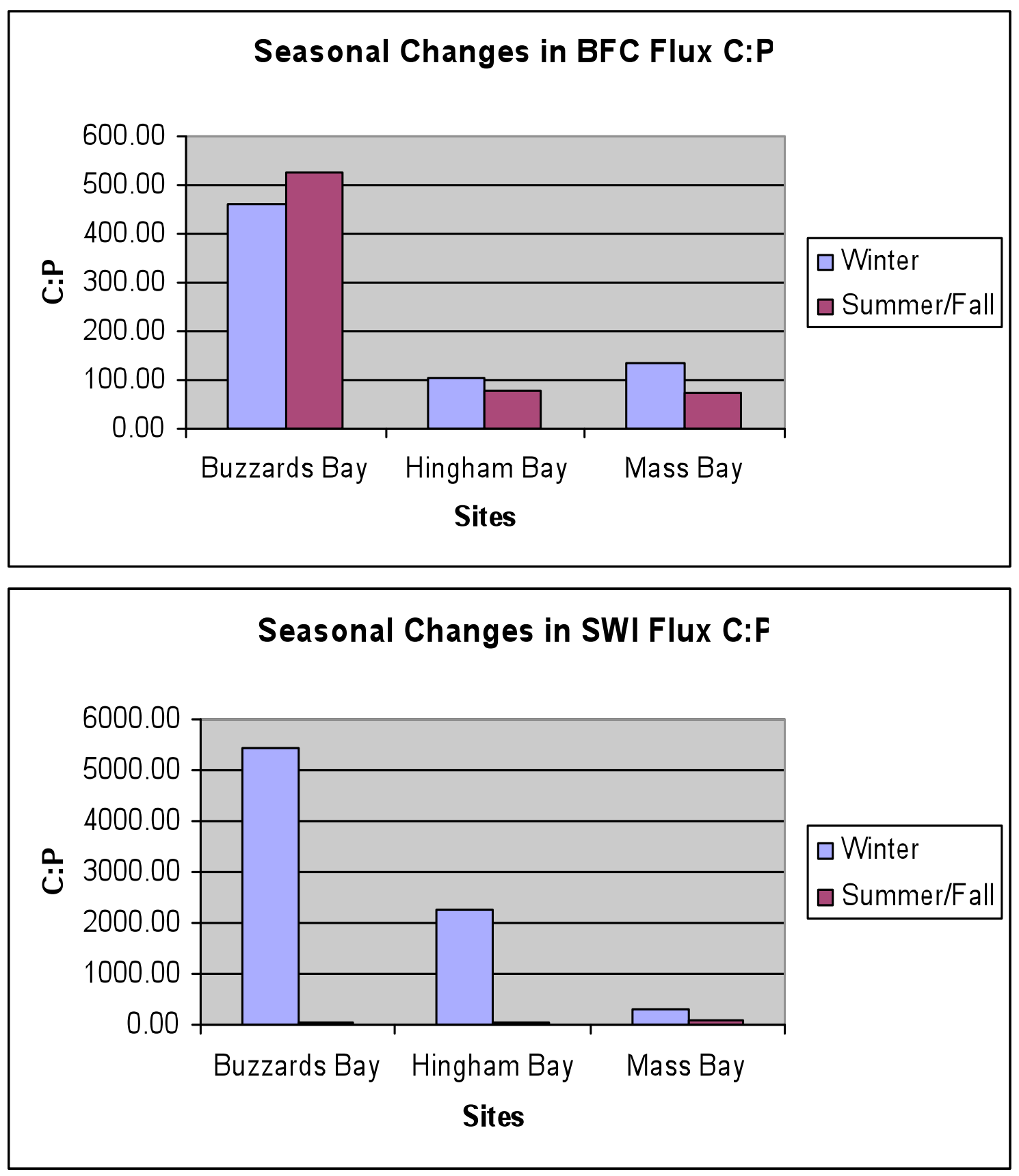


\section{Figure 26: Vivianite Precipitation Curves}

Vivianite Solubility Plot (Buzzards Bay August 2004) Conc. (umolll)

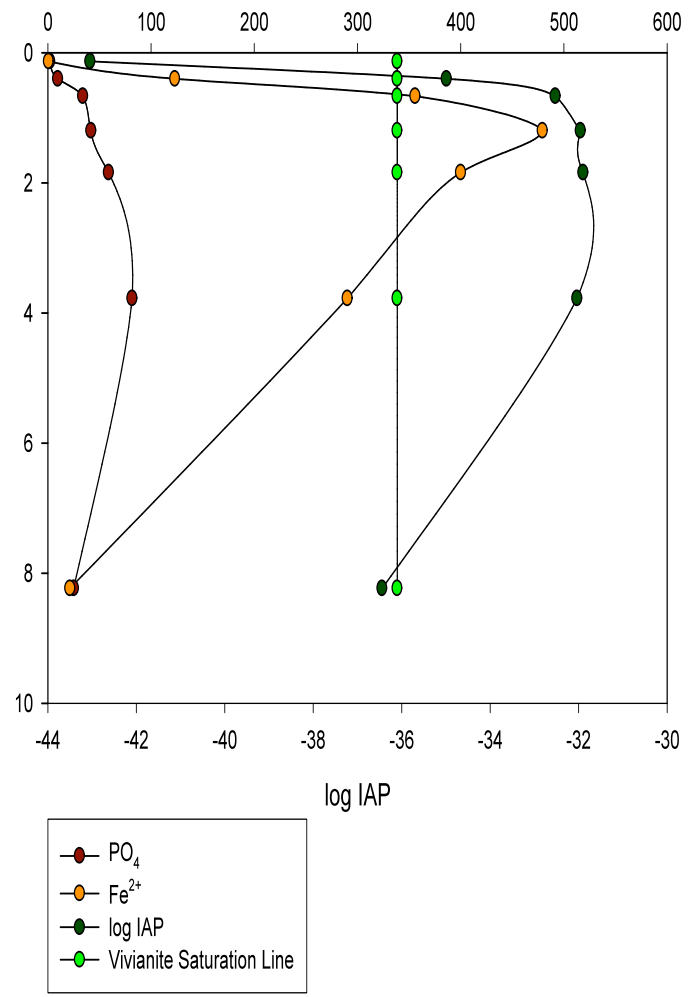

Vivianite Solubility Plot (Buzzards Bay August 2004): pH = 7.5 Conc. (umol/l)

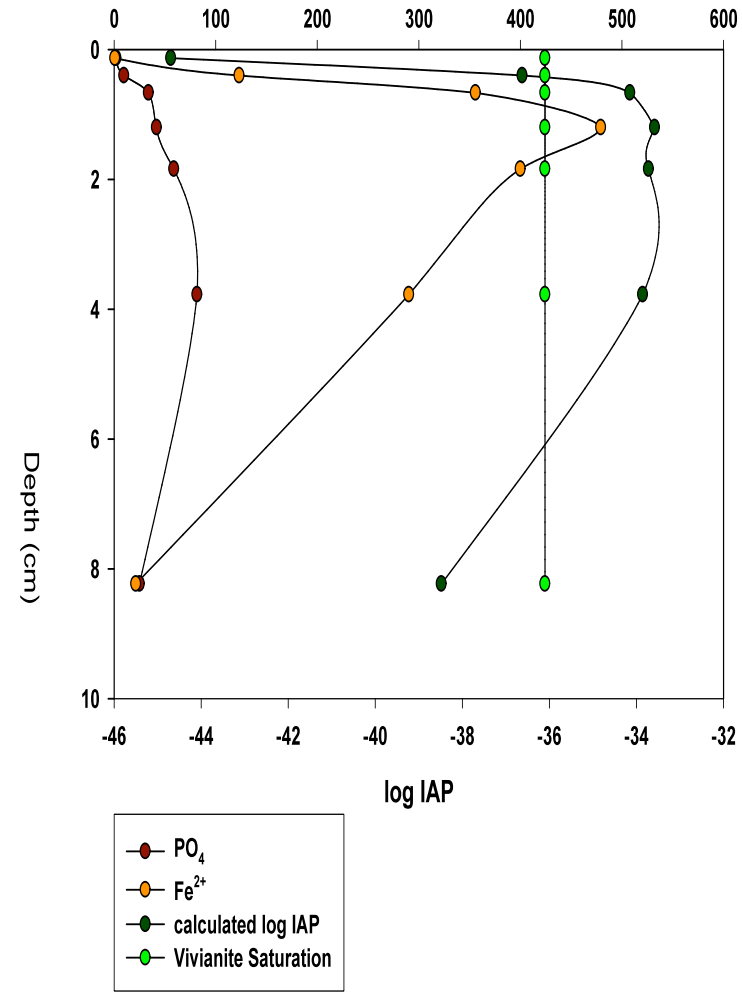

